ULIIVIRRSIIDADIE IDIE SLAO IPALULO

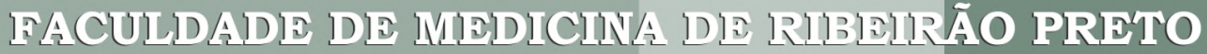

DIDPARTAMIENTO IDIE MIDDICINAS SOCIA口L

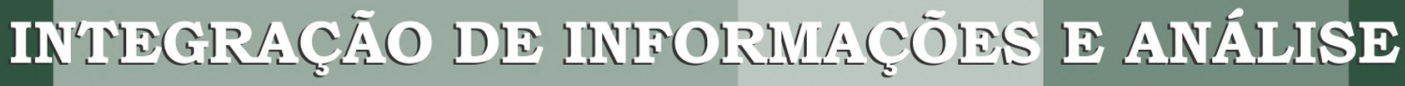

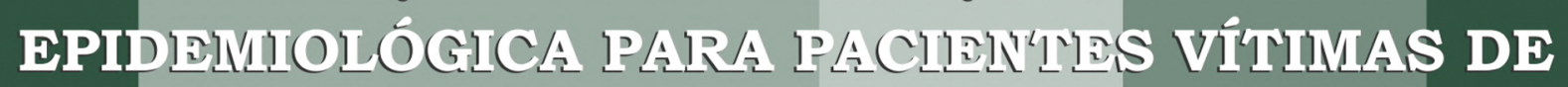

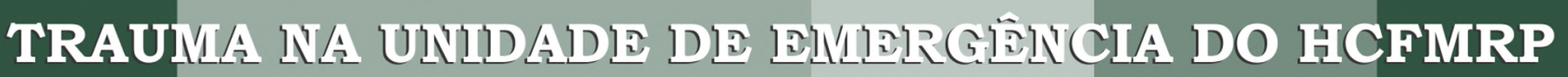
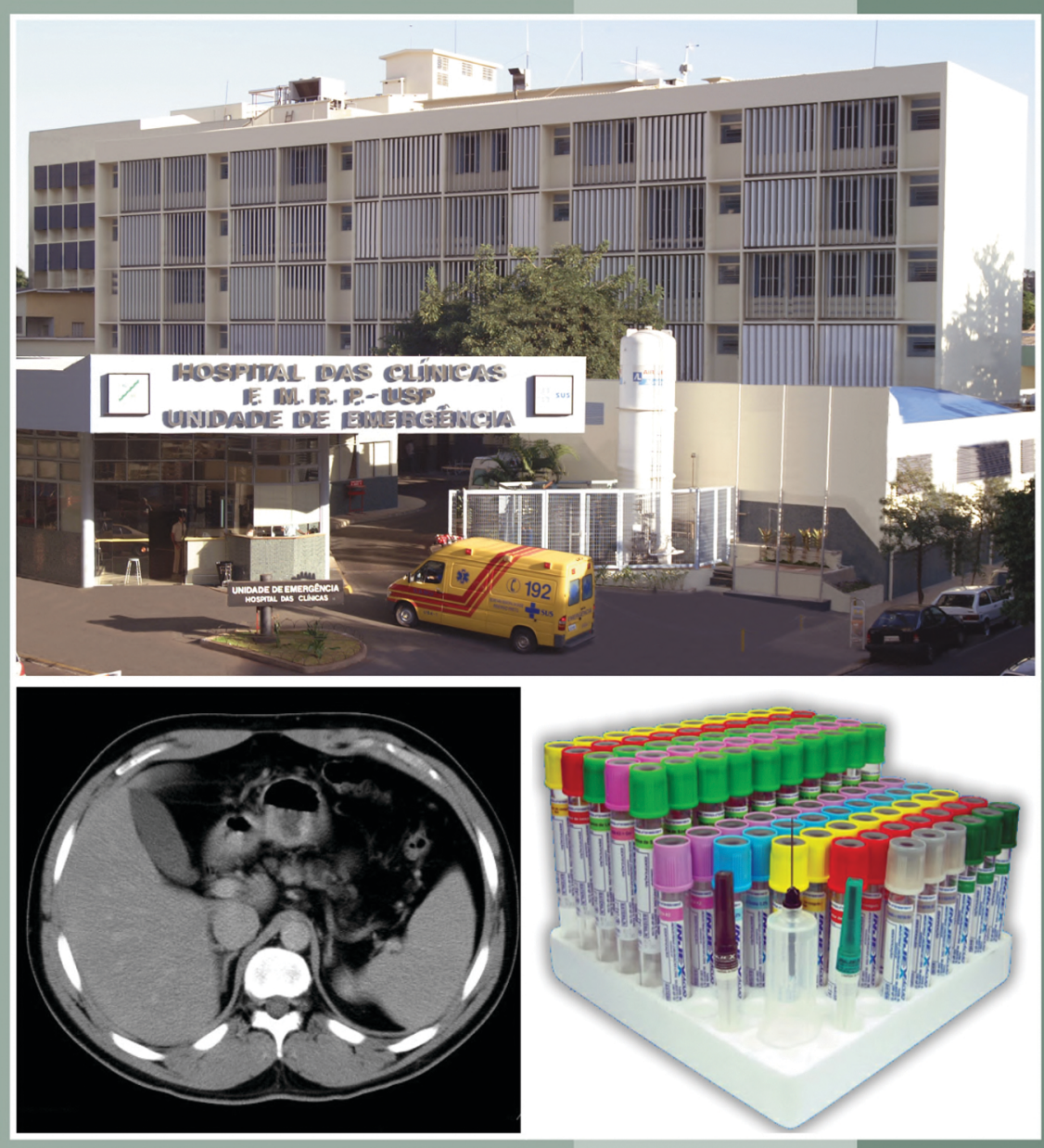

IDDUARIDO ALLDUALIDRID GULA

Ribeină lpiteto 2012 


\author{
UNIVERSIDADE DE SÃO PAULO \\ FACULDADE DE MEDICINA DE RIBEIRÃO PRETO \\ DEPARTAMENTO DE MEDICINA SOCIAL
}

EDUARDO ALEXANDRE GULA

\title{
INTEGRAÇÃO DE INFORMAÇÕES E ANÁLISE EPIDEMIOLÓGICA PARA PACIENTES VÍTIMAS DE TRAUMA NA UNIDADE DE EMERGÊNCIA DO HCFMRP
}

Dissertação apresentada à Faculdade de Medicina de Ribeirão Preto da Universidade de São Paulo, junto ao Departamento de Medicina Social para obtenção do título de Mestre em Ciências da Saúde.

Área: Saúde na Comunidade

Orientador: Prof. Dr. Domingos Alves

Ribeirão Preto 


\section{EDUARDO ALEXANDRE GULA}

\section{INTEGRAÇÃO DE INFORMAÇÕES E ANÁLISE EPIDEMIOLÓGICA PARA PACIENTES VÍTIMAS DE TRAUMA NA UNIDADE DE EMERGÊNCIA DO HCFMRP}

Dissertação apresentada à Faculdade de Medicina de Ribeirão Preto da Universidade de São Paulo, junto ao Departamento de Medicina Social para obtenção do título de Mestre em Ciências da Saúde.

Área: Saúde na Comunidade

Orientador: Prof. Dr. Domingos Alves

Ribeirão Preto 
Gula, Eduardo Alexandre

Integração de informações e análise epidemiológica para pacientes vítimas de trauma na Unidade de Emergência do HCFMRP / Eduardo Alexandre Gula. Orientador: Domingos Alves - Ribeirão Preto, 2012.

$127 f$ : il.

Dissertação (mestrado) - Universidade de São Paulo, Departamento de Medicina Social - FMRP-USP, 2012.

1. Trauma. 2. Exames hospitalares. 3. Sistema de informação em saúde 
UNIVERSIDADE DE SÃO PAULO - USP

DEPARTAMENTO DE MEDICINA SOCIAL

Programa de Pós-Graduação Saúde na Comunidade

Coordenadora: Profa. Dra. Daniela Saes Sartorelli 
"Quanto maior a dificuldade, tanto maior o mérito em superá-la." H. W. Beecher

"Dois importantes fatos nesta vida saltam aos olhos; primeiro, que cada um de nós sofre inevitavelmente derrotas temporárias de formas diferentes, nas ocasiões mais diversas. Segundo, que cada adversidade traz consigo a semente de um benefício equivalente. Ainda não encontrei homem algum bem-sucedido na vida que não houvesse antes sofrido derrotas temporárias. Toda vez que um homem supera os reveses, torna-se mental e espiritualmente mais forte... É assim que aprendemos o que devemos à grande lição da adversidade." Andrew Carnegie 


\section{Dedicatória}

Um dia Martin Luther King disse:

"O que me preocupa não é o grito dos maus. É o silêncio dos bons".

Dedico esse mestrado a você que não silencia.

Dedico esse mestrado a você que é contra o preconceito, que é contra a violência.

Dedico esse mestrado a você que reage perante a injustiça quando poderia simplesmente se omitir.

Dedico esse mestrado a você que ainda faz distinção entre o certo e o errado, em uma sociedade em que a ética e o caráter têm se tornado cada vez mais flexível.

Dedico esse mestrado a você, que tem valores, princípios e consegue vencer na vida sem passar por cima de ninguém.

Dedico esse mestrado a você, que tem a grandeza de torcer e se emocionar com a vitória alheia, de querer o bem do próximo.

Dedico esse mestrado a você, que, se alegra com a vitória alheia, não se sente indignado com isso e não se esforça para destruir as conquistas alheias.

Dedico esse mestrado aos que passaram e estão em minha vida, minha esposa Elaine, meus pais Eduardo e Neide, minha irmã Luci e minhas sobrinhas Thais e Letícia. Vocês são o bem mais valioso que tenho.

(Adaptado de Pablo Dall'Oglio - PHP Programando com Orientação a Objetos) 


\section{Agradecimentos}

A elaboração deste trabalho não teria sido possível sem a colaboração, estímulo e empenho de diversas pessoas. Gostaria de dirigir meus especiais agradecimentos a algumas pessoas que foram essenciais para a realização dessa dissertação de mestrado.

Agradeço ao meu orientador, prof. Domingos Alves, pela confiança depositada e apoio desde o princípio desse estudo. Suas experiências foram de grande apoio e direcionamento.

Agradeço ao Prof. Afonso pela compreensão nos momentos de dificuldade, onde pude atestar sua confiança depositada em mim.

Ao Dr. Gerson Alves Pereira Junior, para quem não há agradecimentos suficientes. Gostaria de mencionar que sua visão do tema e experiência de atuação em trauma foi de fundamental importância para despertar meu interesse pelo assunto quando, durante nossas conversas, apresentou-me a problemática e impacto do trauma na sociedade. Durante nossa convivência descobri uma pessoa extremamente competente em sua área de atuação cujos conhecimentos transmitidos e total disponibilidade foram notáveis. Agradeço por seu ânimo, observações e comentários que forçaram a manter meu foco. Mais do que uma dissertação, mostrou-me como enfrentar as dificuldade que surgiram ao longo da caminhada. Receba minha gratidão.

Agradeço ao Prof. Edson Zangiacomi Martinez, quando após uma troca de e-mails deu-me oportunidade de conversar a respeito de minha primeira ideia de tema de mestrado e mostrou-me o caminho a seguir. Sua atitude receptiva para um primeiro contato foi estimulante.

A todos os professores do Departamento de Medicina Social da FMRP-USP pelo ensinamento transferido durante as aulas e nas conversas fora de aula.

Aos funcionários do Departamento de Medicina Social da FMRP-USP, pela amabilidade e colaboração prestada sempre que necessário.

Aos funcionários da secretaria de pós-graduação do Departamento de Medicina Social da FMRP-USP, Paula Maria Pereira e Sérgio Carlos do Nascimento, por 
toda colaboração durante o estudo. Sempre foram pessoas fantásticas durante nossos contatos.

Ao Sr. Ivan Silva, agradeço pelo apoio, confiança e pelas conversas sempre francas e sinceras durante o período que trabalhei na Unidade de Emergência.

Ao Sr. Marco Pimenta, do CEES da Unidade de Emergência por seu prestimoso atendimento sempre que necessitei.

Ao Srs. Fábio Belavenuto e André Luis Martins Pignata, pelo auxílio na clareza da complexidade técnica envolvida.

Ao Srs. Kleber Alexandre Benatti pelo auxílio na etapa final de escrita da desse trabalho.

À minha esposa Elaine Cristina da Cunha Gula, agradeço por todo o seu amor, carinho, admiração e pela presença constante com que me apoiou ao longo do período de estudo.

A meus pais Eduardo Gula e Neide Aparecida Perboni Gula pela sólida formação de caráter e religião, me proporcionando a continuidade nos estudos até a chegada a este mestrado, os meus eternos agradecimentos.

À minha irmã Luci Elaine Gula Pereira pelo auxílio na compreensão dos dados e compartilhamento do trabalho da enfermagem no ambiente hospitalar.

A todos meus colegas de turma pelo excelente relacionamento durante nossas aulas.

Agradeço por último, mas não menos importante a Deus, pois "Deus coopera em tudo para o bem daqueles que o amam" Rm 8,28.

Aos que, direta ou indiretamente, contribuíram para que esta tese se tornasse uma realidade, quero manifestar a minha gratidão e apreço por permitirem e colaborarem para que esta tese seja uma realidade.

Que Deus abençoe a todos. 


\section{Lista de Trabalhos}

Gula, E. A.; Pereira Jr, G. A. ; Costa Passos, A. D. ; Belavenuto, F; Alves, D. Utilização de um sistema informatizado para a Vigilância Epidemiológica na Unidade de Emergência do HCFMRP. XII CBIS - Congresso Brasileiro de Informática em Saúde, 2010, Porto de Galinhas - PE. XII

Gula, E. A.; Passos, A. D. C.; Bolini, P. H. N. A.; Resende, M.P.; Pereira Junior G. A.; Alves, D. SIGTrauma: Sistema Integrado de Gestão de Trauma - Uma experiência na unificação de dados pré-hospitalares de diversas instituições quanto a acidente de trânsito em Ribeirão Preto - SP. XXVIII Congresso Brasileiro de Cirurgia, 2009, São Paulo - SP. 


\section{Resumo}

Integração de informações e análise epidemiológica para pacientes vítimas de trauma na Unidade de Emergência do HCFMRP

Desde 1980 observa-se um crescente registro de ocorrências de causas externas no Brasil, que passaram a ocupar o segundo lugar dentre as causas de morte em grandes centros urbanos, superando as neoplasias.

Foram analisados os dados de pacientes vítimas de trauma com internação na Unidade de Emergência do HCFMRP, em Ribeirão Preto (SP) entre 2006 e 2009.

Foi realizada uma análise descritiva, envolvendo informações sobre o evento traumático, índices de gravidade RTS, ISS e TRISS, provenientes do software IntegraVep, de uso do Núcleo Hospitalar de Epidemiologia do HCFMRP, além de quantificações de exames laboratoriais e radiológicos demandados aos referidos pacientes, com o intuito de analisar as características e evolução dos pacientes.

Foi possível observar a alta quantia de exames radiológicos e laboratoriais solicitados para pacientes com lesões leves além da distribuição dos pacientes quanto a faixa etária, sexo, mecanismos de trauma e gravidade de lesão.

A utilização de um software específico para análise dos dados existentes no banco de dados do HCRP se mostrou adequada ao ser usado para os pacientes vítimas de trauma, podendo ser expandido para os demais setores do hospital.

Palavras-chave: Trauma, exames hospitalares, sistema de informação em saúde. 


\begin{abstract}
Integration of information and epidemiological analysis for patients victims of trauma in the Emergency Unit of HCFMRP
\end{abstract}

Since 1980 there has been a growing record of occurrences of external causes in Brazil, which now occupy the second place among the causes of death in large urban centers, beating cancer.

We analyzed the data of trauma patients with admission to the Emergency Unit of HCFMRP in Ribeirão Preto (SP) between 2006 and 2009.

We performed a descriptive analysis, involving information about the traumatic event, severity indices RTS, ISS and TRISS, from the IntegraVep software, use of the Center for Hospital Epidemiology of HCFMRP, and quantitions of laboratory and radiological defendants to those patients with the aim of analyzing the characteristics and outcomes of patients.

It was possible to observe the high amount of radiological and laboratory-only bid for patients with minor injuries and the distribution of patients by age, sex, mechanism of trauma and injury severity.

The use of specific software for the analysis of existing data in the database of the HCRP was adequate to be used for trauma patients and can be expanded to other hospital departments.

Keywords: Trauma, hospital tests, health information system.. 


\section{Índice}

Índice de Tabelas ...........................................................................................ii

Índice de Figuras ...............................................................................................

Índice de Gráficos ........................................................................................vi

Lista de siglas........................................................................................................

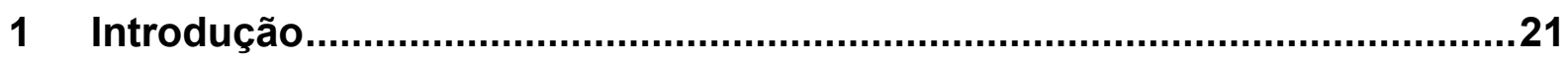

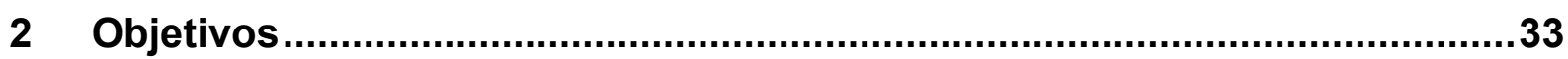

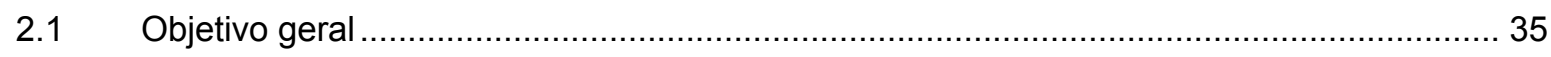

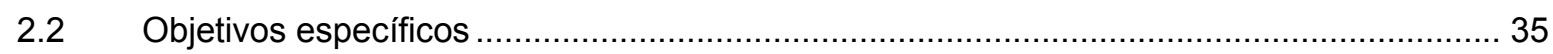

3 Material e Método ….................................................................................

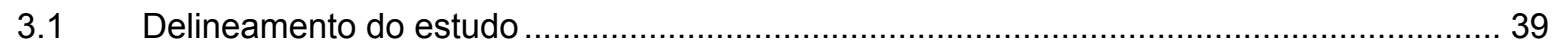

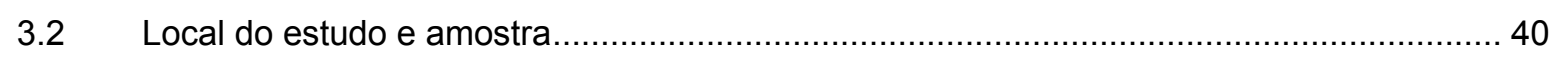

3.3 Fonte Primária de Dados e Dados Complementares .................................................... 42

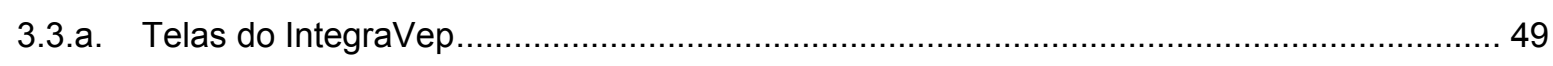

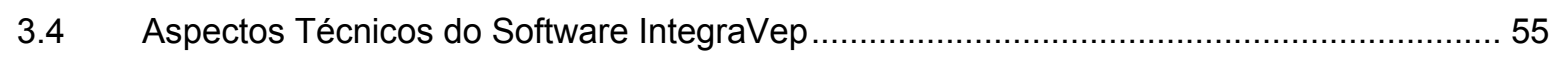

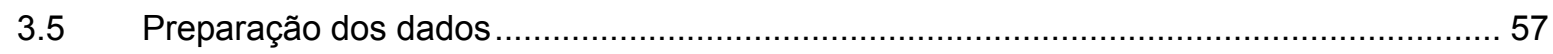

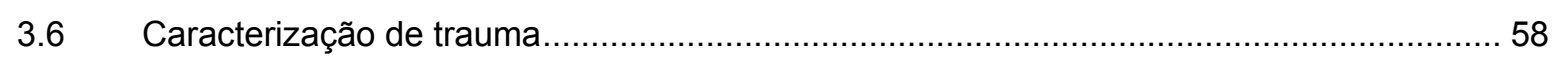

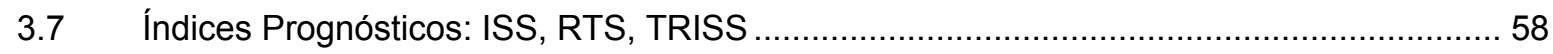

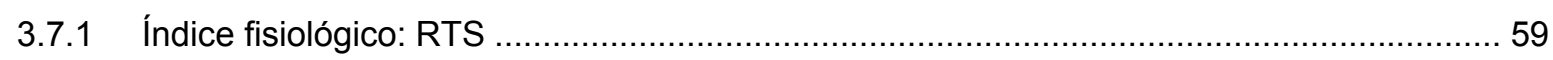

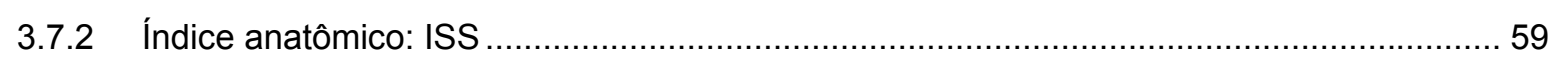

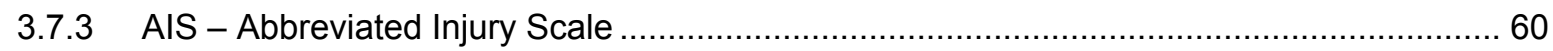

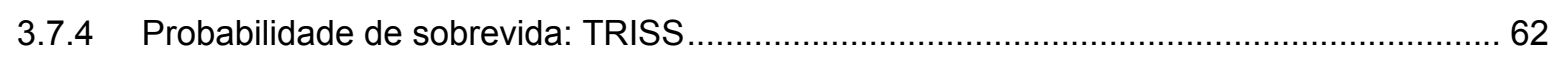

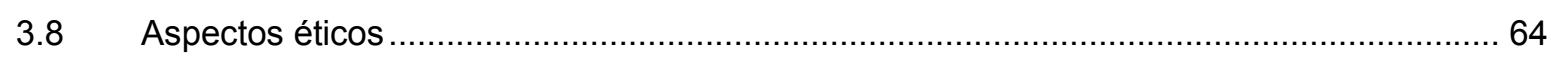

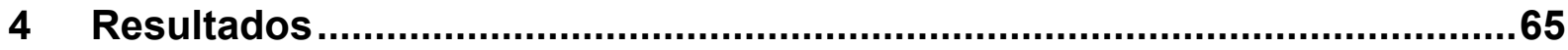

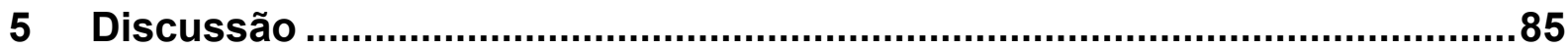

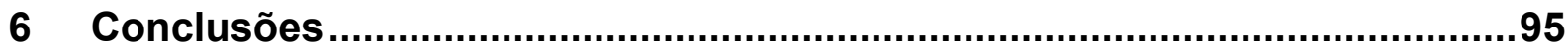

$7 \quad$ Perspectivas de Trabalhos Futuros............................................................101

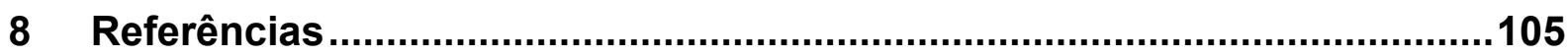

9 Referência de Apoio..................................................................................113

Anexo 1 - Ficha de atendimento do trauma ................................................117

Anexo 2 - Ficha de notificação de trauma .....................................................121 
Anexo 3 - Resumo de diferentes graus de lesão pelo AIS ..............................122 Anexo 5 - Aprovação do Comitê de Ética do HCFMRP ..................................125 Apêndice A - Tabelas utilizadas para os gráficos .......................................127 


\section{Índice de Tabelas}

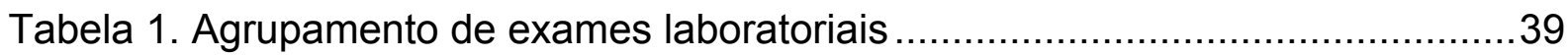

Tabela 2. Agrupamento de exames radiológicos .............................................40

Tabela 3. Coeficientes envolvidos no TRISS ..................................................63

Tabela 4. Distribuição de sexo dos pacientes vítimas de trauma ..........................67

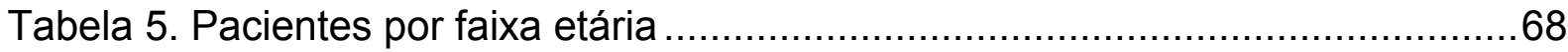

Tabela 6. Mecanismo de trauma para os pacientes vítimas de trauma ..................68

Tabela 7. Mecanismo de trauma para pacientes vítimas de trauma com até 10 anos

Tabela 8. Mecanismo de trauma para pacientes vítimas de trauma entre 11 e 20 anos

Tabela 9. Mecanismo de trauma para pacientes vítimas de trauma entre 21 e 50 anos 70

Tabela 10. Mecanismo de trauma para pacientes vítimas de trauma entre 51 e 60 anos

Tabela 11. Mecanismo de trauma para pacientes vítimas de trauma com 60 anos ou mais. 71

Tabela 12. Internações de pacientes vítimas de trauma por dia da semana ...........72

Tabela 13. Encaminhamentos de Ribeirão Preto e DRS-XIII ..............................73

Tabela 14. Letalidade por mecanismo de trauma .............................................. 74

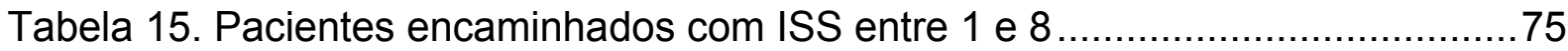

Tabela 16. ISS para pacientes que passaram por cirurgia .................................. 75

Tabela 17. Cirurgias por especialidade para pacientes vítimas de trauma ..............76

Tabela 18. Óbitos de pacientes por faixa de ISS em vítimas de trauma .................76

Tabela 19. Óbitos por faixa etária para pacientes vítimas de trauma......................77

Tabela 20. Meio de transporte dos pacientes vítimas de trauma ..........................78

Tabela 21. Condição de alta dos pacientes vítimas de trauma ............................79

Tabela 22. Quantidade de exames de radiologia convencional por ano ..................79

Tabela 23. Utilização de exames de radiologia convencional de acordo com a faixa de ISS 80

Tabela 24. Radiografia simples de coluna cervical, tórax e bacia por ISS .80 
Tabela 25. Quantidade de exames de tomografia computadorizada realizados por ano

Tabela 26. Utilização de exames de tomografia computadorizada conforme a faixa de ISS

Tabela 27. Utilização de tomografia computadorizada de crânio de acordo com a faixa de ISS.

Tabela 28. Utilização da TC de tórax de acordo com o AIS das lesões traumáticas encontradas

Tabela 29. Utilização de exames laboratoriais séricos de acordo com a gravidade do trauma .83

Tabela 30. Utilização de tipagem sanguínea e tempo de protrombina de acordo com a gravidade do trauma .84

Tabela 31. Pacientes vítimas de trauma por sexo. 127

Tabela 32. Internações de pacientes vítimas de trauma por dia da semana 127

Tabela 33. Distribuição dos pacientes por gravidade de lesões 127 


\section{Índice de Figuras}

Figura 1. Direção Regional de Saúde do Estado de São Paulo ...............................28

Figura 2 Municípios que compõe a DRS-XIII ............................................29

Figura 3. Etapas da prototipação de software ............................................... 43

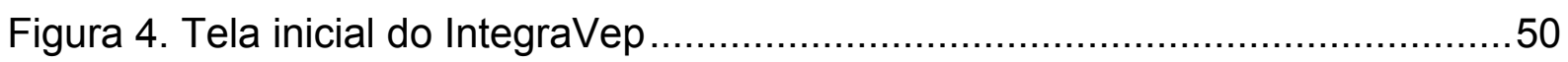

Figura 5. Tela do integraVep exibindo a aba "Informações do paciente" .................51

Figura 6. Tela do integraVep exibindo a aba "Informações sobre o evento" ............52

Figura 7. Tela do IntegraVep exibindo a aba "III - Índices de gravidade" ................53

Figura 8. Tela do IntegraVep exibindo a aba "comorbidades e complicações" .........54

Figura 9. Tela do IntegraVep exibindo a aba "Evolução" ....................................55 


\section{Índice de Gráficos}

Gráfico 1. Distribuição de sexo dos pacientes vítimas de trauma .........................67

Gráfico 2. Porcentagem de pacientes admitidos por dia da semana .......................72

Gráfico 3. Letalidade por mecanismo de trauma........................................... 73

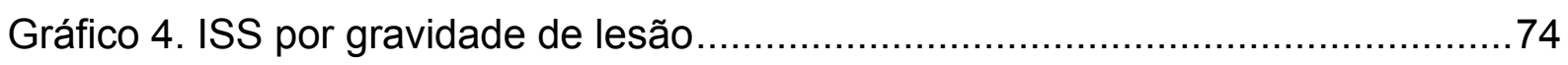

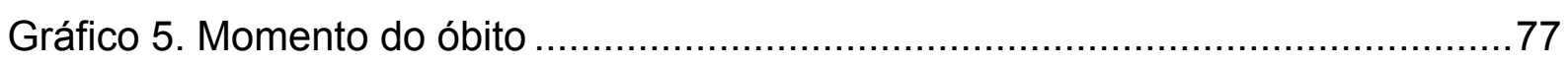

Gráfico 6. Principais causas de óbito de pacientes vítimas de trauma....................78 


\section{Lista de siglas}

AIS:

Abbreviated Injury Scale

ATLS:

Advanced Trauma Life Support

CEES:

Centro de Estudos de Emergência em Saúde

CID-10:

Classificação Internacional de Doenças $-10^{2}$ revisão

CPVE:

Centro de Pesquisa e Vigilância Epidemiológica

CTI:

Centro de Terapia Intensiva

DRS:

Departamento Regional de Saúde

DRS-XIII:

$13^{a}$ Direção Regional de Saúde do Estado de São Paulo

FMRP:

Faculdade de Medicina de Ribeirão Preto da Universidade de São Paulo

FR: $\quad$ Frequência respiratória

HCFMRP: Hospital das Clínicas da Faculdade de Medicina de Ribeirão Preto - USP

IDE:

Integrated Development Environment

ISS:

Injury Severity Scale

MER:

Modelo Entidade-Relacionamento

NHE:

Núcleo Hospitalar de Epidemiologia

NVE:

Núcleo de Vigilância Epidemiológica

OMS: $\quad$ Organização Mundial da Saúde

PAS: $\quad$ Pressão arterial sistólica

RTS: $\quad$ Revised Trauma Score

SAME: $\quad$ Serviço de Arquivo Médico e Estatística

SAMU: $\quad$ Sistema de Atendimento Médico de Urgência

SGBD: $\quad$ Sistema Gerenciador de Banco de Dado

SIM: $\quad$ Sistema de Informação sobre Mortalidade

SINAN: $\quad$ Sistema de Informação de Agravos de Notificação

SINAN Net: $\quad$ Sistema de notificação do SINAN

SUS: $\quad$ Sistema Único de Saúde

TC:

Tomografia computadorizada

TCE:

Trauma crânio encefálico

TRISS:

Trauma and Injury Severity Score 
UE-HCFMRP: $\quad$ Unidade de Emergência do Hospital das Clínicas da Faculdade de Medicina de Ribeirão Preto - USP

UR: $\quad$ Unidade de Resgate (Corpo de Bombeiros)

USA: $\quad$ Unidade de Suporte Avançado

USB: $\quad$ Unidade de Suporte Básico

UTI: $\quad$ Unidade de Terapia Intensiva 
1 Introdução 

Os acidentes e as violências ou causas externas de morbi-mortalidade, segundo a Classificação Internacional de Doenças - 10ª Revisão (CID-10),

"são constituídos pelos acidentes de trânsito, homicídio, suicídio, outras violências (intoxicação, acidentes de trânsito, queimaduras, quedas, afogamento, entre outros) e daquelas causas externas não especificadas se acidentais ou intencionais" (OMS apud PORDEUS, 2003).

Por sua vez, trauma pode ser compreendido como o conjunto de alterações anatômicas e funcionais, locais e gerais, provocadas no organismo por meios violentos agressivos (intencionais) ou acidentais (não intencionais). Por exemplo, de agressões ou espancamentos, ferimentos intencionais por armas e de acidentes, as quedas, queimaduras, os acidentes de trânsito, entre outros. (RASSLAN, 1998).

O trauma por causas externas, além das consequências biológicas e sociais, tem importantes consequências econômicas, podendo ocasionar a morte, incapacidade temporária ou permanente da vítima, produzindo um alto custo com a recuperação, além da possibilidade de comprometer a qualidade de vida (WHITAKER, GUTIERREZ E KOIZUMI, 1998).

As causas externas constam em uma categoria estabelecida pela Organização Mundial da Saúde (OMS, 1994) e padronizada na Classificação Internacional de Doenças em sua décima revisão (CID-10) no capítulo XIX, sob o nome lesões, envenenamento e algumas outras consequências de causas externas. São codificadas de S00 a T98, podendo ser associada à diferentes tipos de traumatismos, suas complicações e sequelas, queimaduras, intoxicações e ferimentos e no capítulo XX, sob o nome causas externas de morbidade e de mortalidade, com a codificação entre V01 e Y98, servindo como uma classificação complementar ao capítulo XIX. Essa codificação permite classificar utilizando os códigos de acidentes de transporte, quedas, afogamentos, lesões auto infligidas, agressões, sequelas de causas externas, dentre outros (DEGANI, 1994).

No estudo do Instituto de Pesquisa Econômica Aplicada (IPEA) de 2003, é possível observar uma mensuração dos custos provocados pelos acidentes de trânsito, chegando ao montante de $\mathrm{R} \$ 5,3$ bilhões para a área urbana, somente em 2001. Dentre os diversos custos envolvidos, foram detectados custo da perda de produção, custos dos danos aos veículos, custo médico-hospitalar, custo de proces- 
sos judiciais, custo de congestionamento, custo previdenciário, custo do resgate de vítimas, custo de remoção de veículos, custo de danos ao mobiliário urbano e à propriedade de terceiros, custo de outro meio de transporte, custo dos danos à sinalização de trânsito, custo do atendimento policial e dos agentes de trânsito e impacto familiar.

Há ainda a possibilidade de caracterizar o trauma como um ferimento que apresenta as variáveis extensão, intensidade e gravidade, sendo ocasionado por agentes externos que podem ser físicos, químicos e outros, de forma não intencional em que o poder do agente agressor supera a resistência encontrada (Ferreira, 1999).

O trauma é um dos mais importantes problemas de saúde pública mundial desde os anos 80, onde ocorria como a terceira causa de morte nos países desenvolvidos, superado apenas pelo câncer e aterosclerose, sendo a principal causa de morte nas primeiras quatro décadas de vida (TRUNKEY, 1983; 1984).

No Brasil, o trauma é uma grande causa de morbidade e mortalidade. A partir da década de 80 passou inclusive, a ser considerado um importante problema de saúde pública (REICHENHEIM, 2011), sendo atualmente quase considerado de proporção epidêmica (IUNES, 1997).

Desde 1980 observa-se um crescente registro de ocorrências de causas externas no Brasil, que passaram a ocupar o segundo lugar de causa morte em grandes centros urbanos, suplantando as neoplasias. A causa externa, nos últimos anos, tem representado $5,2 \%$ do total de internações realizadas em todo o território nacional, bem como o aumento da demanda nos serviços de saúde. Foi somente na década de 80 que este tema passou a integrar, com maior ênfase, os debates da saúde, em virtude dos estragos e danos que afetam a qualidade de vida, interferindo na integridade emocional e provocando sequelas e morte (VIEIRA et al, 2003).

As violências e as lesões têm sido as principais causas de morbidade e mortalidade no Brasil, correspondendo a 12,5\% dos óbitos até 2007 (REICHENHEIM, 2011).

Para exemplificação, (REICHENHEIM, 2011) cita o ano de 2007,

"onde os homens foram responsáveis por 43.890 (92\%) dos 47.707 homicídios e $36.124(81,7 \%)$ das 44.216 internações hospitalares envolvendo 
violência em geral. A faixa etária mais fortemente afetada foi entre 20 a 29 anos para ambos: os óbitos (19.226 [40,3\%] dos 47.707) e as internações hospitalares (13.928 [31,5\%] das 44.216). Das 47.707 vítimas de homicídios, 26.287 (55,1\%) eram pardos (42,5\% da população brasileira é parda; 79.571 .900 dos 187. $228.000)$ e $3.912(8,2 \%)$ eram negros $(7,5 \%$ da população; 14.042 .100 de 187.228.000).

Dos 30.107 homicídios $(63,1 \%)$ a respeito dos quais havia informações disponíveis sobre as vítimas, 13.458 (44,7\%) tinham entre 4 e 7 anos de escolaridade, à medida que apenas $1.174(3,9 \%)$ tinham escolaridade superior a 12 anos.".

Considerando pesquisas recentes, no Brasil, enquanto a população cresceu $19 \%$, a morte por causas externas elevou-se em 34\% no mesmo período, elevando de 70.000 para 94.000 anualmente. O perfil das causas de mortalidade por trauma manteve-se estável. Particularmente, os acidentes com veículos automotores e os suicídios mantiveram-se inalterados com 30\% e 5\%, respectivamente. Outras causas várias, incluindo quedas acidentais, afogamentos, soterramentos e queimaduras foram responsáveis por, aproximadamente, $26 \%$ dos óbitos. Houve, entretanto, um aumento de $4 \%$ nas mortes por homicídios, principalmente nos grandes centros urbanos (UTYIAMA \& BIROLINI, 1997).

Em 2007 no Brasil, houve cerca de 300 óbitos por dia, totalizando cerca de 110 mil óbitos no ano (MINISTÉRIO DO PLANEJAMENTO, 2009), sendo em sua maioria agressões e acidentes de transporte.

Os serviços de saúde no Brasil atendem grande parte desses pacientes vítimas de trauma e fazem parte de uma rede complexa de relações que envolvem esses agravos. (PLACCO, 2003).

Um dos principais motivos de internação hospitalar devido a trauma são os acidentes de trânsito, que geram elevado percentual de internação, além de altos custos hospitalares, perdas materiais, despesas previdenciárias e grande sofrimento para as vítimas e familiares. Dados do Sistema de Informação sobre Mortalidade (SIM/MS) informam que, em 1998, ocorreram no Brasil 30.994 óbitos por acidentes de transporte, significando 26,3\% entre as causas externas. Esses dados expressam a relevância epidemiológica e social do problema e a necessidade de articulação 
intersetorial entre as áreas de saúde, trânsito e a sociedade. Por exemplo, em 2002 foram registrados 118.367 óbitos por causas externas (GAWRYSZWKI, 2004).

Assim, a relação entre violência, acidentes e trauma é extremamente estreita, tratando-se de um problema de impacto no Brasil que envolve aspectos médicos, psicológicos e sociais, demandando soluções integradas. Apesar da amplitude dessa situação, o país conta com um sistema de informação em desenvolvimento e nem sempre os dados referentes às internações e ao atendimento dos serviços públicos e privados são facilmente disponíveis e confiáveis. Muitas vezes, ocorre a subnotificação das ocorrências, inviabilizando um estudo epidemiológico que possibilite conhecer o comportamento das ocorrências de violência, acidentes e trauma.

Um fator preocupante é a possibilidade de que alguns casos de óbitos estejam atualmente sendo considerados no grupo de causas mal definidas ao invés de serem enquadrados no grupo de causas externas em virtude de ausência de informações ou por não ser possível a confirmação da causa do óbito para o correto enquadramento (TAMBELLINI, 2001).

Além disso, comparação de resultados de estudos clínicos entre diferentes cirurgiões e diferentes serviços de trauma foi prejudicada durante anos pela inexistência de índices que pudessem ser universais e reprodutíveis. Tal ausência tornava simplesmente impossível qualquer análise de estudos de trauma devido às diferentes metodologias e definições utilizadas (COIMBRA et al., 1997).

As enfermidades traumáticas graves são uma das principais causas de morbimortalidade em adultos jovens, que quando sobrevivem apresentam algum tipo de sequela e/ou incapacidade. Os tipos de sequelas e disfunções, extensão e gravidade, impacto sobre a vida dos vitimizados tem sido pouco estudados (GARCIA DELGADO et al, 2001).

Em um estudo conduzido, houve conclusão que $80 \%$ dos traumas múltiplos resultem em algum tipo de sequela. Destes, somente $6 \%$ se tornam independentes nas atividades de vida diária, enquanto $66 \%$ apresentaram pouca ou nenhuma capacidade de realizar tarefas não laborais, que geralmente estão associadas a disfunções cognitivas e físicas. Os autores recomendam uma assistência 
individualizada e multidisciplinar para melhorar a qualidade de vida desses pacientes (ANKE et al 1997).

Há alguns métodos atualmente utilizados para a quantificação da gravidade de lesões de modo a avaliar o atendimento dispensado aos pacientes vítimas de trauma (GABBE, 2004).

O cálculo dos índices de gravidade Revised Trauma Score (RTS), Injurity Severity Scale (ISS), Trauma and Injury Severity Score (TRISS) é utilizado em todos os pacientes vítimas de trauma na Unidade de Emergência do HCFMRP desde 2004, assim como em centros de trauma internacionais (BOYD, 1987). Estes cálculos permitem a avaliação das alterações fisiológicas (RTS), a gravidade das lesões anatômicas (ISS) e a quantificação da probabilidade de sobrevida (TRISS).

Uma das medidas que tem melhorado as condições de atendimento intrahospitalar no Brasil é a sistematização do atendimento inicial ao politraumatizado proposta pelo Colégio Americano de Cirurgiões (AMERICAN COLLEGE OF SURGEONS - COMMITTEE ON TRAUMA, 1993), chamado de Advanced Trauma Life Support (ATLS). O Advanced Trauma Life Support (ATLS) é um curso criado e gerenciado pelo Colégio Americano de Cirurgiões, com sede em Chicago e, difundido para o mundo inteiro desde o início da década de 80.

O ATLS tem possibilitado o treinamento de um número cada vez maior de médicos, habilitando-os ao manejo mais adequado destes pacientes, sistematizando e uniformizando as etapas do atendimento inicial do paciente.

A cidade de Ribeirão Preto no estado de São Paulo, com 605.114 habitantes (IBGE, 2012), em termos de saúde, é considerada o polo da $13^{a}$ Direção Regional de Saúde do Estado de São Paulo (DRS-XIII), sendo referência para as outras 25 cidades da região, num total de 1.349.170 habitantes (IBGE, 2012).

A divisão administrativa da Secretaria da Saúde do Estado de São Paulo se faz através dos Departamentos Regionais de Saúde (DRS), atendendo ao Decreto DOE $n^{\circ} 51.433$, de 28 de dezembro de 2006. Por meio deste Decreto o Estado foi dividido em 17 Departamentos de Saúde, que são responsáveis por coordenar as atividades da Secretaria da Saúde do Estado de São Paulo no âmbito regional e promover a articulação intersetorial, com os municípios e organismos da sociedade civil. (SECRETARIA DA SAÚDE, 2012). 
O mapa apresentado na Figura 1 (SECRETARIA DA SAÚDE, 2012) apresenta todos os DRS e sua área correspondente.

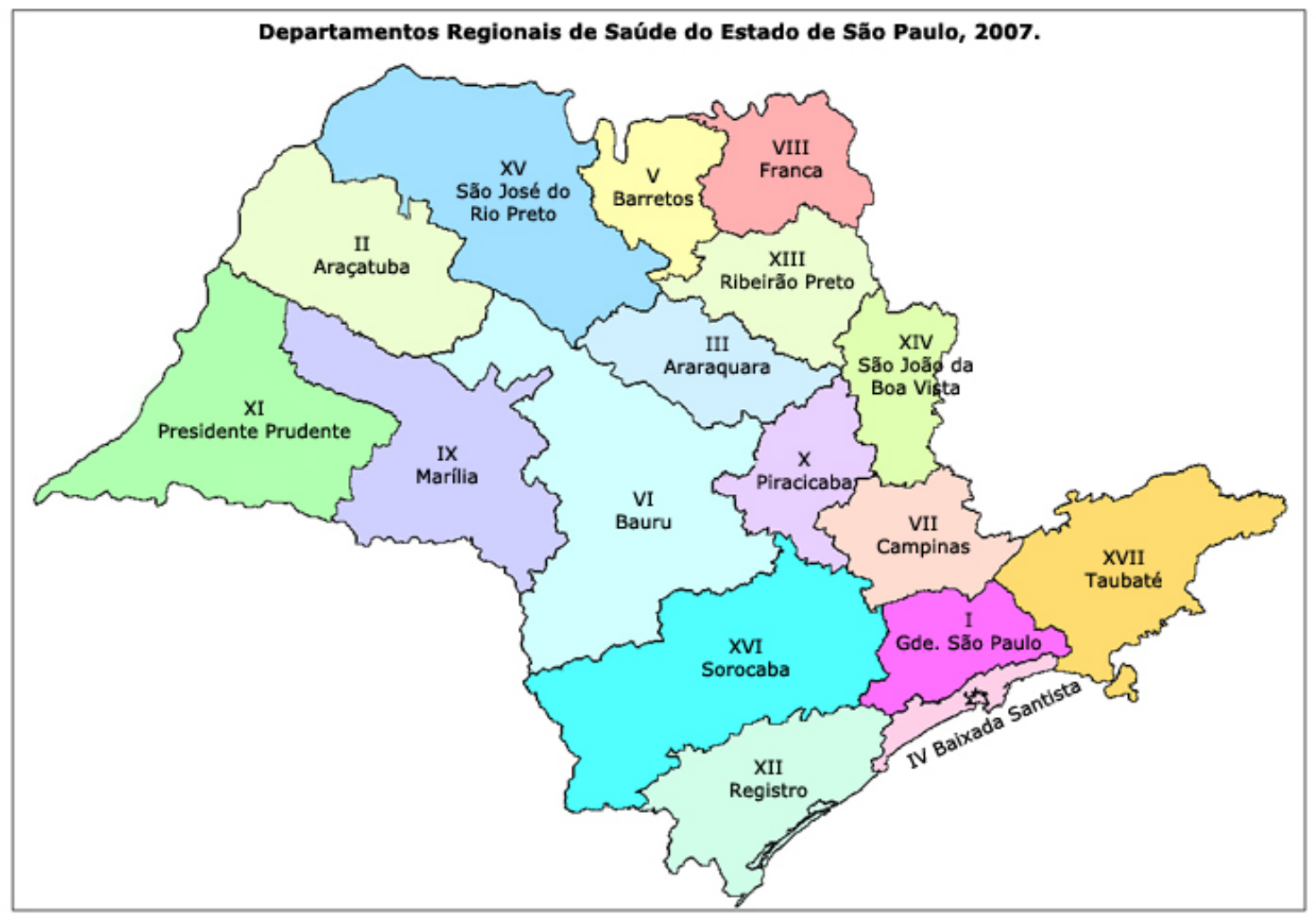

Figura 1. Direção Regional de Saúde do Estado de São Paulo

As cidades que compõe a DRS-XIII são Altinópolis, Barrinha, Batatais, Brodowski, Cajuru, Cássia dos Coqueiros, Cravinhos, Dumont, Guariba, Guatapará, Jaboticabal, Jardinópolis, Luis Antônio, Monte Alto, Pitangueiras, Pontal, Pradópolis, Ribeirão Preto, Santa Cruz da Esperança, Santa Rita do Passa Quatro, Santa Rosa de Viterbo, Santo Antônio da Alegria, São Simão, Serra Azul, Serrana, Sertãozinho, conforme apresentadas na Figura 2. (SECRETARIA DA SAÚDE, 2012).

Particularmente, há em Ribeirão Preto o atendimento pré-hospitalar prestado pelas ambulâncias de suporte básico (USB) e de suporte avançado (USA) do Sistema de Atendimento Médico de Urgência (SAMU) da Secretaria Municipal de Saúde e pela Unidade de Resgate do Corpo de Bombeiros (UR). 


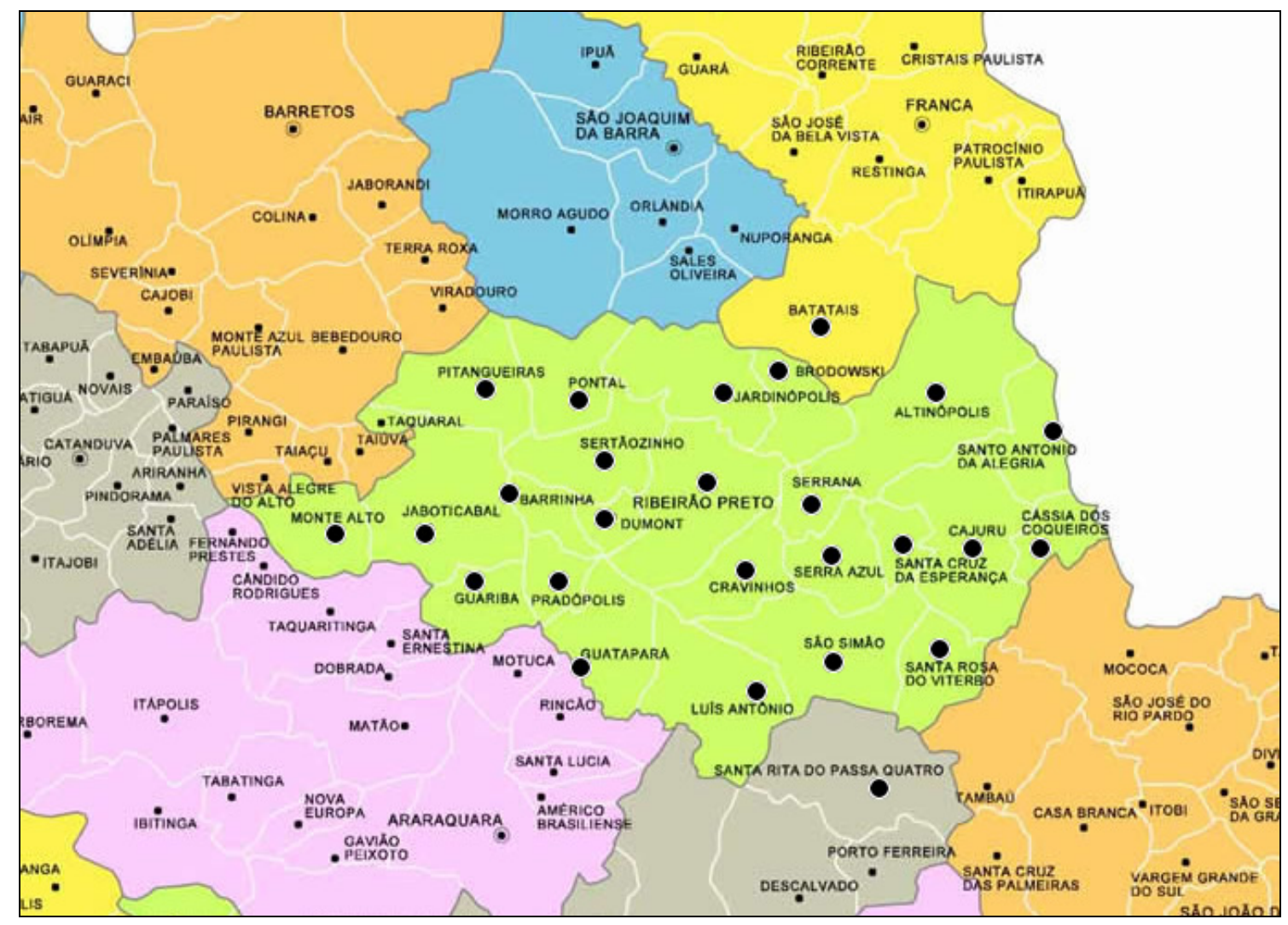

Figura 2 Municípios que compõe a DRS-XIII

O hospital de referência municipal e regional de atendimento a pacientes vítimas de trauma é a Unidade de Emergência do Hospital das Clínicas da Faculdade de Medicina de Ribeirão Preto da Universidade de São Paulo (UE-HCFMRP), que abrange toda a região nordeste e parte das regiões norte e sudeste do Estado de São Paulo, Triângulo Mineiro e sul de Minas Gerais. Trata-se de um hospital universitário de atendimento nível terciário. O atendimento prestado aos habitantes de Ribeirão Preto e diversas outras cidades pela Unidade de Emergência cobre uma população de 1.349.170, segundo o Censo IBGE de 2010.

Neste contexto, o Núcleo Hospitalar de Epidemiologia (NHE) do Hospital das Clínicas de Ribeirão Preto (HCFMRP) originou-se em 02 de março de 1998, havendo a criação do então chamado Centro de Pesquisa e Vigilância Epidemiológica (CPVE), tendo como finalidade atividades de vigilância das doenças objeto de notificação que fossem diagnosticadas no HCFMRP.

Para maior clareza, o termo "Vigilância Epidemiológica" pode ser definido sinteticamente como "informação para a ação". Trata-se de um dos principais pilares de sustentação da saúde pública. Também pode ser considerado como um conjunto 
de ações que informam, detectam ou previnem todas e quaisquer alterações nos fatores que determinam ou afetam a saúde individual ou coletiva, considerando-se a finalidade de tomar medidas de prevenção e controle.

Um dos principais propósitos da Vigilância Epidemiológica é oferecer orientação técnica para os profissionais de saúde, os quais tomam decisões sobre doenças e agravos, disponibilizando sempre informações atualizadas sobre sua ocorrência (Guia de Vigilância Epidemiológica, 2005). De acordo com a lei 8080, que instituiu o Sistema Único de Saúde (SUS), no Brasil em 1990, o termo vigilância epidemiológica pode ser definido como um conjunto de ações que informam, detectam ou previnem quaisquer alterações nos fatores que determinam ou afetam a saúde individual ou coletiva, com a finalidade de tomar medidas de prevenção e controle. Desse modo, a Vigilância Epidemiológica é responsável pelas atividades de coleta, análise, processamento, interpretação de dados, aplicação de medidas controle e divulgação de informações (Guia de Vigilância Epidemiológica, 2005).

É através da Vigilância Epidemiológica que é realizada a comunicação das ocorrências de agravos de interesse da saúde coletiva, além de ser responsável pelas atividades de coleta, análise, processamento, interpretação de dados, aplicação de medidas controle e divulgação de informações podendo ser consideradas como suas atribuições a coleta de dados; o processamento dos dados coletados; a análise e interpretação desses dados; recomendação e promoção das medidas de controle apropriadas; avaliação da eficácia e efetividade das medidas tomadas; e a divulgação de informações pertinentes.

Em março de 1992, o CPVE foi oficialmente formalizado, passando a ser designado como Núcleo de Vigilância Epidemiológica (NVE).

Em 29 de novembro de 2004, através da Portaria $n^{\circ} 2529$, o Ministério da Saúde instituiu o Subsistema Nacional de Vigilância Epidemiológica em Âmbito Hospitalar, criando a Rede Nacional de Hospitais de Referência para o referido Subsistema e definindo critérios para a qualificação dos estabelecimentos. Assim o NVE do HCFMRP foi enquadrado na categoria de Referência Nível III, a de mais elevada complexidade. Nesse momento, o NVE passa a ser renomeado como Núcleo Hospitalar de Epidemiologia (NHE). 
Diante desse cenário, o Núcleo Hospitalar de Epidemiologia do Hospital das Clínicas de Ribeirão Preto efetua notificação de agravos e doenças através do Sistema de Informação de Agravos de Notificação (SINAN), que é disponibilizado pelo Ministério da Saúde. Este sistema contempla quase que, exclusivamente, doenças infecto-contagiosas, campo tradicional de atuação dos sistemas de vigilância implantados em nosso meio. A partir de 1996, numa atitude inovadora, o NHE passou a realizar a notificação compulsória de agravos relacionados aos acidentes de trânsito, cujas vítimas eram atendidas na Unidade de Emergência do HCFMRP. (NHE-HCFMRP, 2012).

A partir de 2004, a ficha de coleta de dados de acidentes de trânsito foi acrescida de informações sobre os demais tipos de lesões por causas externas e não somente produzidas por acidentes de transporte. Essa ficha incorporou também informações que permitem o cálculo de índices de gravidade das lesões, indicador fundamental para avaliar a qualidade da atenção médica prestada às vítimas e para permitir comparabilidade do serviço em diferentes momentos e com outros serviços. Tem-se, assim, um sistema regular de coleta de dados de morbidade que cobre a totalidade dos atendimentos por causas externas cujas vítimas são recebidas em uma unidade hospitalar universitária de nível terciário, responsável por atendimentos a traumas de alta complexidade em Ribeirão Preto e região.

As informações decorrentes dessas investigações são de extrema importância para fins de monitoramento da ocorrência de traumas na cidade de Ribeirão Preto e região. Foi estabelecida uma rotina de coleta de dados de todos os pacientes vítimas de traumas que dessem entrada na Unidade de Emergência. Instituiu-se o preenchimento de uma ficha de coleta de dados demográficos e relacionados ao evento traumático, bem como relativos à evolução de cada paciente. A coleta dessas informações é realizada desde então pelo corpo de médicos e enfermeiros ligados ao NHE.

Assim, de uma maneira mais geral, considerando o cenário que abrange o termo "vítimas de trauma", as informações sobre os pacientes são extremamente relevantes para a compreensão da realidade dos problemas, facilitando atividades de intervenções promocionais, planejamento dos serviços e recursos disponíveis bem como análise epidemiológica do problema. 
Nessa direção e como prosseguimento e aperfeiçoamento do processo de coleta de informações, foi desenvolvido junto ao NHE, para utilização da Vigilância Epidemiológica do HCFMRP, um software chamado IntegraVep com o intuito de armazenar os dados de trauma existentes em fichas em papel a fim de permitir fácil recuperação e geração de relatórios estatísticos (FEKETE, 2008).

Esse sistema de notificação e vigilância do trauma permite que os dados do paciente como nome, idade, naturalidade, passagem (data de internação e alta), CID, dentre outros, sejam importados diretamente do banco de dados do Hospital das Clínicas de Ribeirão Preto. Mais ainda, no momento da inserção de um registro de trauma, juntamente à importação do banco de dados do HCFMRP, são fornecidas informações de escores prognósticos Revised Trauma Score (RTS), Injury Severity Scale (ISS), Trauma and Injury Severity Score (TRISS), necessidade de cirurgias pelas diversas especialidades e condição de alta, dentre outros parâmetros hospitalares. Isso tem permitido uma melhora na captura e integração das informações sobre o evento traumático, dados clínicos, índices de gravidade e parâmetros hospitalares.

Neste contexto, o presente estudo visa utilizar os dados existentes no IntegraVep como referência de informações hospitalares dos pacientes vítimas de trauma, associando dados referentes à solicitação de exames radiológicos e laboratoriais durante a avaliação inicial do paciente traumatizado, incrementando o poder de análise crítica dos atendimentos, o que poderá permitir inferências na sua aplicação clínica. 
2 Objetivos 



\subsection{Objetivo geral}

Analisar as características e a evolução dos pacientes vítimas de trauma admitidos no período de 2006 a 2009 na Unidade de Emergência do HCFMRP.

\subsection{Objetivos específicos}

- Identificar e caracterizar o perfil dos pacientes.

- Calcular as medidas de frequência de trauma.

- Descrever a evolução do trauma.

- Verificar a existência de relação entre mecanismo e gravidade.

- Verificar a existência de relação entre gravidade do trauma e demanda de exames laboratoriais e radiológicos.

- Verificar a existência de relação entre a utilização de exames laboratoriais e radiológicos em casos de trauma leve, particularizando alguns exames específicos (radiologia simples de coluna cervical, tórax e bacia; tomografia computadorizada de crânio, tórax e abdome, e tipagem sanguínea e coagulograma). 

3 Material e Método 



\subsection{Delineamento do estudo}

A condução do estudo deu-se com foco em uma análise quantitativa, nãoexperimental com característica retrospectiva e exploratória, cuja principal finalidade foi analisar o perfil e evolução de pacientes vítimas de trauma, atendidos em um hospital terciário de Ribeirão Preto.

Pesquisas com característica não-experimental ou também chamado de observacional são utilizados com maior interesse para apresentar um fenômeno referente a pessoas ou fatos que ocorrem naturalmente (DEGANI apud Polit et al, 2011).

O termo retrospectivo refere-se a um fenômeno que ocorreu no passado e é observado no presente. A pesquisa com característica exploratória tem seu início a partir de um acontecimento que desperta interesse, passando a investigar sua natureza e demais fatores associados (DEGANI apud Polit et al, 2011).

Após a obtenção dos dados iniciais a partir do IntegraVep, foram obtidos os dados referente à quantidade de exames laboratoriais (sangue) e radiológicos (ultrassonografia, tomografia computadorizada e radiografia simples) realizados pelo paciente durante o atendimento inicial.

Os agrupamentos de exames laboratoriais e radiológicos foram realizados conforme as Tabelas 1 e 2, respectivamente, baseados na maior utilização dos mesmos durante a avaliação inicial do paciente traumatizado.

Tabela 1. Agrupamento de exames laboratoriais

\begin{tabular}{ll}
\hline & Gasometria \\
& Lactato \\
& HB-HT \\
& Tipagem ABO/RH \\
& Triagem de anticorpos \\
Exames laboratoriais & TP \\
& TTPA \\
& Ureia \\
& Creatinina \\
& Eletrólitos \\
\hline
\end{tabular}


Tabela 2. Agrupamento de exames radiológicos

\begin{tabular}{cl}
\hline & Coluna cervical \\
& Tórax \\
& Bacia \\
\hline \multirow{3}{*}{ Radiografia simples } & Crânio \\
& Face \\
\hline Demais colunas \\
\hline Membros superiores \\
\hline Membros inferiores \\
\hline Crânio \\
\hline Tórax \\
\hline Abdome \\
\hline Abdome e torax \\
\hline Face \\
\hline Coluna cervical \\
\hline Membros superiores \\
\hline Membros inferiores \\
\hline Demais colunas \\
\hline
\end{tabular}

\subsection{Local do estudo e amostra}

Conforme divulgado pelo HCFMRP (HCFMRP, 2011), a Unidade de Emergência dispõe de uma variedade de setores tais como: Box para atendimento às Urgências não traumáticas de pacientes menos graves, atendimento de Ginecologia, atendimento de Ortopedia e Urgências Pediátricas. A Unidade de Emergência possui leitos internação de UTI (Unidade de Terapia Intensiva) Adulta e Pediátrica, Unidade de Queimados, Semi-Intensivos, Isolamento, Clínica Cirúrgica e Médica, Neurologia, Neurocirurgia, Ginecologia, Pediatria, Moléstias Infecciosas Infantil, Cirurgia de Cabeça e Pescoço, Ortopedia e Psiquiatria.

A Unidade de Emergência do HCFMRP conta em sua porta de entrada com uma Sala de Estabilização Clínica para pacientes clínicos em estado grave e uma Sala de Trauma para pacientes traumatizados, que após estabilização inicial podem ser transferidos para as diversas áreas do hospital, de acordo com as suas necessidades.

A equipe médica da sala de trauma é composta de cirurgiões, neurologistas, ortopedistas e, conforme a necessidade, médicos de outras especialidades são a- 
cionados, tais como cirurgia de cabeça e pescoço, neurocirurgia, otorrinolaringologia, oftalmologia, ginecologia/obstetrícia e pediatria. Há também diversos outros profissionais como enfermeiros, auxiliares e técnicos de enfermagem, e demais profissionais de apoio.

Conforme mencionado em (DEGANI, 2011), há o Decreto $\mathrm{n}^{\circ} 13297$ de março de 1979 que atribui ao Hospital das Clínicas a finalidade de servir de campo de ensino e treinamento a estudantes de cursos de graduação e pós-graduação da Faculdade de Medicina de Ribeirão Preto da Universidade de São Paulo (FMRP) e de escolas superiores de "curriculum" relacionados com as ciências da Saúde de forma a prover campo de aperfeiçoamento para profissionais relacionados com a assistência médico-hospitalar, prestar assistência médico-hospitalar e proporcionar meios para o desenvolvimento de pesquisas científicas, realizar cursos especiais no campo da medicina e da saúde e colaborar para o exercício da medicina preventiva e para a educação sanitária da comunidade (SÃO PAULO, 1979).

Os pacientes compreendidos nessa pesquisa foram admitidos na Sala de Trauma, setor que dispõe de equipamentos de monitoração para pacientes vítimas de trauma, independente da faixa etária.

Dentre as etapas de coleta, armazenamento e geração de estatísticas, uma das etapas mais importantes é a coleta de informações, sendo essencial para permitir dados confiáveis e passíveis de cruzamentos estatísticos posteriormente. No caso da Vigilância Epidemiológica, quanto mais rápido forem obtidas informações relevantes de cada caso de doença de notificação compulsória, melhor será a vigilância das doenças e mais rápido serão tomadas decisões efetivas localmente (GULA apud Vaughan J.P, 2010).

No caso do NHE da Unidade de Emergência do HCFMRP, as causas externas fazem parte das doenças de notificação compulsória desde 2004. Para o estudo, foram considerados estes pacientes cujos dados estavam inseridos no IntegraVep, com admissão entre janeiro de 2006 a dezembro de 2009.

Foram acrescidas às informações extraídas do IntegraVep, os dados de quantificação de exames laboratoriais e radiológicos obtidos a partir do sistema informatizado do HCFMRP. 


\subsection{Fonte Primária de Dados e Dados Complementares}

O IntegraVep é um software desenvolvido na linguagem Java e executado nos computadores do NHE do HCFMRP.

Para o desenvolvimento do software, foi utilizado o NetBeans, que é um ambiente de desenvolvimento IDE que pode ser obtido gratuitamente pela internet. Ele dispõe de ferramentas e recursos necessários para desenvolver sistemas na linguagem Java, além de outras linguagens como por exemplo $\mathrm{C}, \mathrm{C}++$ e $\mathrm{PHP}$ (NETBEANS, 2012).

Como mencionado, o NetBeans é um IDE. O termo IDE, ou como também pode ser mencionado "ambiente de programação integrado" é um software composto por um editor de código-fonte, um compilador, um depurador e um construtor de interface gráfica de usuário. É possível encontrar diversos IDEs no mercado, podendo ser obtido pela internet ou vindo acompanhado de outro software. O principal motivo para a utilização de um IDE é pelo fato de prover um ambiente amigável para desenvolver em diversas linguagens de programação modernas como Java (FUREY, 2012).

A linguagem Java foi escolhida devido às características como portabilidade, manutenibilidade, facilidade de documentação e reuso de código (DEITEL, 1998).

No início do levantamento de requisitos foi observado que um dos principais fatores solicitados é que o sistema começasse a ser utilizado em curto tempo. Com a urgência na implementação do sistema, foi escolhida uma metodologia de desenvolvimento que permitisse a análise progressiva e interativa dos requisitos. Assim, para o desenvolvimento foi utilizado o modelo de prototipação, que é considerado um modelo evolucionário (PRESSMAN, 2005).

Os passos do processo de prototipação podem ser observados na Figura 3.

A metodologia de desenvolvimento de prototipação interativa tem como base o desenvolvimento inicial do sistema, apresentá-lo aos usuários de forma a obter comentários e durante as diversas etapas, ir aproximando o sistema cada vez mais de forma a atender os requisitos solicitados. Essas etapas são constantes até que possa ser considerado que o sistema atingiu plenamente os requisitos. Nesse momento pode-se considerá-lo como finalizado (SOMMERVILLE, 2003). 


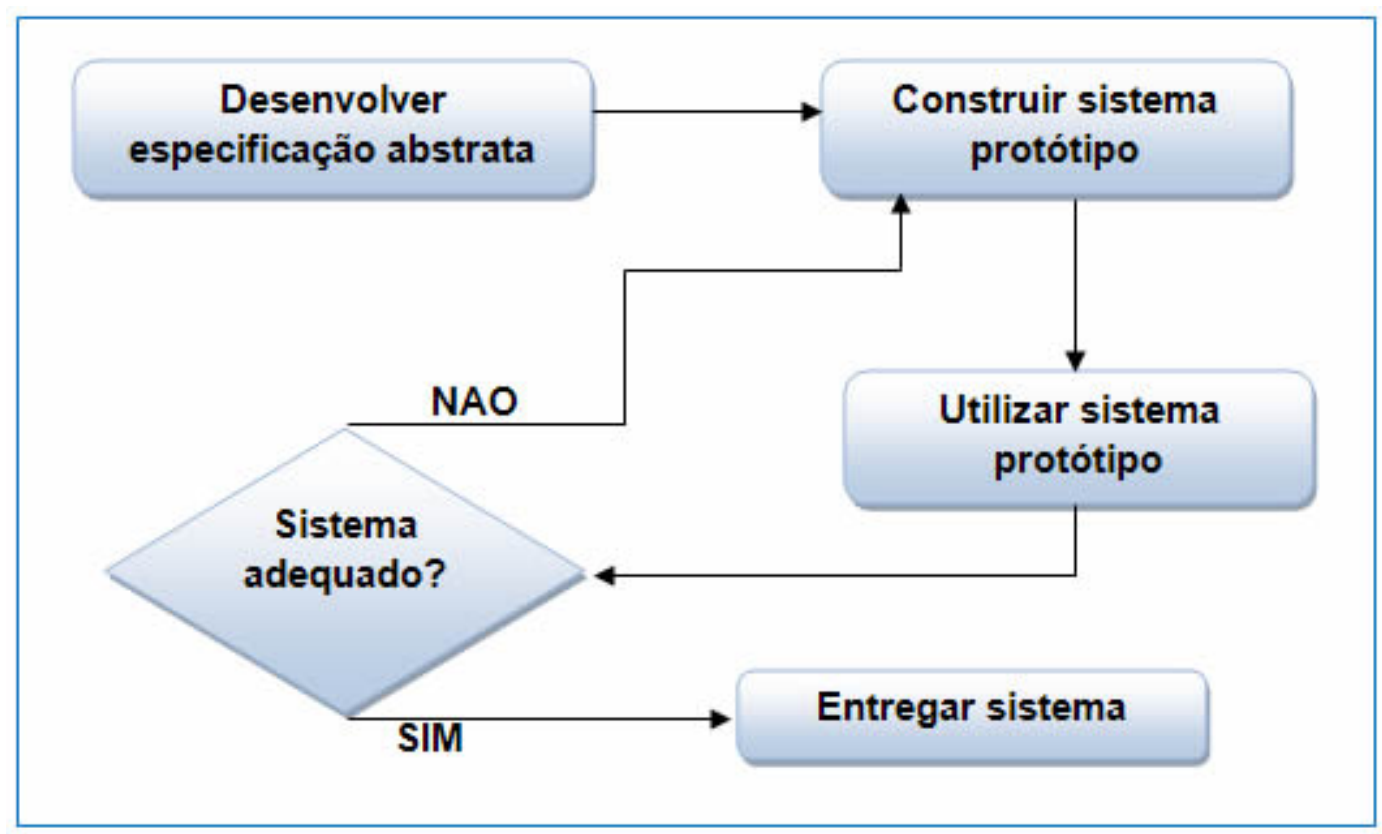

Figura 3. Etapas da prototipação de software

Os dados do IntegraVep são armazenados em um banco de dados PostgreSQL em um servidor do NHE, localizado fisicamente na Unidade de Emergência do HCFMRP.

Por definição:

"Um banco de dados é uma coleção de informações, preferencialmente relacionadas e organizadas. Um banco de dados consiste de arquivos existentes fisicamente no computador onde está instalado o sistema gerenciador de banco de dados.

Uma base de dados é muito mais um conceito do que um objeto físico e é utilizado para armazenar as tabelas que receberão os dados. Por definição, um banco de dados é um objeto estruturado, composto de estruturada de dados e metadados, onde os metadados são a parte estruturada. Os dados de um banco de dados são a informação armazenada, como os dados dos pacientes e suas informações relacionadas.

Os metadados descrevem a estrutura aplicada pelo banco de dadospara os dados dos pacientes, ou seja, os metadados são a definição das tabelas existentes em uma base de dados (POWEL, 2006).”. 
O PostgreSQL é um Sistema Gerenciador de Banco de Dados (SGBD), objeto-relacional de código aberto, tendo mais de uma década de vida. Trata-se de um banco de dados extremamente robusto e confiável, sendo também flexível e rico em recursos. É considerado um banco de dados objeto-relacional, pois implementa as características de um SGBD relacional e algumas características de orientação a objetos, como herança e tipos personalizados (POSTGRESQL, 2012).

O banco de dados foi modelado com o software DBDesigner. Esse software oferece recursos de modelagem de dados para permitir criar diagramas de Modelo Entidade-Relacionamento (MER) (FABFORCE, 2012).

Para as tarefas de criação do banco de dados e gerenciamento foi utilizado o software PgAdmin (PGADMIN, 2011). O PgAdmin é um software voltado para gestão de banco de dados PostgreSQL para diversas plataformas de computadores e pode ser copiado e utilizado gratuitamente (PGADMIN, 2012).

Juntamente ao PgAdmin, foi também utilizado o software EMS SQL Manager. Trata-se de um software que faz tarefas similares ao PgAdmin, porém oferece recursos mais fáceis e de maneira mais simplificada e automatizada para o processo de desenvolvimento, design, exploração e manutenção das bases da dados PostgreSQL. Permite também construir declarações de consulta compostas e estruturadas e gerenciar direitos de usuários do banco de dados PostgreSQL (EMS SQL Manager, 2012). No desenvolvimento do sistema foi usada a versão Lite do EMS SQL Manager que é oferecida para download gratuitamente a partir do site do fabricante.

A criação e modelagem do banco de dados foram feitas usando o modelo relacional, pelo fato de apresentar um conjunto de regras necessárias ao projeto como, por exemplo:

- Apresentar a informação de maneira única, sem duplicidade;

- Permitir acesso lógico e de maneira única a todo valor atômico através do nome de tabela, valor de chave primária e nome da coluna;

- Permitir entrada de valores nulos quando desejado;

- Permitir criar e manipular relacionamentos para os métodos de consulta, inserção, alteração e remoção de dados (DATE, 1999). 
Alguns dos softwares utilizados, como por exemplo, o PgAdmin e o NetBeans são intitulados "software livre". Esse termo se refere a um software que possui uma licença que permite ao usuário o que a Free Software Foundation (FSF) define como "as quatro liberdades do usuário" (FREE SOFTWARE, 2012), sendo:

- Liberdade $n^{\circ} 0$ : A liberdade para executar o programa, para qualquer propósito;

- Liberdade $n^{\circ}$ 1: A liberdade de estudar como o programa funciona, e adaptá-lo para as suas necessidades. Acesso ao código-fonte é um pré-requisito para esta liberdade;

- Liberdade $n^{\circ}$ 2: A liberdade de redistribuir, inclusive vender, cópias de modo que você possa ajudar ao seu próximo;

- Liberdade $n^{\circ}$ 3: A liberdade de modificar o programa, e liberar estas modificações, de modo que toda a comunidade se beneficie. Acesso ao código-fonte é um pré-requisito para esta liberdade;

A entidade FSF (Free Software Foundation) é a principal articuladora e defensora desse tipo de licenciamento de software.

Os dados coletados pelo IntegraVep são integrados em uma ficha de notificação de trauma que contém várias variáveis, a saber:

1) Informações do paciente:

a. nome completo.

b. número de registro.

c. Idade: em anos completos, até a data do trauma

d. Data de nascimento: dia/mês/ano de nascimento

e. Sexo: masculino ou feminino

f. Estado Civil: solteiro, casado, amasiado, viúvo, separado, desquitado, divorciado.

g. Município e estado: local de residência

h. Escolaridade: $1^{\circ} \mathrm{grau}, 2^{\circ} \mathrm{grau}$, ensino superior, nehum.

i. Profissão: conforme lista de profissões existentes no Sistema do hospital.

2) Informações sobre o evento traumático: 
a. Data do trauma: dia/mês/ano do trauma.

b. Hora do trauma: a hora de ocorrência.

c. Dia da semana: os dias da semana de segunda-feira a domingo.

d. Cidade de ocorrência do trauma: município e estado

e. mecanismo do trauma: acidente com máquina, queda pedestre, ciclista, queimadura, veículo automotor, arma de fogo, arma branca, motocicleta, agressão, outro

f. Etiologia do trauma: contuso, penetrante, combinado ou queimadura.

g. Tipo de transporte: Unidade de Suporte Básico (USB) de Ribeirão Preto, Unidade de Suporte Básico de outra cidade, Unidade de Suporte Avançado (USA) de Ribeirão Preto, Unidade de Suporte Avançado de outra cidade, Resgate/Bombeiros, Concessionária, Polícia ou Particular.

h. Código CID das lesões traumáticas: no capítulo XIX, sob o nome lesões, envenenamento e algumas outras consequências de causas externas. São codificadas de S00 a T98, podendo ser associadas a diferentes tipos de traumatismos, suas complicações e sequelas, queimaduras, intoxicações e ferimentos.

i. Código CID da causa externa: Classificação do trauma, considerando os códigos dos acidentes de transporte, quedas, afogamentos, lesões autoprovocadas voluntariamente, agressões e outros mencionados no capítulo XX - Causas externas de morbidade e de mortalidade (V01 a Y98).

j. Tentativa de autoextermínio: dado binário (sim/não).

k. Acidente de trabalho: dado binário (sim/não).

I. Intoxicação exógena: dado binário (sim/não).

3) Índices de gravidade:

a. Revised Trauma Score (RTS): é um índice fisiológico proveniente da avaliação do estado neurológico pela escala de coma de Glasgow, da pressão arterial sistólica (PAS) e da 
frequência respiratória (FR), calculado na admissão do paciente. Correlaciona-se com a mortalidade precoce.

b. Injurity Severity Score (ISS): é um índice anatômico que permite a estratificação numérica da gravidade da lesão por levar em consideração as lesões provocadas nos vários segmentos do corpo. A gravidade das lesões anatômicas é determinada através do exame físico, testes radiológicos, cirurgia e autópsia. Seu valor varia de 1 a 75 e o risco de morte aumenta quanto maior o escore. Consideram-se os traumas com ISS de 1 a 8 como leves; 9 a 15 como moderados; 16 a 24 como graves e maiores que 24 como muito graves. É calculado após completada a investigação diagnóstica e instituído o tratamento.

C. Trauma and Injury Severity Score (TRISS): permite 0 cálculo da probabilidade de sobrevida através da associação entre o índice fisiológico (RTS), o índice anatômico (ISS), levando em consideração ainda, a idade e o mecanismo de trauma, se contuso ou penetrante.

\section{4) Comorbidades \& Complicações:}

a. Código CID de comorbidades ou doenças preexistentes: patologias diagnosticadas em data anterior à admissão do paciente devido ao trauma, como por exemplo: hipertensão arterial, diabetes, síndromes coronarianas agudas, epilepsia, hepatopatias, insuficiência renal crônica, AIDS, neoplasias e distúrbios psiquiátricos.

b. Código CID de complicações: complicações ocorridas após a admissão do paciente devido ao trauma, como por exemplo: sepse, insuficiência renal aguda, síndrome da disfunção de múltiplos órgãos.

\section{5) Evolução clínica:}

a. Cirurgia: dado binário (sim/não). 
b. Especialidade(s) cirúrgica(s): Especialidades que submeteu(ram) o(s) paciente(s) a procedimentos operatórios.

c. Data de alta: data da alta do hospital

d. Condição de alta: Condição que o paciente recebeu alta, sendo: Limitações moderadas, Limitações Graves, Boa Recuperação, Estado vegetativo persistente, Alta a pedido, Evasão, Transferência ou Óbito.

e. Data de internação no CTI: dia/mês/ano de internação

f. Data de alta do CTI: dia/mês/ano de alta do CTI

g. Causa mortis principal e secundária: choque circulatório, traumatismo crânio encefálico, sepse, insuficiência renal aguda, complicações cardíacas, síndrome da insuficiência de múltiplos órgãos.

Para a existência desses dados no IntegraVep, informações como CID, período de internação em CTI e dados pessoais como nome e idade são importadas diretamente do banco de dados do Hospital das Clínicas de Ribeirão Preto (HCFMRP). Um digitador insere algumas informações como, por exemplo, os scores prognósticos ISS, RTS, TRISS e Glasgow, necessidade de cirurgia nas diversas especialidades, condição de alta e quantidade de cirurgias.

Os dados referentes aos exames laboratoriais e radiológicos foram agregados posteriormente para possibilidade de quantificações.

A obtenção de informação dos exames radiológicos e laboratoriais foi possível através da disponibilização da equipe de informática do HCFMRP de um recurso que permitisse ao IntegraVep fornecer o registro do paciente, sua data de internação, data de alta e o tipo de exame desejado, podendo ser radiológico ou laboratorial.

Os dados foram todos armazenados no PostgreSQL. Alguns campos foram relacionados diretamente no PostgreSQL e outros através de planilhas com os dados exportados.

Durante a digitação dos dados, a partir do registro do paciente e do período de internação hospitalar (data de internação e alta), o IntegraVep executa algumas 
stored procedures ${ }^{1}$ no banco de dados do HCFMRP com a finalidade de importar os dados do paciente (nome, idade, etc); importar período de internação em CTI, quando houver; importar os CIDs de sua causa de externa, os CIDs de lesões traumáticas e os CIDs de complicações.

Para a importação das informações existentes no banco de dados do HCFMRP, foi utilizado um web service, que se trata de uma solução usada para integrar diferentes sistemas, fazendo com que estabeleçam comunicação entre si (MOLLER, 2006). Um web service é um componente, acessível através de protocolos padrões da Internet. Como componentes, esses serviços possuem uma funcionalidade que pode ser reutilizada sem a preocupação de como é implementada. Web Services combinam os melhores aspectos do desenvolvimento baseado em componentes e os recursos de acesso cruzado de informação, onde o web service pode prover a um software, fácil acesso aos dados de outro software.

Foi então, criado um software para ficar em execução no servidor, ficando responsável por estabelecer comunicação entre o sistema IntegraVep e o banco de dados do HCFMRP à medida que fosse necessária a obtenção de dados dos pacientes. Esse software residente no servidor era o responsável para, a partir do registro do paciente, trazer os dados básicos do mesmo como, por exemplo, nome, idade e estado civil.

\section{3.a. Telas do IntegraVep}

O funcionamento do IntegraVep é restrito aos computadores do NHE da Unidade de Emergência do HCFMRP, onde os computadores do setor têm o software instalado.

O IntegraVep possui um cadastro dos usuários com permissão de seu uso, que têm acesso ao uso do software mediante login com usuário e senha.

\footnotetext{
${ }^{1}$ Uma Stored Procedure é um conjunto de comandos que fica armazenado no banco de dados e pode ser chamado a qualquer momento tanto pelo SGBD (sistema Gerenciador de Banco de Dados) quanto por um sistema que faz interface com o mesmo, no caso, pelo IntegraVep. O uso de Stored Procedures é uma técnica eficiente de executar operações repetitivas
} 
Logo que o usuário faz seu login, visualizada a primeira tela do software, onde é possível Visualizar os menus principais "SV1" e "Trauma", podendo ter fácil acesso para inserir os dados de um paciente vítima de trauma ou também buscar por um paciente previamente cadastrado (Figura 4).

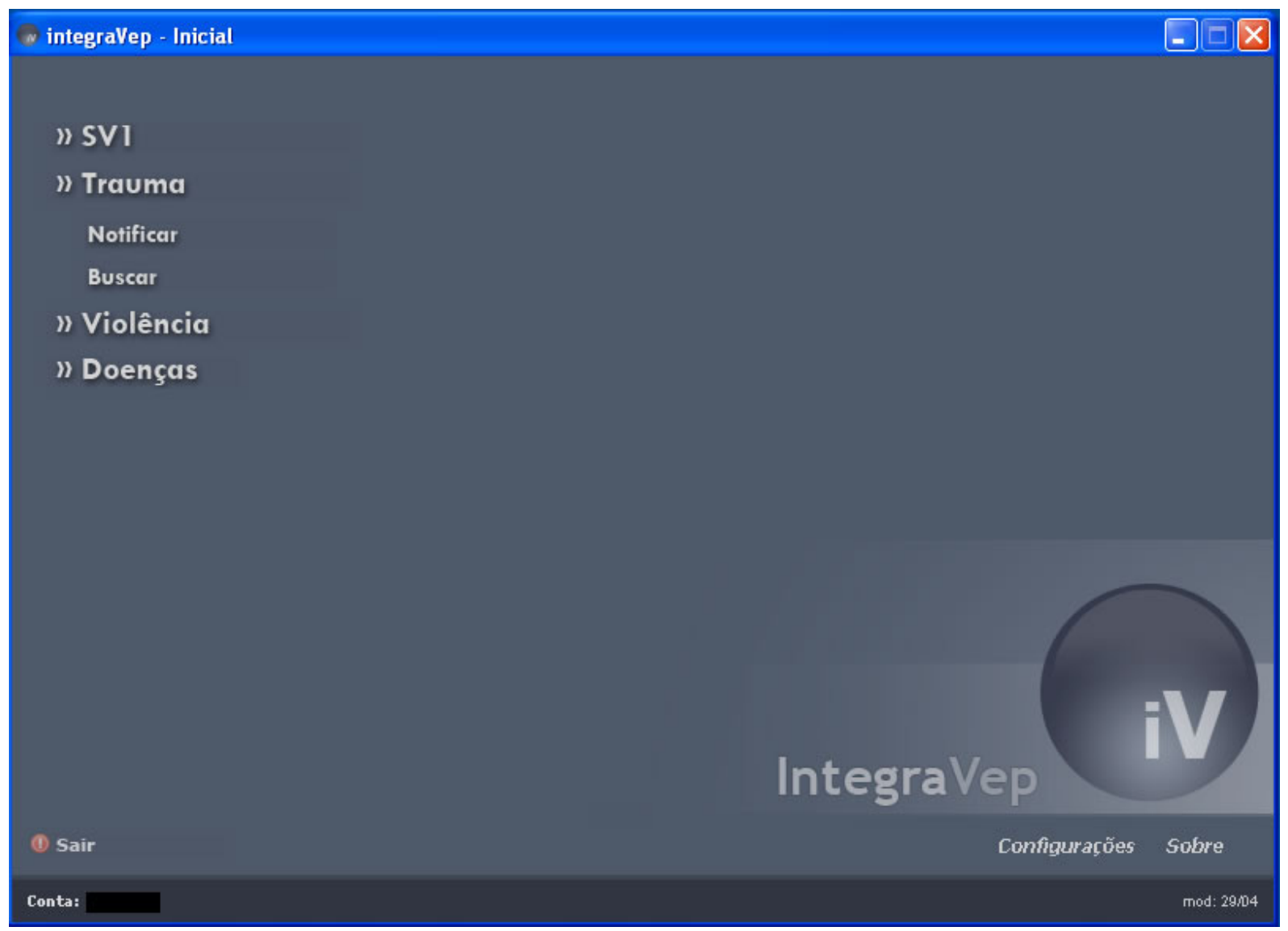

Figura 4. Tela inicial do IntegraVep

Ao optar pela opção de notificação de um paciente vítima de trauma, Ihe será apresentada uma tela com a aba "I - Informações do paciente", onde é possível inserir manualmente os dados pessoais do paciente como por exemplo nome, estado civil, endereço e demais dados. Nessa mesma tela existe um botão "Dados HC" que aciona o web service do IntegraVep para que a pessoa que está entrando com os dados no IntegraVep necessite apenas inserir o registro do paciente. Assim, todos os demais dados pessoais são automaticamente trazidos do banco de dados do sistema hospitalar do HCFMRP. Após os dados serem trazidos e exibidos cada qual em seu campo correspondente, o digitador pode alterar alguma informação, caso 
necessário. Ainda nessa tela existe um campo que calcula automaticamente a idade completa da pessoa a partir de seu nascimento e da data do trauma (Figura 5).

Estando completos os dados desta aba, o digitador pode passar à segunda aba, chamada "II - Informações sobre o evento".

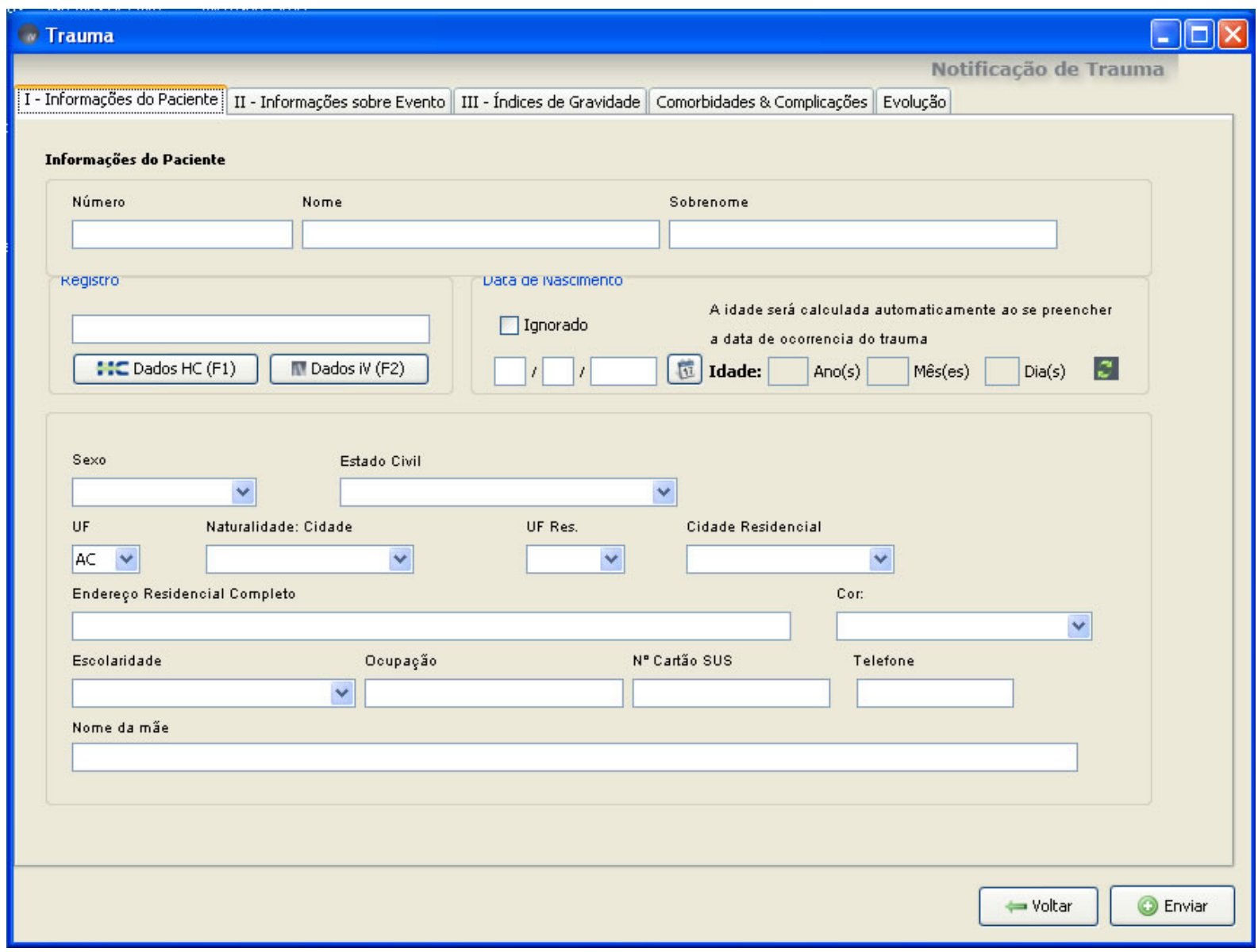

Figura 5. Tela do integraVep exibindo a aba "Informações do paciente"

Na segunda aba, chamada "II - Informações do evento" é inserido dentre vários dados, informações a respeito do mecanismo de trauma, local de ocorrência, data da ocorrência, meio de transporte e também as datas de admissão e alta (Figura 6$)$.

Nessa tela, existe um botão que aciona o web service do IntegraVep de forma que, a partir da data de admissão e data de alta, o IntegraVep obtêm automaticamente o(s) CIDs associados ao paciente em sua internação. O digitador pode, conforme sua escolha, inserir o CID manualmente. 
Após a análise prévia dos possíveis CIDs associados ao paciente vítima de trauma, os códigos são distribuídos em uma listagem tabular na parte inferior da janela conforme a região do corpo associada ao CID. Esse formato de exibição permitiu maior clareza aos usuários do IntegraVep para visualização das lesões.

Estando completos os dados desta aba, o digitador pode passar à terceira aba, chamada "III - Índices de gravidade".

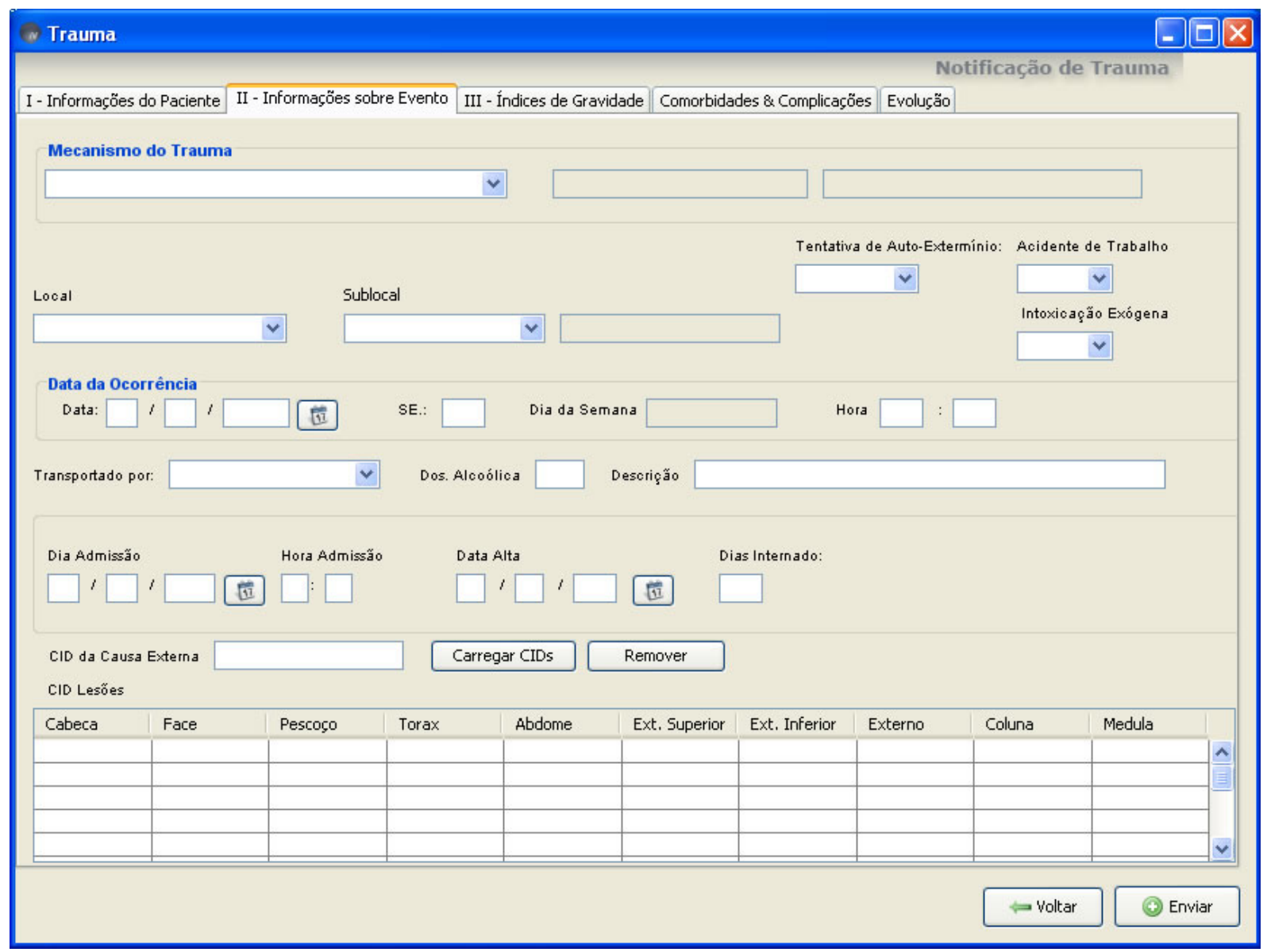

Figura 6. Tela do integraVep exibindo a aba "Informações sobre o evento"

Na terceira aba, chamada "III - Índices de gravidade" são inseridos os dados das lesões por região do corpo (AIS) que irão compor o ISS (Figura 7).

Também são inseridos os parâmetros de escore da escala de coma de Glasgow, pressão arterial sistólica e frequência respiratória para que o IntegraVep calcule automaticamente o RTS e também o TRISS com os dados da faixa etária do pacien- 
te (maior ou menor que 54 anos) e do mecanismo de trauma, se contuso ou penetrante.

Após inserir os dados dos índices de gravidade, o digitador passa para a quarta aba, chamada "Comorbidades e complicações".

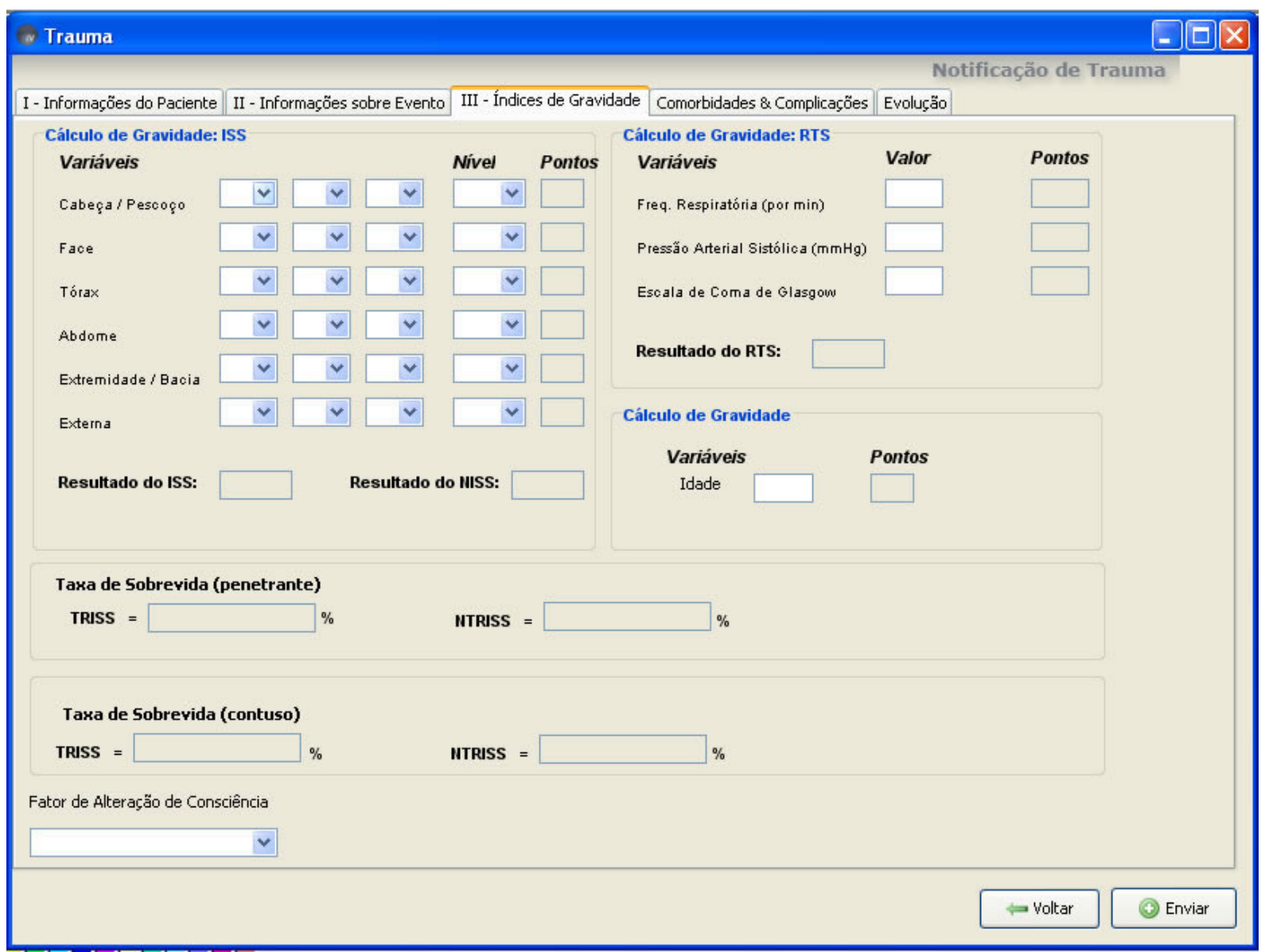

Figura 7. Tela do IntegraVep exibindo a aba "III - Índices de gravidade"

$\mathrm{Na}$ quarta aba, chamada "Comorbidades e complicações" é possível cadastrar doenças preexistentes e complicações do paciente (Figura 8). 


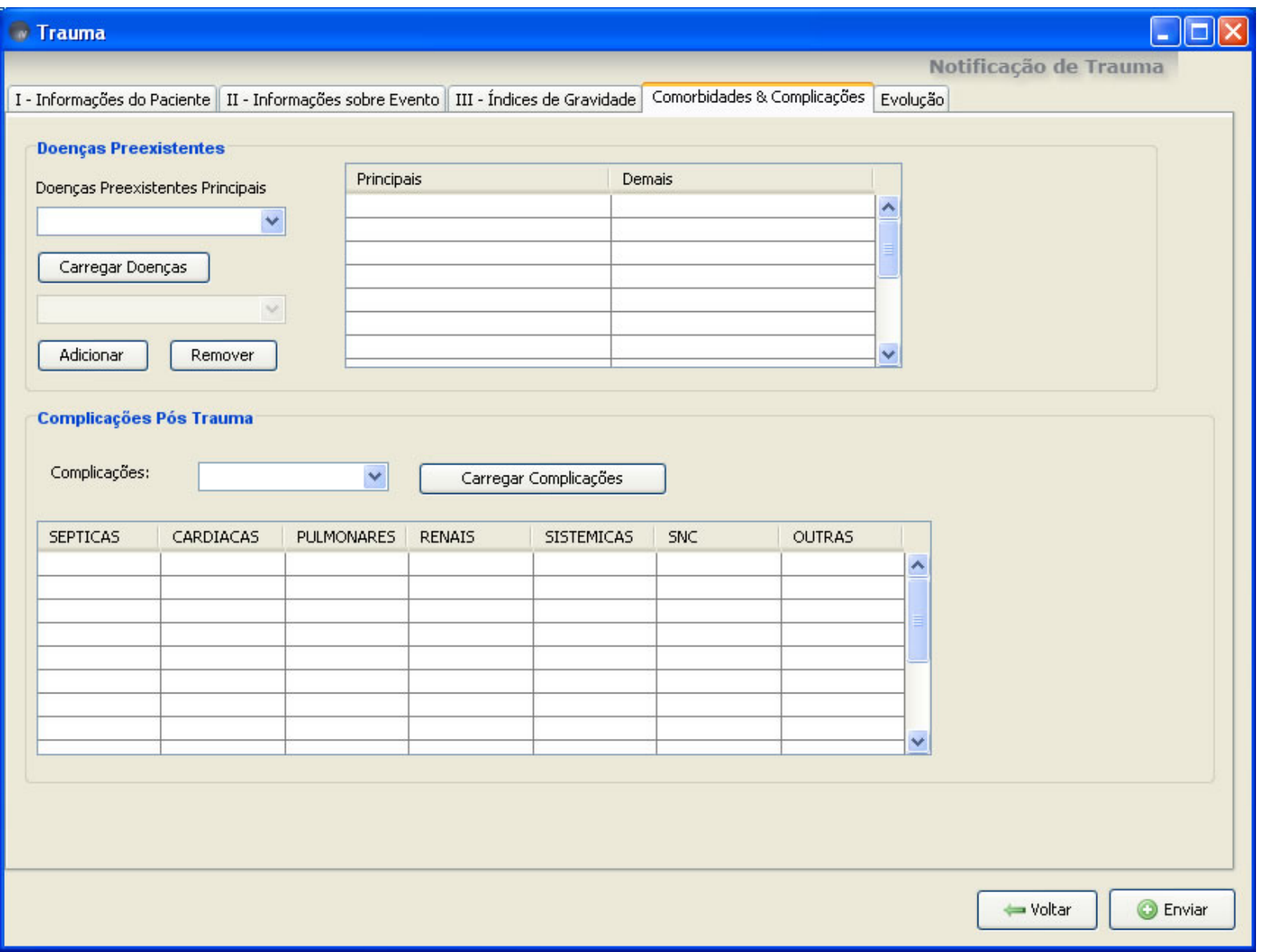

Figura 8. Tela do IntegraVep exibindo a aba "comorbidades e complicações"

Por fim, é possível inserir na quinta aba, chamada de "Evolução", onde são cadastrados dados de cirurgia como quantidade de cirurgias por especialidade, passagem pela UTI, constando a data de entrada e saída da UTI, a condição de alta e informações de óbito, quando houver (Figura 9). 


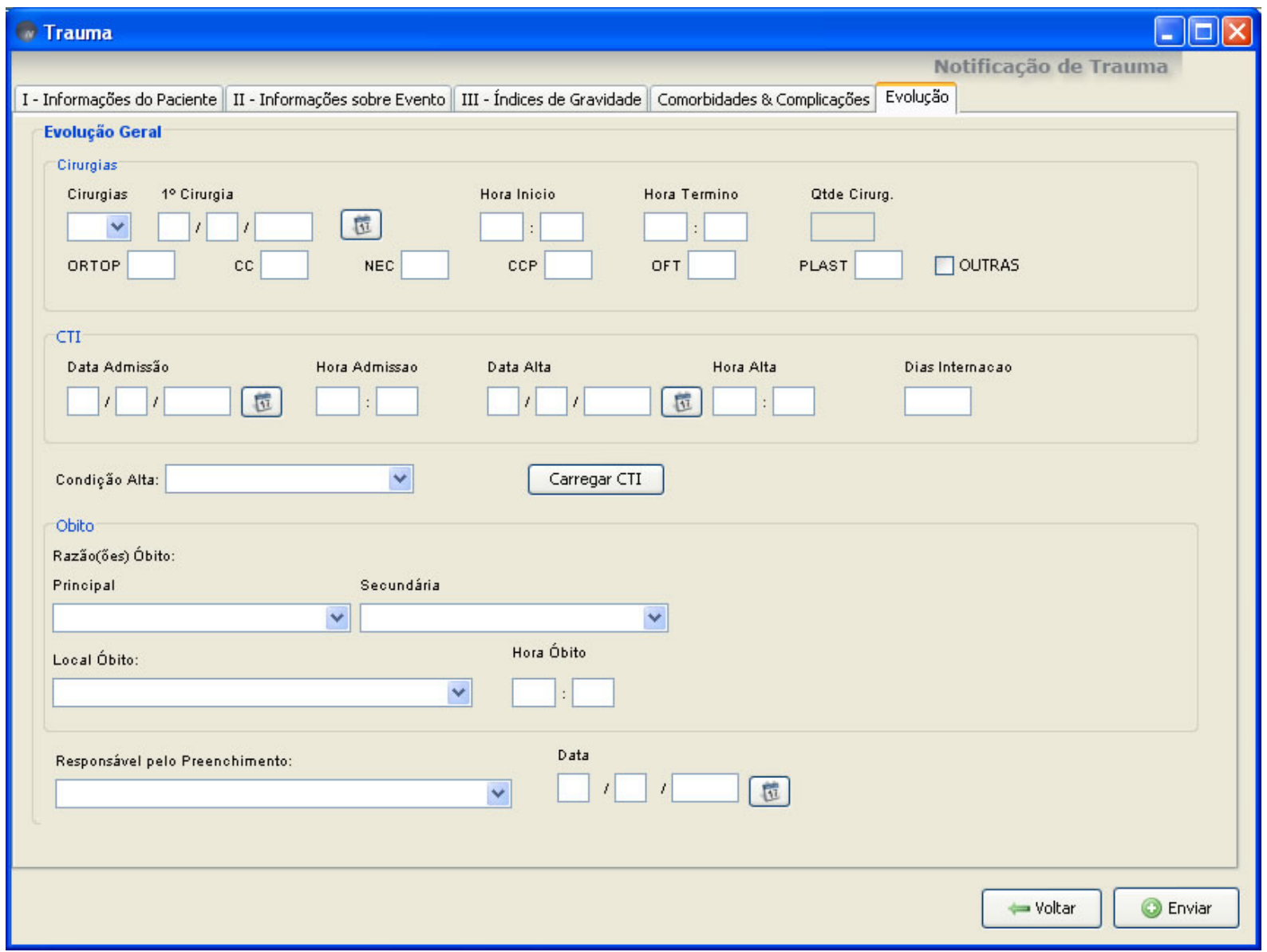

Figura 9. Tela do IntegraVep exibindo a aba "Evolução"

\subsection{Aspectos Técnicos do Software IntegraVep}

O software IntegraVep surgiu com o intuito de maior agilidade, evitar retrabaIho, redução de falha no cadastramento de notificação e mais facilidade na obtenção de estatísticas em relação ao processo anterior que era feito manualmente e armazenado em papel, dificultando o levantamento posterior de informações.

Para melhor compreensão do grande trabalho envolvido no processo de registro e notificação de um paciente, é salutar mencionar (FEKETE, 2008) que fez um estudo do fluxo das fichas do HCFMRP e observou que antes da existência do IntegraVep, os profissionais da Vigilância Epidemiológica necessitavam buscar por pacientes no ambulatório a partir de uma lista com o intuito de localizar quais pacientes deveriam ser notificados. Também precisavam verificar para saber quais pacientes já haviam sido notificados, a fim de não haver dupla notificação. 
Depois de localizado o paciente, caso o mesmo não tivesse ainda sido notificado, as informações básicas do mesmo como, por exemplo: nome e endereço, eram buscadas no sistema do HCFMRP. A partir dessa consulta, era preenchida em papel uma ficha com os dados básicos do paciente chamada de SV1. A SV1 podia também ser recebida já preenchida pelas funcionárias da Unidade de Emergência do HCFMRP.

Uma vez com a SV1 preenchida ou recebida, era então solicitado ao SAME o prontuário do paciente que seria notificado.

Um fator facilitador do preenchimento de todos os dados do atendimento inicial do paciente traumatizado foi a confecção e utilização de uma ficha padronizada com informações do atendimento pré-hospitalar e de cada fase do atendimento hospitalar em 2000 (anexo 1).

Com os prontuários em mãos, uma enfermeira da Vigilância Epidemiológica passa para as fichas de notificação do trauma (anexo 2) o que foi diagnosticado pelo médico ao analisar o prontuário, sendo que existe uma ficha específica para cada doença notificável. Após esse processo, une-se essa ficha com a SV1, sendo estas encaminhadas para outra funcionária digitá-las no SINAN NET (sistema de notificação do SINAN), onde são por fim digitados todos os campos da ficha (os dados específicos da doença a ser notificada como também os dados básicos do paciente).

O IntegraVep é um software que possui uma interface direta com os dados do sistema hospitalar utilizado no HCFMRP e de seus respectivos subsistemas, fazendo com que haja um grande reaproveitamento de dados referentes a pacientes já cadastrados em tal sistema.

É um sistema desenvolvido em Java, sendo executado localmente em cada computador, acessando um banco de dados PostgreSQL em um servidor.

O servidor utilizado para o armazenamento do banco de dados também aloca webservices em Java de forma que, ao ser fornecido o registro do paciente, seus dados pessoais são importados a partir do banco de dados do sistema hospitalar do HCFMRP. Essa ação é extremamente importante por reduzir os possíveis erros e inconsistência de digital, além de trazer maior agilidade no preenchimento dos registros. 
O processo do preenchimento dos registros é posterior ao preenchimento de uma ficha em papel, de forma manual, onde constam as informações referentes ao trauma.

O desenvolvimento do software IntegraVep ocorreu após várias reuniões com profissionais do NHE e médico da cirurgia do trauma, de forma a obter os requisitos iniciais.

Durante o desenvolvimento, outras reuniões periódicas foram realizadas a cada liberação de novos recursos para demonstração do sistema e com o objetivo tanto de definir os próximos passos para o desenvolvimento quanto melhorias dos recursos já existentes.

O resultado foi um software que obtêm os dados do paciente, internação em CTI (quando houver) e CID de maneira automatizada, conseguindo maior confiabilidade das informações e agilidade no preenchimento das fichas. Os demais campos que constam na ficha em papel, preenchida no NHE, são digitados manualmente e, sempre que possível, foram utilizados campos com caixas de seleção fechadas, também para agilizar o preenchimento e evitar erros de digitação, tornando mais fácil a obtenção posterior de estatísticas.

\subsection{Preparação dos dados}

O software IntegraVep, utilizando o método de prototipação e tendo seu desenvolvimento de forma incremental, passou por diversas alterações de interface, funcionalidades, cálculos automáticos e, consequentemente, de esquema de banco de dados.

A ação inicial foi em busca de uniformizar os dados existentes no banco de dados. Há alguns campos no IntegraVep composto de uma caixa de seleção. Em alguns anos, esses campos armazenava um identificador numérico, já, em outros anos, era armazenado de forma textual. Por exemplo, o campo que armazena o meio de transporte do paciente, em alguns anos era armazenado apenas o valor numérico. Em outros anos, era armazenado textualmente: "1 - USA", "2 - USB RP”, "3 USB outra cidade" e assim por diante. Esses dados foram normalizados, de forma que fosse possível obter uniformidade. 


\subsection{Caracterização de trauma}

Trauma pode ser entendido como o conjunto de perturbações causadas subitamente por um agente físico, de etiologia, natureza e extensão variadas. O trauma é proveniente da ação de agentes etiológicos conhecidos, exige atitudes e procedimentos terapêuticos específicos, e, acima de tudo, pode ser evitável.

Todo tipo de lesão externa ocorrida, desde escoriações superficiais sem nenhum risco de vida aparente até grandes contusões ou ferimentos graves, com chance de óbito do paciente é considerado trauma.

O trauma pode ser caracterizado como contuso, que ocorre quando há transferência de energia em uma grande área do corpo, podendo ocorrer por uma aceleração/desaceleração brusca de velocidade, deslocando uma estrutura ou parte dela, provocando sua laceração ou ainda, com um impacto que comprima uma estrutura ou parte dela, sobre outra região, causando a lesão. Pode também ser caracterizado como penetrante, cuja principal característica é a transferência de energia em uma área concentrada, dessa forma, há pouca dispersão de energia, o que causa laceração da pele.

As lesões geradas pelo trauma penetrante não incluem somente os tecidos na trajetória do objeto. Uma lesão provocada por arma de fogo onde houve uma alta transferência de energia, não se resume apenas na trajetória do projétil, mas também nas estruturas adjacentes que sofreram um deslocamento temporário. (SALES apud PEPULIM, 2010).

\section{7 Índices Prognósticos: ISS, RTS, TRISS}

O trauma pode ter variação desde escoriações superficiais, não oferecendo qualquer risco de vida, até grandes contusões ou ferimentos graves que causam a morte instantânea da vítima.

Dessa forma, é importante o conhecimento do nível de gravidade do paciente vítima de trauma. Esse conhecimento é fator decisivo para orientar a conduta e o 
nível de complexidade hospitalar exigido, podendo também ser usado para aferir a qualidade do atendimento prestado.

Existem diversos índices prognósticos para diferentes perfis de pacientes. Os índices de trauma são sistemas de pontuação criados para avaliar as alterações fisiológicas, a gravidade das lesões anatômicas e a probabilidade de sobrevida dos pacientes vítimas de trauma (COIMBRA et al., 1997).

A correta definição da gravidade do paciente infere na probabilidade de sobrevida para do mesmo, o que compromete o médico responsável pelo atendimento por um resultado até certo ponto previsível, baseado no escore de gravidade. (PEREIRA Jr., 1999)

\subsection{1 Índice fisiológico: RTS}

O RTS é um score fisiológico e considera parâmetros de sinais vitais do paciente como Escala de Coma de Glasgow (E.C.G.), pressão arterial sistólica (PAS) e freqüência respiratória (FR), com valores entre 0 e 7,84 e é obtido por: $\mathrm{RTS}=0,9368$ $\times \mathrm{ECG}+0,7326 \times \mathrm{PAS}+0,2908 \times \mathrm{FR}$.

\subsection{2 Índice anatômico: ISS}

O ISS é um score anatômico, considerando as lesões em áreas do corpo, sendo:

1- cabeça e pescoço

2- face

3- tórax

4- abdome/conteúdo pélvico

5- extremidades e anel pélvico

6- geral ou externo. 
Cada uma dessas áreas tem sua lesão classificada em:

1- leve

2- moderada

3- grave, sem risco iminente de vida

4- grave, com risco iminente de vida

5- crítica, de sobrevida duvidosa

6- quase sempre fatal.

Sua pontuação varia de 1 a 75 .

Para seu cálculo, os níveis de severidade das três regiões anatômicas mais severamente lesadas são elevados ao quadrado e então somados.

\subsubsection{AIS - Abbreviated Injury Scale}

O Abbreviated Injury Scale (AIS) foi concebido a mais de trinta anos como uma forma sistemática de descrever a severidade de lesões em toda a extensão do corpo de um paciente.

O primeiro intuito do AIS é estabelecer diversos tipos de lesões anatômicas a partir de vários parâmetros (dissipação de energia, risco à vida, sequelas permanentes, tempo de tratamento e tipo de acidente). (GENNARELLI, 2008).

Os princípios que norteiam o AIS são:

- O AIS deve ser um método simples para classificar as lesões por gravidade;

- A terminologia usada para descrever as lesões deve ser padronizada;

- O AIS deve ser utilizável para muitos tipos de lesões;

- O AIS deve ser compatível para coletas de dados em pequena ou grande dimensão;

- Os descritores de lesão devem ser organizados anatomicamente e não fisiologicamente; 
- Cada escala de gravidade deve refletir uma única lesão quando existente;

- O AIS para deve ser único para cada lesão, independente do tempo;

- O AIS deve considerar a lesão e não suas consequências a longo prazo;

- O AIS deve ser mais do que uma taxa de mortalidade ou de probabilidade de vida;

- A pontuação do AIS deve refletir a gravidade da lesão em um adulto saudável;

- A gravidade de uma lesão específica deve ser descrita em relação à sua importância para todo o corpo.

O AIS considera as lesões existentes a partir das seguintes regiões do corpo:

- Cabeça (incluindo crânio e cérebro)

- Rosto (incluindo olhos e ouvidos)

- Pescoço

- Tórax

- Abdômen e pelve interior

- Coluna (cervical, torácica, lombar)

- Extremidades superiores

- Extremidades inferiores

- Pelve e nádegas

- Externa (pele)

- Queimaduras

- Outros traumas

Para cada uma das regiões do corpo mencionada, é aplicado um valor que corresponde à severidade, sendo:

- pequeno 
- moderado

- grave

- grave

- crítico

- máximo

O anexo 3 mostra as lesões traumáticas mais frequentes nas diversas regiões do corpo e cada uma das seis faixas de gravidade.

\subsubsection{Probabilidade de sobrevida: TRISS}

O IntegraVep realiza o cálculo do score prognóstico Trauma and Injury Severity Score (TRISS), que permite estabelecer a probabilidade de sobrevida do paciente, podendo-se avaliar a qualidade do serviço e fazer comparação entre eles (PEREIRA Jr, 1999).

O TRISS é útil para avaliar a possibilidade de uma morte ser evitável (CHIARA, 2009). A avaliação dos números entre mortes evitáveis e mortes reais pode ser um importante indicativo da qualidade do atendimento ao paciente vítima de trauma (TEIXEIRA et al, 2007).

O TRISS trata-se de um cálculo da probabilidade de sobrevida (Ps). Sua obtenção se dá através de:

$$
P S=\frac{1}{\left(1+e^{-b}\right)}
$$

Sendo $b$ uma variável dependente do ISS, RTS, idade e tipo de trauma podendo ser contuso ou penetrante. Seu resultado será um valor entre $0 \%$ e 100\%, sendo que quanto menor for o valor, menor é a chance de sobrevida, e vice-versa.

A variável $b$ é calculada através de combinação linear desses resultados, sendo:

$$
b=b_{0}+b 1(R T S)+b 2(I S S)+b 3(\text { idade })
$$


Os coeficientes $b_{0}, b_{1}, b_{2}, b_{3}$ são derivados de análise de regressão logística e considerando que eles assumem valores diferentes conforme o tipo de trauma (Tabela 3).

Os coeficientes $b_{0}, b_{1}, b_{2}, b_{3}$ se baseiam em um estudo realizado com pacientes vítimas de trauma onde o objetivo era avaliar o resultado da assistência prestada (BOYD CR, 1987).

Segundo (SALES, 2010), o resultado encontrado será dentro de um intervalo de $0 \%$ a $100 \%$ por ser um cálculo de probabilidade, onde o valor de Ps será o valor TRISS correspondente do paciente. A partir do resultado, estima-se que os pacientes com TRISS < 50\% terão pouca ou nenhuma probabilidade de sobreviver, podendo ir a óbito. Já os pacientes com TRISS $\geq 50 \%$ terão probabilidade de sobreviver.

Ainda em (SALES, 2010), encontramos a consideração de que a literatura especializada considera que o TRISS também é importante para monitorar a qualidade do desempenho de um hospital quanto ao atendimento ao paciente vítima de trauma. Pode-se observar através do TRISS que alguns pacientes, mesmo tendo uma probabilidade mais de $50 \%$ de sobreviver vêm a óbito. Indicadores como esse podem apontar para uma possível melhoria do atendimento ao paciente.

Tabela 3. Coeficientes envolvidos no TRISS

\begin{tabular}{ccc}
\hline Coeficiente & Contuso & Penetrante \\
\hline $\boldsymbol{b}_{0}$ & $-0,4499$ & $-2,5355$ \\
$\boldsymbol{b}_{1}$ & 0,8085 & 0,9934 \\
$\boldsymbol{b}_{2}$ & $-0,0835$ & $-0,0651$ \\
$\boldsymbol{b}_{3}$ & $-1,7430$ & $-1,1360$ \\
\hline
\end{tabular}

O TRISS é composto pelo Injury Severity Score (ISS) e Revisited Trauma Score (RTS), a faixa etária do paciente (se maior ou menor que 54 anos) e o mecanismo de trauma, se contuso ou penetrante. 


\subsection{Aspectos éticos}

O Conselho Científico do Centro de Estudos de Emergência em Saúda da Unidade de Emergência do HCFMRP apresentou parecer favorável a este projeto de pesquisa em 25 de novembro de 2011 (anexo 4), sendo encaminhado a seguir ao Comitê de Ética em Pesquisa do HCFMRP.

O Comitê de Ética em Pesquisa do HCFMRP, sob o processo número 15104/2011 aprovou na data de 09/04/2012 este projeto de pesquisa. Esta aprovação é mostrada no anexo 5.

O estudo envolve os bancos do IntegraVep e demais informações provenientes do banco de dados do Hospital das Clínicas da FMRP-USP, onde os dados são utilizados apenas de maneira quantitativa, não envolvendo qualquer identificação do indivíduo. 
4 Resultados 



\section{Análise dos dados}

Os anos de 2006 a 2009 foram analisados e foi observado que ao longo do período, a média de admissões de pacientes vítimas de trauma foi de 2033 pacientes, correspondendo a 2387, 1926, 2180 e 1927 pacientes para os anos de 2006 a 2009, respectivamente (Tabela 4).

Tabela 4. Distribuição de sexo dos pacientes vítimas de trauma

\begin{tabular}{|c|c|c|c|c|}
\hline Sexo & 2006 & 2007 & 2008 & 2009 \\
\hline Masculino & $1778(74,49 \%)$ & $1362(70,72 \%)$ & $1607(73,72 \%)$ & $1398(72,55 \%)$ \\
\hline Feminino & $609(25,51 \%)$ & $564(29,28 \%)$ & $573(26,28 \%)$ & $529(27,45 \%)$ \\
\hline Total & $2387(100,00 \%)$ & $1926(100,00 \%)$ & $2180(100,00 \%)$ & $1927(100,00 \%)$ \\
\hline
\end{tabular}

É possível observar que a maior parte dos pacientes é do sexo masculino, correspondendo a cerca de 70 a $75 \%$, conforme a tendência mundial de casos de trauma (Gráfico 1).

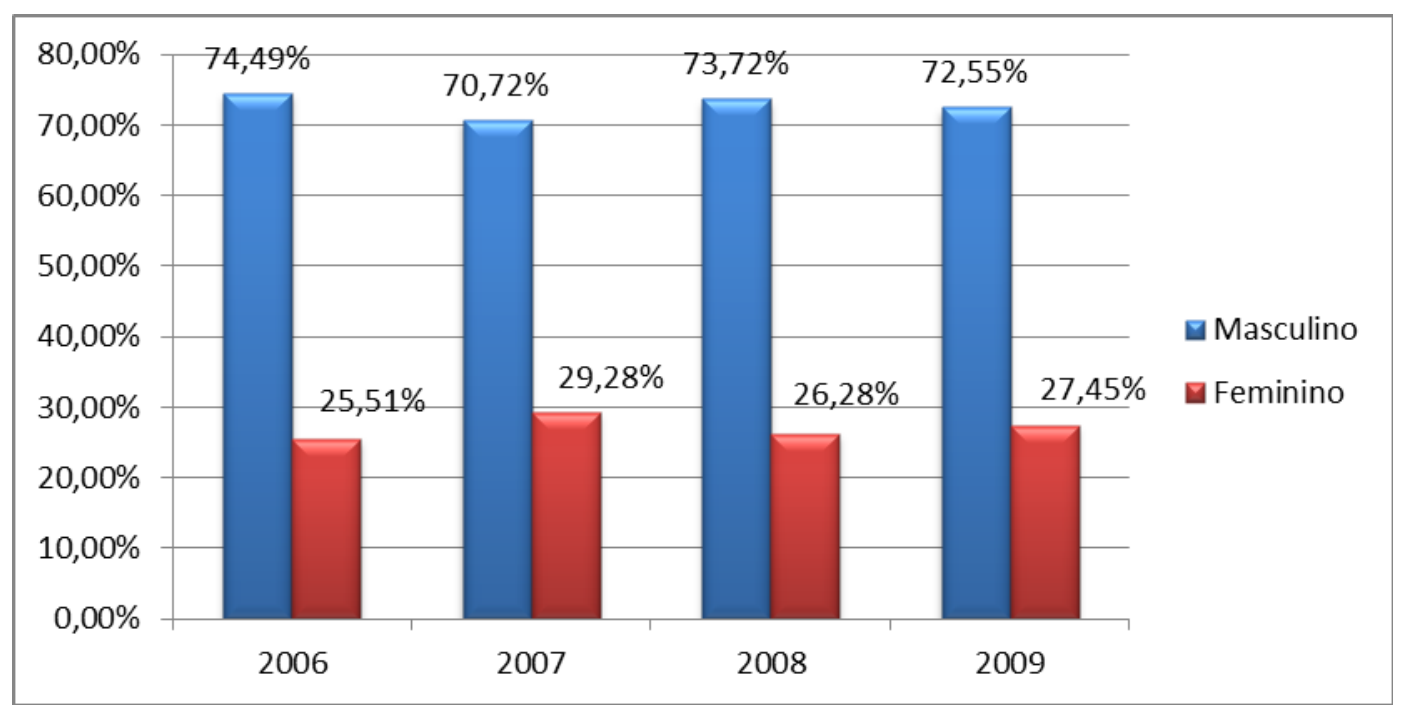

Gráfico 1. Distribuição de sexo dos pacientes vítimas de trauma

Ao observar os pacientes vítimas de trauma admitidos no período de 2006 a 2009 separados por sexo, observa-se que a porcentagem de $71 \%$ a $74 \%$ de homens e $26 \%$ a $29 \%$ de mulheres ao ano se repete durante todo o período. 
A distribuição por faixa etária mostra que 76,54\% (2006), 73,78\% (2007), 72,98 (2008) e 72,40\% (2009) dos pacientes pertencem às quatro primeiras décadas de vida. (Tabela 5).

Tabela 5. Pacientes por faixa etária

\begin{tabular}{|c|c|c|c|c|}
\hline Idade & 2006 & 2007 & 2008 & 2009 \\
\hline$\leq 10 a$ & $573(24,01 \%)$ & $416(21,60 \%)$ & $357(16,38 \%)$ & $354(18,37 \%)$ \\
\hline $11-20 a$ & 397 (16,63\%) & $321(16,67 \%)$ & $360(16,51 \%)$ & $280(14,53 \%)$ \\
\hline $21-30 a$ & $515(21,58 \%)$ & $416(21,60 \%)$ & $512(23,39 \%)$ & $464(24,08 \%)$ \\
\hline $31-40 a$ & 342 (14,33\%) & $268(13,91 \%)$ & 362 (16,61\%) & 303 (15,72\%) \\
\hline $41-50 a$ & $253(10,60 \%)$ & $218(11,32 \%)$ & $250(11,47 \%)$ & $222(11,52 \%)$ \\
\hline $51-60 a$ & $129(5,40 \%)$ & $133(6,91 \%)$ & $162(7,43 \%)$ & $141(7,32 \%)$ \\
\hline $61-70 a$ & $85(3,56 \%)$ & $78(4,05 \%)$ & $83(3,81 \%)$ & $70(3,63 \%)$ \\
\hline$>71 a$ & $93(3,90 \%)$ & $76(3,95 \%)$ & $94(4,31 \%)$ & $93(4,83 \%)$ \\
\hline Total & $2387(100,00 \%)$ & $1926(100,00 \%)$ & $2180(100,00 \%)$ & $1927(100,00 \%)$ \\
\hline
\end{tabular}

Em relação aos mecanismos de trauma no período analisado, as quedas, como causa isolada, foi a mais frequente, sendo de $28,15 \%, 26,27 \%, 22,89 \%$ e $22,45 \%$ para os anos de 2006 a 2009, enquanto os acidentes de transporte (automóveis, motocicletas, atropelamentos e bicicletas) contribuíram com 39,39\% $43,51 \%, 45,28 \%$ e $41,41 \%$ nos anos de 2006 a 2009. (Tabela 6).

Tabela 6. Mecanismo de trauma para os pacientes vítimas de trauma

\begin{tabular}{lcccc}
\hline Mecanismos de trauma & $\mathbf{2 0 0 6}$ & $\mathbf{2 0 0 7}$ & $\mathbf{2 0 0 8}$ & $\mathbf{2 0 0 9}$ \\
\hline Acidente automobilístico (AA) & $205(8,59 \%)$ & $184(9,55 \%)$ & $205(9,40 \%)$ & $156(8,10 \%)$ \\
\hline Acidente motociclístico (AM) & $340(14,24 \%)$ & $320(16,61 \%)$ & $455(20,87 \%)$ & $357(18,53 \%)$ \\
Atropelamento (AT) & $172(7,21 \%)$ & $158(8,20 \%)$ & $178(8,17 \%)$ & $156(8,10 \%)$ \\
Acidente ciclístico (BIC) & $223(9,34 \%)$ & $176(9,14 \%)$ & $149(6,83 \%)$ & $129(6,69 \%)$ \\
Ferimento arma branca (FAB) & $92(3,85 \%)$ & $57(2,96 \%)$ & $75(3,44 \%)$ & $81(4,20 \%)$ \\
Ferimento arma de fogo (FAF) & $70(2,93 \%)$ & $52(2,70 \%)$ & $51(2,34 \%)$ & $57(2,96 \%)$ \\
Quedas (QUE) & $672(28,15 \%)$ & $506(26,27 \%)$ & $499(22,89 \%)$ & $433(22,47 \%)$ \\
Queimaduras (QUEI) & $129(5,40 \%)$ & $117(6,07 \%)$ & $144(6,61 \%)$ & $146(7,58 \%)$ \\
Acidente com máquina (MAQ) & $63(2,64 \%)$ & $37(1,92 \%)$ & $50(2,29 \%)$ & $43(2,23 \%)$ \\
Agressão (AGR) & $216(9,05 \%)$ & $186(9,66 \%)$ & $227(10,41 \%)$ & $223(11,57 \%)$ \\
\hline Outras (OUT) & $205(8,59 \%)$ & $133(6,91 \%)$ & $147(6,74 \%)$ & $146(7,58 \%)$ \\
\hline Total & $\mathbf{2 3 8 7 ( 1 0 0 , 0 0 \% )}$ & $\mathbf{1 9 2 6}(\mathbf{1 0 0} \%, 00 \%)$ & $\mathbf{2 1 8 0 ( 1 0 0 , 0 0 \% )}$ & $\mathbf{1 9 2 7}(\mathbf{1 0 0 , 0 0 \% )}$ \\
\hline
\end{tabular}


Observa-se diferença no principal mecanismo de trauma conforme a faixa etária dos pacientes.

Nos pacientes de até 10 anos, há prevalência de quedas e atropelamentos, maior concentração de acidentes com moto, bicicleta, quedas e agressão para a faixa etária entre 11 e 20 anos, sendo que na faixa etária dos 21 a 50 anos há incremento dos casos de acidentes com automóveis, motocicletas, além de quedas e agressões. As quedas voltam a ter maior número em pacientes na faixa etária entre 51 a 60 anos, com maior quantidade de casos de queda acima dos 61 anos e incremento da quantidade de atropelamentos (Tabelas 7, 8, 9, 10 e 11).

Há mecanismos de trauma que têm pouco ou quase nenhum paciente conforme a idade. É o caso de ferimento por arma branca e por arma de fogo (Tabela 8).

Tabela 7. Mecanismo de trauma para pacientes vítimas de trauma com até 10 anos

\begin{tabular}{lcccc}
\hline Mecanismo de trauma & $\mathbf{2 0 0 6}$ & $\mathbf{2 0 0 7}$ & $\mathbf{2 0 0 8}$ & $\mathbf{2 0 0 9}$ \\
\hline Acidente automobilístico (AA) & $17(2,97 \%)$ & $19(4,57 \%)$ & $16(4,48 \%)$ & $16(4,52 \%)$ \\
\hline Acidente motociclístico (AM) & $1(0,17 \%)$ & $5(1,20 \%)$ & $9(2,52 \%)$ & $4(1,13 \%)$ \\
\hline Atropelamento (AT) & $58(10,12 \%)$ & $57(13,70 \%)$ & $64(17,93 \%)$ & $57(16,10 \%)$ \\
\hline Acidente ciclístico (BIC) & $67(11,69 \%)$ & $57(13,70 \%)$ & $23(6,44 \%)$ & $31(8,76 \%)$ \\
\hline Ferimento arma branca (FAB) & $1(0,17 \%)$ & $1(0,24 \%)$ & $0(0,00 \%)$ & $1(0,28 \%)$ \\
\hline Ferimento arma de fogo (FAF) & $1(0,17 \%)$ & $0(0,00 \%)$ & $1(0,28 \%)$ & $1(0,28 \%)$ \\
\hline Quedas (QUE) & $287(50,09 \%)$ & $177(42,55 \%)$ & $139(38,94 \%)$ & $126(35,59 \%)$ \\
\hline Queimaduras (QUEI) & $39(6,81 \%)$ & $32(7,69 \%)$ & $19(5,32 \%)$ & $27(7,63 \%)$ \\
Acidente com máquina (MAQ) & $2(0,35 \%)$ & $0(0,00 \%)$ & $2(0,56 \%)$ & $1(0,28 \%)$ \\
\hline Agressão (AGR) & $38(6,63 \%)$ & $34(8,17 \%)$ & $47(13,17 \%)$ & $57(16,10 \%)$ \\
\hline Outras (OUT) & $62(10,82 \%)$ & $34(8,17 \%)$ & $37(10,36 \%)$ & $33(9,32 \%)$ \\
\hline Total & $\mathbf{5 7 3 ( 1 0 0 , 0 0 \% )}$ & $\mathbf{4 1 6 ( 1 0 0 , 0 0 \% )}$ & $\mathbf{3 5 7}(\mathbf{1 0 0 , 0 0} \%)$ & $\mathbf{3 5 4}(\mathbf{1 0 0 , 0 0} \%)$ \\
\hline
\end{tabular}


Tabela 8. Mecanismo de trauma para pacientes vítimas de trauma entre 11 e 20 anos

\begin{tabular}{lcccc}
\hline Mecanismo de trauma & $\mathbf{2 0 0 6}$ & $\mathbf{2 0 0 7}$ & $\mathbf{2 0 0 8}$ & $\mathbf{2 0 0 9}$ \\
\hline Acidente automobilístico (AA) & $33(8,31 \%)$ & $22(6,85 \%)$ & $32(8,89 \%)$ & $19(6,79 \%)$ \\
\hline Acidente motociclístico (AM) & $73(18,39 \%)$ & $74(23,05 \%)$ & $84(23,33 \%)$ & $64(22,86 \%)$ \\
Atropelamento (AT) & $26(6,55 \%)$ & $21(6,54 \%)$ & $17(4,72 \%)$ & $14(5,00 \%)$ \\
\hline Acidente ciclístico (BIC) & $61(15,37 \%)$ & $40(12,46 \%)$ & $44(12,22 \%)$ & $45(16,07 \%)$ \\
Ferimento arma branca (FAB) & $12(3,02 \%)$ & $9(2,80 \%)$ & $7(1,94 \%)$ & $6(2,14 \%)$ \\
Ferimento arma de fogo (FAF) & $13(3,27 \%)$ & $13(4,05 \%)$ & $16(4,44 \%)$ & $8(2,86 \%)$ \\
Quedas (QUE) & $64(16,12 \%)$ & $52(16,20 \%)$ & $48(13,33 \%)$ & $35(12,50 \%)$ \\
\hline Queimaduras (QUEI) & $17(4,28 \%)$ & $12(3,74 \%)$ & $21(5,83 \%)$ & $17(6,07 \%)$ \\
Acidente com máquina (MAQ) & $5(1,26 \%)$ & $5(1,56 \%)$ & $9(2,50 \%)$ & $7(2,50 \%)$ \\
Agressão (AGR) & $50(12,59 \%)$ & $42(13,08 \%)$ & $55(15,28 \%)$ & $40(14,29 \%)$ \\
Outras (OUT) & $43(10,83 \%)$ & $31(9,66 \%)$ & $27(7,50 \%)$ & $25(8,93 \%)$ \\
\hline
\end{tabular}

Tabela 9. Mecanismo de trauma para pacientes vítimas de trauma entre 21 e 50 anos

\begin{tabular}{lcccc}
\hline Mecanismo de trauma & $\mathbf{2 0 0 6}$ & $\mathbf{2 0 0 7}$ & $\mathbf{2 0 0 8}$ & $\mathbf{2 0 0 9}$ \\
\hline Acidente automobilístico (AA) & $127(11,44 \%)$ & $123(13,64 \%)$ & $132(11,74 \%)$ & $95(9,61 \%)$ \\
Acidente motociclístico (AM) & $252(22,70 \%)$ & $224(24,83 \%)$ & $336(29,89 \%)$ & $276(27,91 \%)$ \\
Atropelamento (AT) & $59(5,32 \%)$ & $44(4,88 \%)$ & $56(4,98 \%)$ & $38(3,84 \%)$ \\
Acidente ciclístico (BIC) & $73(6,58 \%)$ & $62(6,87 \%)$ & $59(5,25 \%)$ & $42(4,25 \%)$ \\
Ferimento arma branca (FAB) & $73(6,58 \%)$ & $45(4,99 \%)$ & $64(5,69 \%)$ & $71(7,18 \%)$ \\
Ferimento arma de fogo (FAF) & $50(4,50 \%)$ & $32(3,55 \%)$ & $31(2,76 \%)$ & $45(4,55 \%)$ \\
Quedas (QUE) & $168(15,14 \%)$ & $134(14,86 \%)$ & $165(14,68 \%)$ & $130(13,14 \%)$ \\
Queimaduras (QUEI) & $63(5,68 \%)$ & $56(6,21 \%)$ & $81(7,21 \%)$ & $77(7,79 \%)$ \\
Acidente com máquina (MAQ) & $47(4,23 \%)$ & $26(2,88 \%)$ & $28(2,49 \%)$ & $25(2,53 \%)$ \\
Agressão (AGR) & $116(10,45 \%)$ & $101(11,20 \%)$ & $106(9,43 \%)$ & $111(11,22 \%)$ \\
Outras (OUT) & $82(7,39 \%)$ & $55(6,10 \%)$ & $66(5,87 \%)$ & $79(7,99 \%)$ \\
\hline Total & $\mathbf{1 1 1 0 ( 1 0 0 , 0 0 \% )}$ & $\mathbf{9 0 2 ( 1 0 0 , 0 0 \% )}$ & $\mathbf{1 1 2 4 ( 1 0 0 , 0 0 \% )}$ & $\mathbf{9 8 9}(100,00 \%)$ \\
\hline
\end{tabular}


Tabela 10. Mecanismo de trauma para pacientes vítimas de trauma entre 51 e 60 anos

\begin{tabular}{lcccc}
\hline Mecanismo de trauma & $\mathbf{2 0 0 6}$ & $\mathbf{2 0 0 7}$ & $\mathbf{2 0 0 8}$ & $\mathbf{2 0 0 9}$ \\
\hline Acidente automobilístico (AA) & $16(12,40 \%)$ & $11(8,21 \%)$ & $13(8,02 \%)$ & $18(12,77 \%)$ \\
\hline Acidente motociclístico (AM) & $10(7,75 \%)$ & $14(10,45 \%)$ & $21(12,96 \%)$ & $11(7,80 \%)$ \\
\hline Atropelamento (AT) & $10(7,75 \%)$ & $19(14,18 \%)$ & $21(12,96 \%)$ & $20(14,18 \%)$ \\
\hline Acidente ciclístico (BIC) & $14(10,85 \%)$ & $11(8,21 \%)$ & $16(9,88 \%)$ & $8(5,67 \%)$ \\
Ferimento arma branca (FAB) & $4(3,10 \%)$ & $2(1,49 \%)$ & $3(1,85 \%)$ & $3(2,13 \%)$ \\
Ferimento arma de fogo (FAF) & $3(2,33 \%)$ & $5(3,73 \%)$ & $1(0,62 \%)$ & $2(1,42 \%)$ \\
Quedas (QUE) & $38(29,46 \%)$ & $43(32,09 \%)$ & $47(29,01 \%)$ & $42(29,79 \%)$ \\
\hline Queimaduras (QUEI) & $7(5,43 \%)$ & $12(8,96 \%)$ & $11(6,79 \%)$ & $14(9,93 \%)$ \\
Acidente com máquina (MAQ) & $7(5,43 \%)$ & $3(2,24 \%)$ & $10(6,17 \%)$ & $6(4,26 \%)$ \\
Agressão (AGR) & $9(6,98 \%)$ & $4(2,99 \%)$ & $8(4,94 \%)$ & $9(6,38 \%)$ \\
Outras (OUT) & $11(8,53 \%)$ & $10(7,46 \%)$ & $11(6,79 \%)$ & $8(5,67 \%)$ \\
\hline Total & $\mathbf{1 2 9}(\mathbf{1 0 0 , 0 0} \%)$ & $\mathbf{1 3 4}(\mathbf{1 0 0 , 0 0 \% )}$ & $\mathbf{1 6 2 ( 1 0 0 , 0 0 \% )}$ & $\mathbf{1 4 1}(\mathbf{1 0 0 , 0 0 \% )}$ \\
\hline
\end{tabular}

Tabela 11. Mecanismo de trauma para pacientes vítimas de trauma com 60 anos ou mais

\begin{tabular}{lcccc}
\hline Mecanismo de trauma & $\mathbf{2 0 0 6}$ & $\mathbf{2 0 0 7}$ & $\mathbf{2 0 0 8}$ & $\mathbf{2 0 0 9}$ \\
\hline Acidente automobilístico (AA) & $12(6,74 \%)$ & $9(5,88 \%)$ & $12(6,78 \%)$ & $8(4,91 \%)$ \\
\hline Acidente motociclístico (AM) & $4(2,25 \%)$ & $3(1,96 \%)$ & $5(2,82 \%)$ & $2(1,23 \%)$ \\
\hline Atropelamento (AT) & $19(10,67 \%)$ & $17(11,11 \%)$ & $20(11,30 \%)$ & $27(16,56 \%)$ \\
\hline Acidente ciclístico (BIC) & $8(4,49 \%)$ & $6(3,92 \%)$ & $7(3,95 \%)$ & $3(1,84 \%)$ \\
Ferimento arma branca (FAB) & $2(1,12 \%)$ & $0(0,00 \%)$ & $1(0,56 \%)$ & $0(0,00 \%)$ \\
\hline Ferimento arma de fogo (FAF) & $3(1,69 \%)$ & $2(1,31 \%)$ & $2(1,13 \%)$ & $1(0,61 \%)$ \\
Quedas (QUE) & $115(64,61 \%)$ & $100(65,36 \%)$ & $100(56,50 \%)$ & $100(61,35 \%)$ \\
\hline Queimaduras (QUEI) & $3(1,69 \%)$ & $5(3,27 \%)$ & $12(6,78 \%)$ & $11(6,75 \%)$ \\
\hline Acidente com máquina (MAQ) & $2(1,12 \%)$ & $3(1,96 \%)$ & $1(0,56 \%)$ & $4(2,45 \%)$ \\
\hline Agressão (AGR) & $3(1,69 \%)$ & $5(3,27 \%)$ & $11(6,21 \%)$ & $6(3,68 \%)$ \\
\hline Outras (OUT) & $7(3,93 \%)$ & $3(1,96 \%)$ & $6(3,39 \%)$ & $1(0,61 \%)$ \\
\hline Total & $\mathbf{1 7 8 ( 1 0 0 , 0 0 \% )}$ & $\mathbf{1 5 3 ( 1 0 0 , 0 0 \% )}$ & $\mathbf{1 7 7}(\mathbf{1 0 0 , 0 0 \% )}$ & $\mathbf{1 6 3}(\mathbf{1 0 0 , 0 0 \% )}$ \\
\hline
\end{tabular}

A distribuição do número de pacientes por dia da semana apresenta aumento nos finais de semana. O dia com menor porcentagem de internações foi na terçafeira, apresentando $13,20 \%, 11,47 \%, 12,20 \%, 12,56 \%$ de pacientes enquanto o sábado foi o dia com maior porcentagem, com 16,67\%, 18,59\%, 16,79\% e 16,61\%, respectivamente para os anos de 2006 a 2009 (Tabela 12 e Gráfico 2). 
Tabela 12. Internações de pacientes vítimas de trauma por dia da semana

\begin{tabular}{lcccc}
\hline Dia da semana & $\mathbf{2 0 0 6}$ & $\mathbf{2 0 0 7}$ & $\mathbf{2 0 0 8}$ & $\mathbf{2 0 0 9}$ \\
\hline Domingo & $392(16,42 \%)$ & $314(16,30 \%)$ & $342(15,69 \%)$ & $314(16,29 \%)$ \\
Segunda-feira & $338(14,16 \%)$ & $234(12,15 \%)$ & $290(13,30 \%)$ & $250(12,97 \%)$ \\
Terça-feira & $315(13,20 \%)$ & $221(11,47 \%)$ & $266(12,20 \%)$ & $242(12,56 \%)$ \\
Quarta-feira & $307(12,86 \%)$ & $252(13,08 \%)$ & $320(14,68 \%)$ & $254(13,18 \%)$ \\
Quinta-feira & $290(12,15 \%)$ & $257(13,34 \%)$ & $296(13,58 \%)$ & $259(13,44 \%)$ \\
Sexta-feira & $347(14,54 \%)$ & $290(15,06 \%)$ & $300(13,76 \%)$ & $288(14,95 \%)$ \\
Sábado & $398(16,67 \%)$ & $358(18,59 \%)$ & $366(16,79 \%)$ & $320(16,61 \%)$ \\
\hline Total & $\mathbf{2 3 8 7 ( 1 0 0 , 0 0 \% )}$ & $\mathbf{1 9 2 6 ( 1 0 0 , 0 0 \% )}$ & $\mathbf{2 1 8 0 ( 1 0 0 , 0 0 \% )}$ & $\mathbf{1 9 2 7}(100,00 \%)$ \\
\hline
\end{tabular}

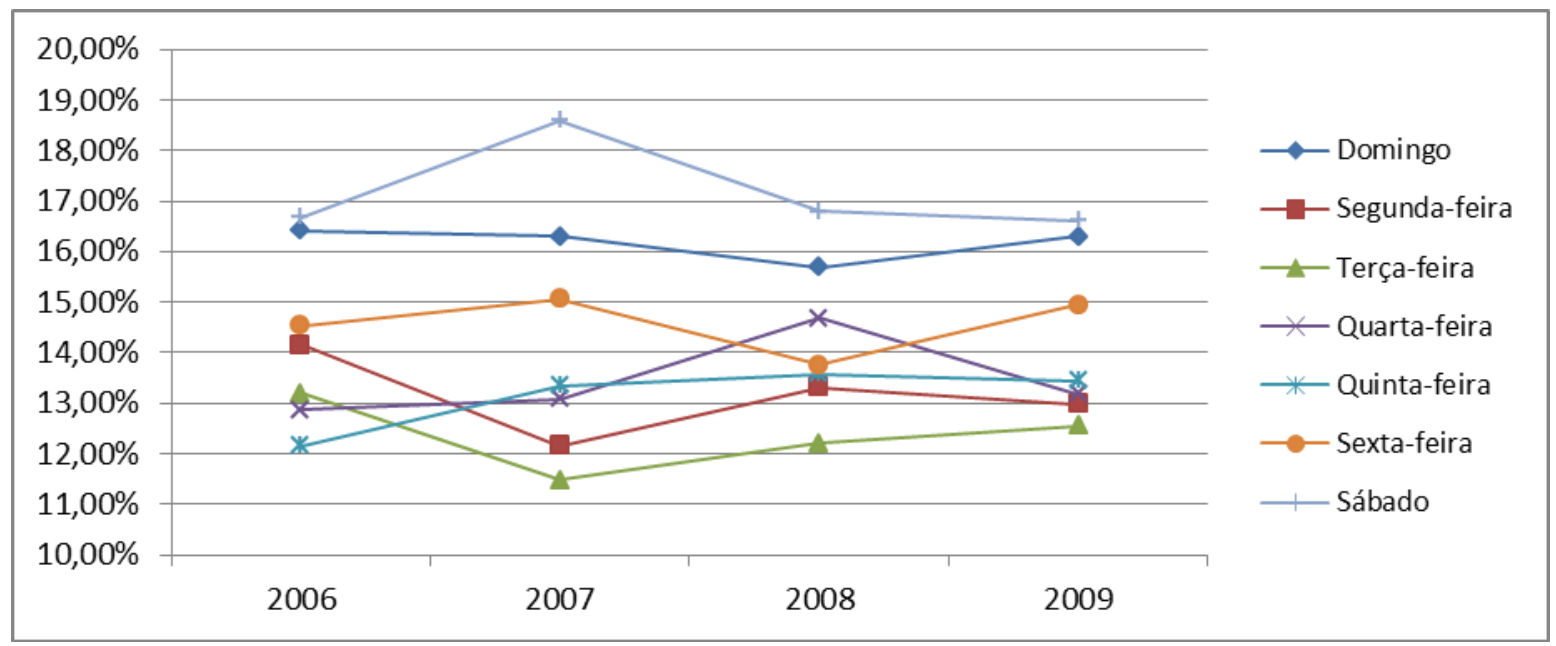

Gráfico 2. Porcentagem de pacientes admitidos por dia da semana

A distribuição da gravidade do trauma segundo a microrregião do DRS-XIII de origem do paciente mostrou que Ribeirão Preto possui atualmente $44,85 \%$ da população e encaminhou $61,92 \%, 59,81 \%, 62,11 \%$ e $63,10 \%$, enquanto os demais municípios da DRS-XIII encaminharam 33,05\%, 33,96\%, 31,38\% e 31,71\% para os anos de 2006 a 2009, respectivamente (Tabela 13).

No período de 2006 a 2009, respectivamente 53,37\%, 64,54\%, 71,50 e $72,03 \%$ dos pacientes tiveram lesões com AIS $>1$. 
Tabela 13. Encaminhamentos de Ribeirão Preto e DRS-XIII

\begin{tabular}{|c|c|c|c|c|}
\hline Municípios & 2006 & 2007 & 2008 & 2009 \\
\hline$\overline{\mathbf{R P}}$ & $1478(61,92 \%)$ & $1152(59,81 \%)$ & $1354(62,11 \%)$ & $1216(63,10 \%)$ \\
\hline DRS-XIII & $789(33,05 \%)$ & $654(33,96 \%)$ & $684(31,38 \%)$ & $611(31,71 \%)$ \\
\hline \multirow[t]{2}{*}{ Outros } & $120(5,03 \%)$ & $120(6,23 \%)$ & $142(6,51 \%)$ & $100(5,19 \%)$ \\
\hline & $2387(100,00 \%)$ & $1926(100,00 \%)$ & $2180(100,00 \%)$ & $1927(100,00 \%)$ \\
\hline
\end{tabular}

As áreas lesadas mais frequentes foram as extremidades, variando de 22,58\% em 2006 a 31,03\% em 2009 (sendo o menor e maior valor dessa região corpóreo no período), seguidas pela cabeça e pescoço, variando de $12,48 \%$ a 15,46\% para 2006 e 2009, respectivamente, considerando o mesmo período analisado e o total de pacientes internados.

A letalidade, sendo a relação entre o número de óbitos resultantes de determinada causa e o número de pessoas que foram acometidos pela causa, apresentou-se maior quando o mecanismo de trauma foi arma de fogo, variando entre $15,38 \%$ a $18,57 \%$ no período de 2006 a 2009, tendo o menor valor em 2007 e o maior em 2006 (Tabela 14 e Gráfico 3).

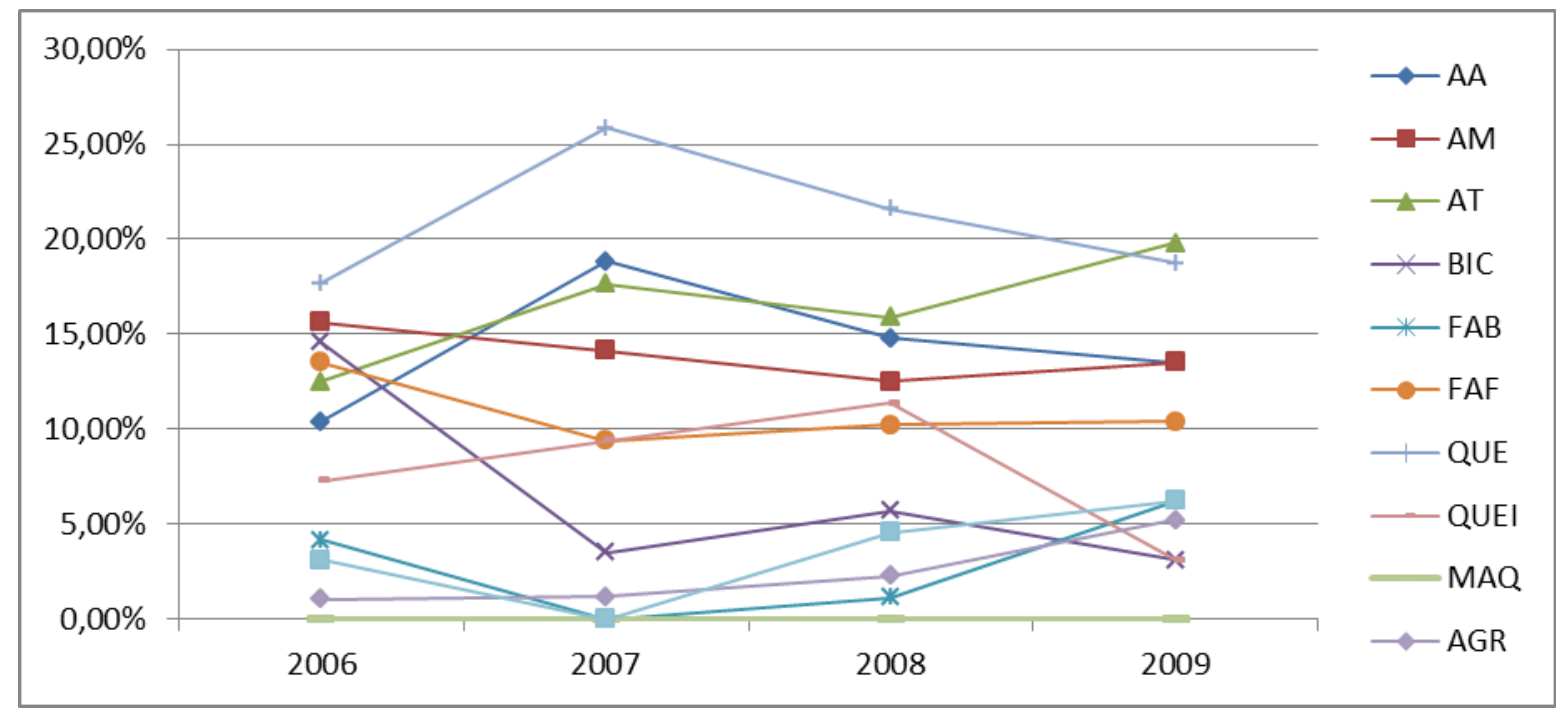

Gráfico 3. Letalidade por mecanismo de trauma

O ISS é um índice anatômico que permite a estratificação numérica da gravidade da lesão por levar em consideração as lesões provocadas nos vários 
segmentos do corpo. A gravidade das lesões anatômicas é determinada através do exame físico, testes radiológicos, cirurgia e autópsia. Seu valor varia de 1 a 75 e o risco de morte aumenta quanto maior o valor. Consideram-se os traumas com ISS de 1 a 8 como leves; 9 a 15 como moderados; 16 a 24 como graves e maiores que 24 como muito graves. O trauma é considerado grave quando o ISS é maior ou igual a 16.

Tabela 14. Letalidade por mecanismo de trauma

\begin{tabular}{lcccc}
\hline Mecanismo de trauma & $\mathbf{2 0 0 6}$ & $\mathbf{2 0 0 7}$ & $\mathbf{2 0 0 8}$ & $\mathbf{2 0 0 9}$ \\
\hline Acidente automobilístico (AA) & $10(4,88 \%)$ & $16(8,70 \%)$ & $13(6,34 \%)$ & $13(8,33 \%)$ \\
Acidente motociclístico (AM) & $15(4,41 \%)$ & $12(3,75 \%)$ & $11(2,42 \%)$ & $13(3,64 \%)$ \\
Atropelamento (AT) & $12(6,98 \%)$ & $15(9,49 \%)$ & $14(7,87 \%)$ & $19(12,18 \%)$ \\
Acidente ciclístico (BIC) & $14(6,28 \%)$ & $3(1,70 \%)$ & $5(3,36 \%)$ & $3(2,33 \%)$ \\
Ferimento arma branca (FAB) & $4(4,35 \%)$ & $0(0,00 \%)$ & $1(1,33 \%)$ & $6(7,41 \%)$ \\
Ferimento arma de fogo (FAF) & $13(18,57 \%)$ & $8(15,38 \%)$ & $9(17,65 \%)$ & $10(17,54 \%)$ \\
Quedas (QUE) & $17(2,53 \%)$ & $22(4,35 \%)$ & $19(3,81 \%)$ & $18(4,16 \%)$ \\
Queimaduras (QUEI) & $7(5,43 \%)$ & $8(6,84 \%)$ & $10(6,94 \%)$ & $3(2,05 \%)$ \\
Acidente com máquina (MAQ) & $0(0,00 \%)$ & $0(0,00 \%)$ & $0(0,00 \%)$ & $0(0,00 \%)$ \\
Agressão (AGR) & $1(0,46 \%)$ & $1(0,54 \%)$ & $2(0,88 \%)$ & $5(2,24 \%)$ \\
Outras (OUT) & $3(1,46 \%)$ & $0(0,00 \%)$ & $4(2,72 \%)$ & $6(4,11 \%)$ \\
\hline Total & $\mathbf{9 6 ( 4 , 0 2 \% )}$ & $\mathbf{8 5 ( 4 , 4 1 \% )}$ & $\mathbf{8 8}(\mathbf{4 , 0 4 \% )}$ & $\mathbf{9 6}(\mathbf{4 , 9 8 \% )}$ \\
\hline
\end{tabular}

No (Gráfico 4) é exibida a distribuição de pacientes por gravidade de lesão durante o período analisado, onde nota-se grande porcentagem de pacientes com ISS $\leq 8$.

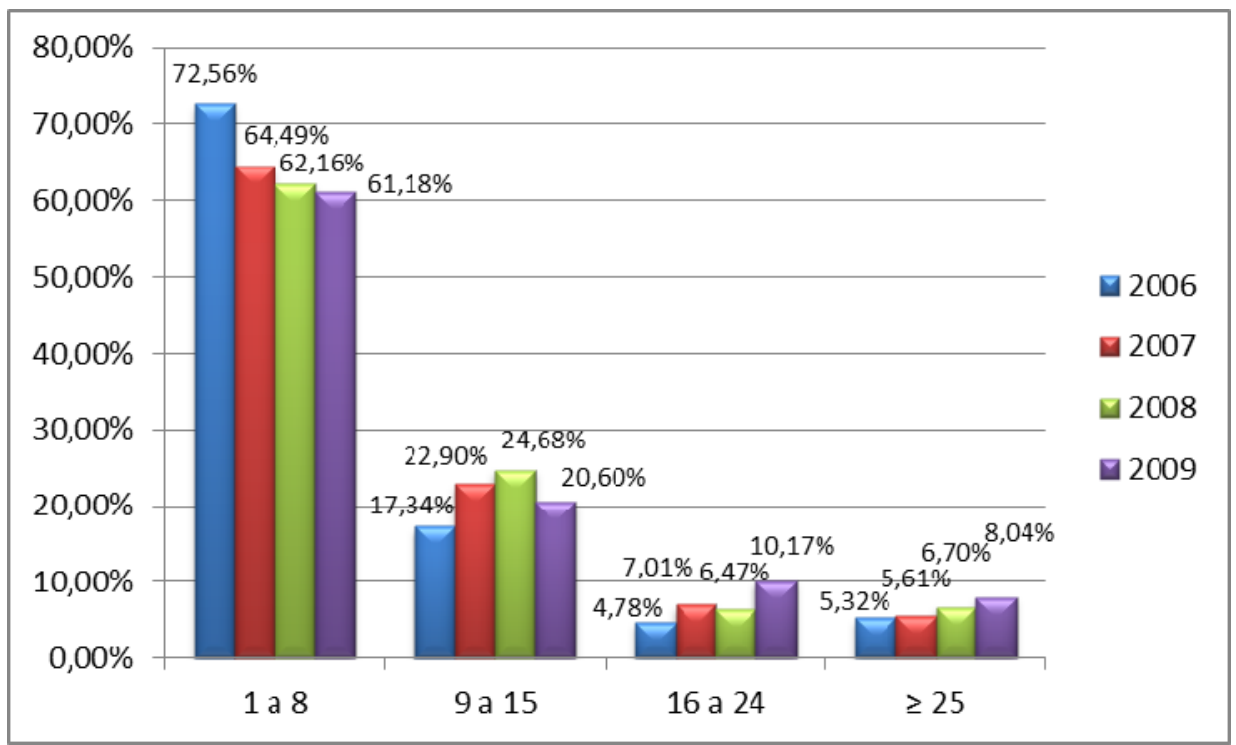

Gráfico 4. ISS por gravidade de lesão 
Verifica-se uma maior quantidade de pacientes com trauma leve, ficando em 72,73\% em 2006, 64,64\% em 2007, 62,11\% em 2008 e 61,08\% em 2009. Ao longo do período é possível observar um incremento de pacientes com trauma grave (ISS $\geq 16$ ) e consequente redução de pacientes de trauma leve (ISS entre 1 e 8).

Considerando os encaminhamentos de pacientes com ISS entre 1 e 8 , os encaminhamentos de Ribeirão Preto foram de 1155 (78,15\%), 816 (70,83\%), 915 $(67,58 \%)$ e $787(64,72 \%)$ e das demais cidades da DRS-XIII foram de $51965,78 \%)$, $384(58,72 \%), 391(57,16 \%)$ e $346(56,63 \%)$, para os anos de 2006 a 2009, respectivamente (Tabela 15$)$.

Tabela 15. Pacientes encaminhados com ISS entre 1 e 8

\begin{tabular}{lcccc}
\hline Município & $\mathbf{2 0 0 6}$ & $\mathbf{2 0 0 7}$ & $\mathbf{2 0 0 8}$ & $\mathbf{2 0 0 9}$ \\
\hline RP & $1155(78,15 \%)$ & $816(70,83 \%)$ & $915(67,58 \%)$ & $787(64,72 \%)$ \\
DRS-XIII & $519(65,78 \%)$ & $384(58,72 \%)$ & $391(57,16 \%)$ & $346(56,63 \%)$ \\
Outros & $62(51,67 \%)$ & $45(37,50 \%)$ & $48(33,80 \%)$ & $44(44,00 \%)$ \\
\hline Total & $\mathbf{1 7 3 6 ( \mathbf { 7 2 , 7 3 } \% )}$ & $\mathbf{1 2 4 5 ( 6 4 , 6 4 \% )}$ & $\mathbf{1 3 5 4 ( 6 2 , 1 1 \% )}$ & $\mathbf{1 . 1 7 7}(\mathbf{6 1 , 0 8 \% )}$ \\
\hline
\end{tabular}

Pode-se deduzir que o sistema de saúde, particularmente a Central de Regulação Médica, têm monitorado suas ações em direção ao melhor encaminhamento de pacientes, de forma que a Unidade de Emergência do HCFMRP tem atendido mais pacientes com maior gravidade de lesão.

A distribuição dos pacientes que passaram por cirurgia a partir dos intervalores de ISS demonstra que mais de $80 \%$ dos pacientes com ISS entre 16 a 24 passaram por pelo menos uma cirurgia, reforçando o conceito de que o trauma é uma doença cirúrgica (Tabela 16).

Tabela 16. ISS para pacientes que passaram por cirurgia

\begin{tabular}{lcccc}
\hline ISS & $\mathbf{2 0 0 6}$ & $\mathbf{2 0 0 7}$ & $\mathbf{2 0 0 8}$ & $\mathbf{2 0 0 9}$ \\
\hline $\mathbf{1}$ a $\mathbf{8}$ & $336(19,35 \%)$ & $245(19,68 \%)$ & $287(21,20 \%)$ & $221(18,78 \%)$ \\
$\mathbf{9}$ a $\mathbf{1 5}$ & $288(70,76 \%)$ & $299(68,42 \%)$ & $380(70,90 \%)$ & $305(75,87 \%)$ \\
$\mathbf{1 6}$ a $\mathbf{2 4}$ & $95(80,51 \%)$ & $119(88,15 \%)$ & $117(81,25 \%)$ & $171(88,60 \%)$ \\
$\mathbf{2} \mathbf{2 5}$ & $80(63,49 \%)$ & $79(72,48 \%)$ & $114(78,08 \%)$ & $114(73,55 \%)$ \\
\hline Total & $\mathbf{7 9 9 ( 3 3 , 4 7 \% )}$ & $\mathbf{7 4 2 ( 3 8 , 5 3 \% )}$ & $\mathbf{8 9 8 ( 4 1 , 1 9 \% )}$ & $\mathbf{8 1 1}(42,09 \%)$ \\
\hline
\end{tabular}


Em relação às cirurgias realizadas aos pacientes vítimas de trauma, a maior parte é de ortopedia, ficando responsável por 59,86\%, 58,26\%, 59,62\% e 55,02\% para os anos de 2006 a 2009, respectivamente. (Tabela 17).

Tabela 17. Cirurgias por especialidade para pacientes vítimas de trauma

\begin{tabular}{lcccc}
\hline Especialidades & $\mathbf{2 0 0 6}$ & $\mathbf{2 0 0 7}$ & $\mathbf{2 0 0 8}$ & $\mathbf{2 0 0 9}$ \\
\hline Ortopedia & $516(59,86 \%)$ & $490(58,26 \%)$ & $558(59,62 \%)$ & $422(55,02 \%)$ \\
CLC & $92(10,67 \%)$ & $75(8,92 \%)$ & $63(6,73 \%)$ & $74(9,65 \%)$ \\
NEC & $82(9,51 \%)$ & $107(12,72 \%)$ & $107(11,43 \%)$ & $97(12,65 \%)$ \\
CCP & $105(12,18 \%)$ & $99(11,77 \%)$ & $113(12,07 \%)$ & $108(14,08 \%)$ \\
Oftalmo & $6(0,70 \%)$ & $1(0,12 \%)$ & $9(0,96 \%)$ & $8(1,04 \%)$ \\
Outras & $61(7,08 \%)$ & $69(8,20 \%)$ & $86(9,19 \%)$ & $58(7,56 \%)$ \\
\hline Total & $\mathbf{8 6 2 ( 1 0 0 , 0 0 \% )}$ & $\mathbf{8 4 1 ( 1 0 0 , 0 0 \% )}$ & $\mathbf{9 3 6 ( 1 0 0 , 0 0 \% )}$ & $\mathbf{7 6 7}(\mathbf{1 0 0 , 0 0 \% )}$ \\
\hline
\end{tabular}

Dentre as faixas de ISS, os pacientes com ISS $\geq 25$ foram a óbito em 59,52\%, $55,96 \%, 45,89 \%, 50,32 \%$ dos casos, para os anos de 2006 a 2009, respectivamente. (Tabela 18 ).

Tabela 18. Óbitos de pacientes por faixa de ISS em vítimas de trauma

\begin{tabular}{lcccc}
\hline ISS & $\mathbf{2 0 0 6}$ & $\mathbf{2 0 0 7}$ & $\mathbf{2 0 0 8}$ & $\mathbf{2 0 0 9}$ \\
\hline $\mathbf{3}$ a $\mathbf{8}$ & $2(0,12 \%)$ & $1(0,08 \%)$ & $1(0,07 \%)$ & $1(0,08 \%)$ \\
$\mathbf{9}$ a $\mathbf{1 5}$ & $10(2,46 \%)$ & $4(0,92 \%)$ & $6(1,12 \%)$ & $5(1,24 \%)$ \\
$\mathbf{1 6}$ a $\mathbf{2 4}$ & $9(7,63 \%)$ & $19(14,07 \%)$ & $14(9,72 \%)$ & $12(6,22 \%)$ \\
$\geq \mathbf{2 5}$ & $75(59,52 \%)$ & $61(55,96 \%)$ & $67(45,89 \%)$ & $78(50,32 \%)$ \\
\hline Total & $\mathbf{9 6 ( 4 , 0 2 \% )}$ & $\mathbf{8 5 ( 4 , 4 1 \% )}$ & $\mathbf{8 8 ( 4 , 0 4 \% )}$ & $\mathbf{9 6}(4,98 \%)$ \\
\hline
\end{tabular}

Se considerarmos a faixa etária dos 21 anos aos 50 como uma faixa etária de grande parte da força de trabalho, nota-se $50,00 \%, 45,88 \%, 40,91 \%$ e $62,50 \%$ de óbitos para os pacientes internados nessa faixa etária, demonstrando uma alta porcentagem de óbitos (Tabela 19).

No período de 2006 a 2009, respectivamente 96, 85, 88 e 96 pacientes vieram a óbito, onde a maior porcentagem de óbito foi devido a TCE, sendo de $51,04 \%, 55,29 \%, 42,05 \%$ e $48,96 \%$ para os anos de 2006 a 2009 , respectivamente (Gráfico 6). 
Os pacientes mortos ao chegar corresponderam a 18,75\%, 10,59\%, 14,77\% e 13,54\%, respectivamente para os anos de 2006 e 2009 (Gráfico 5 e 6).

Tabela 19. Óbitos por faixa etária para pacientes vítimas de trauma

\begin{tabular}{|c|c|c|c|c|}
\hline Idade & 2006 & 2007 & 2008 & 2009 \\
\hline$\leq 10 a$ & $2(2,08 \%)$ & $2(2,35 \%)$ & $4(4,55 \%)$ & $5(5,21 \%)$ \\
\hline $11-20 a$ & $19(19,79 \%)$ & $11(12,94 \%)$ & $8(9,09 \%)$ & $7(7,29 \%)$ \\
\hline $21-30 a$ & $16(16,67 \%)$ & $16(18,82 \%)$ & $12(13,64 \%)$ & $28(29,17 \%)$ \\
\hline $31-40 a$ & $19(19,79 \%)$ & $12(14,12 \%)$ & $12(13,64 \%)$ & $17(17,71 \%)$ \\
\hline $41-50 a$ & $13(13,54 \%)$ & $11(12,94 \%)$ & $12(13,64 \%)$ & $15(15,63 \%)$ \\
\hline $51-60 a$ & $8(8,33 \%)$ & $12(14,12 \%)$ & $23(26,14 \%)$ & $10(10,42 \%)$ \\
\hline $61-70 a$ & $6(6,25 \%)$ & $8(9,41 \%)$ & $8(9,09 \%)$ & $7(7,29 \%)$ \\
\hline$\geq 71 a$ & $13(13,54 \%)$ & $13(15,29 \%)$ & $9(10,23 \%)$ & $7(7,29 \%)$ \\
\hline Total & $96(100,00 \%)$ & $85(100,00 \%)$ & $88(100,00 \%)$ & $96(100,00 \%)$ \\
\hline
\end{tabular}

Os pacientes mortos ao chegar tiveram a menor porcentagem em 2007 $(10,59 \%)$ e a maior porcentagem em 2006 (18,75\%), dentro do período analisado (Gráfico 5).

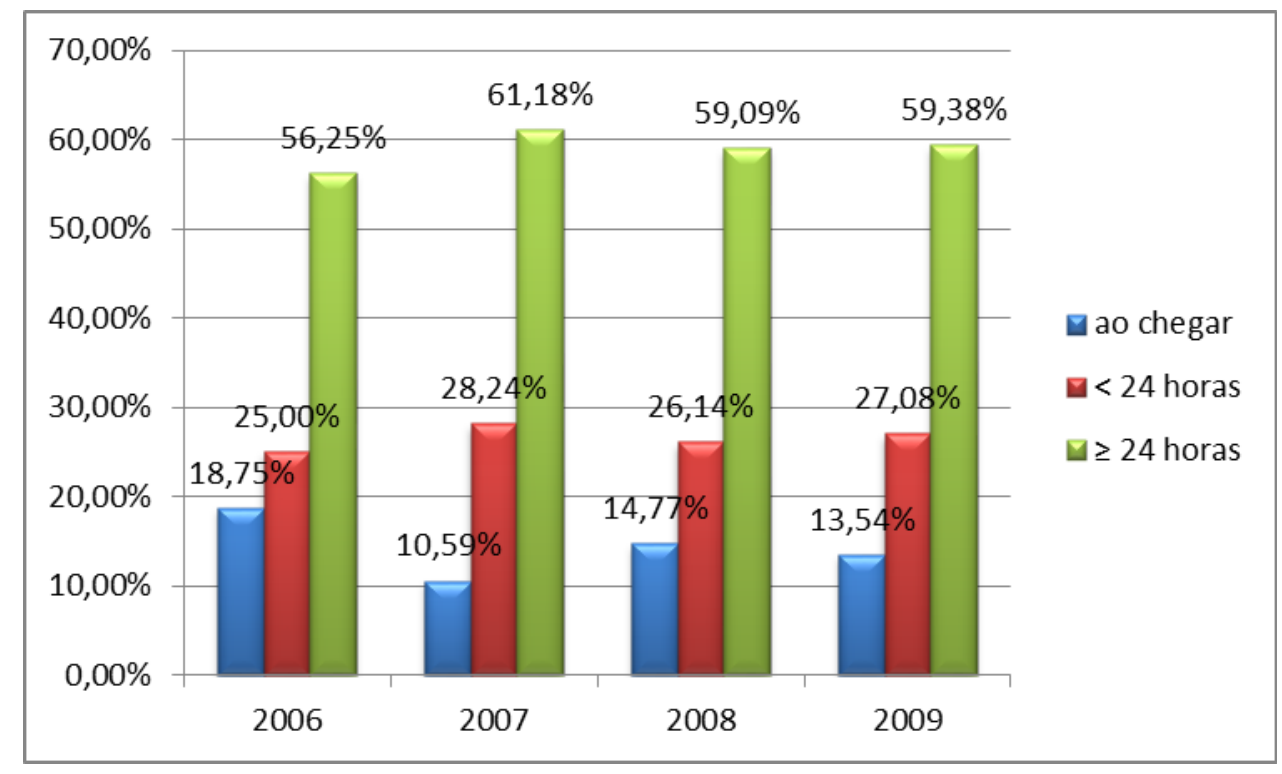

Gráfico 5. Momento do óbito 


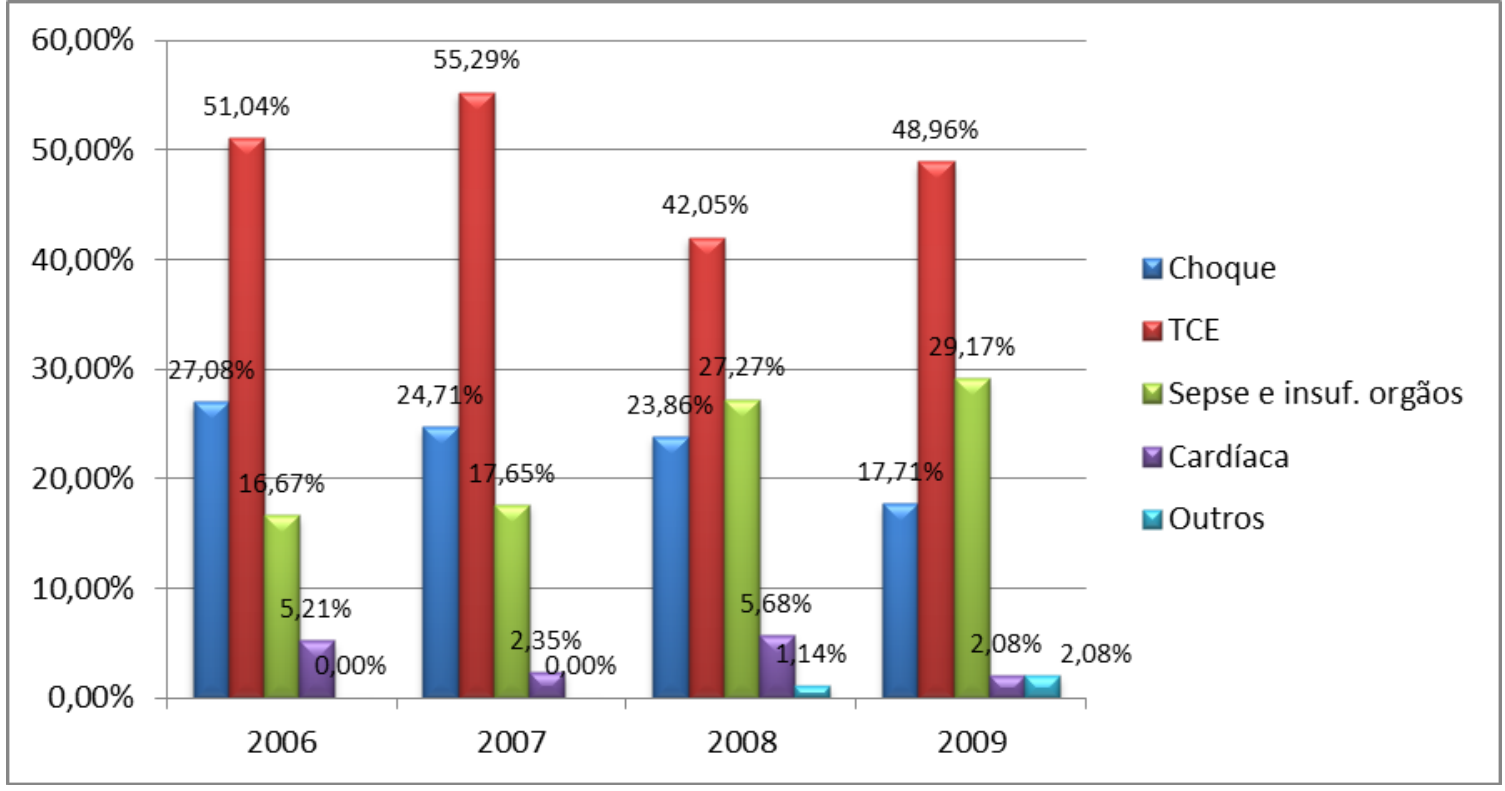

Gráfico 6. Principais causas de óbito de pacientes vítimas de trauma

A maior parte dos pacientes foi transportada em unidades de suporte básico (USB), correspondendo a 68,20\%, 71,18\%, 77,11\% e 50,49\%, para os anos de 2006 a 2009, respectivamente (Tabela 20).

É possível ainda observar um aumento dos pacientes transportados por unidade de suporte avançado (USA), também conhecidas como UTI móvel, sendo 7,37\% em 2006 e 21,54\% em 2009 (Tabela 20).

Tabela 20. Meio de transporte dos pacientes vítimas de trauma

\begin{tabular}{lcccc}
\hline Meio de transporte & $\mathbf{2 0 0 6}$ & $\mathbf{2 0 0 7}$ & $\mathbf{2 0 0 8}$ & $\mathbf{2 0 0 9}$ \\
\hline USA & $164(6,87 \%)$ & $174(9,03 \%)$ & $215(9,86 \%)$ & $393(20,39 \%)$ \\
USB Rib. Preto & $785(32,89 \%)$ & $602(31,26 \%)$ & $906(41,56 \%)$ & $407(21,12 \%)$ \\
USB demais cidades & $773(32,38 \%)$ & $713(37,02 \%)$ & $716(32,84 \%)$ & $506(26,26 \%)$ \\
USA Rodovias & $12(0,50 \%)$ & $14(0,73 \%)$ & $15(0,69 \%)$ & $22(1,14 \%)$ \\
Polícia & $20(0,84 \%)$ & $27(1,40 \%)$ & $27(1,24 \%)$ & $21(1,09 \%)$ \\
Particular & $166(6,95 \%)$ & $175(9,09 \%)$ & $226(10,37 \%)$ & $245(12,71 \%)$ \\
Bombeiros & $70(2,93 \%)$ & $56(2,91 \%)$ & $59(2,71 \%)$ & $60(3,11 \%)$ \\
Outros & $397(16,63 \%)$ & $165(8,57 \%)$ & $16(0,73 \%)$ & $273(14,17 \%)$ \\
\hline Total & $\mathbf{2 3 8 7 ( 1 0 0 , 0 0 \% )}$ & $\mathbf{1 9 2 6 ( 1 0 0 , 0 0 \% )}$ & $\mathbf{2 1 8 0 ( 1 0 0 , 0 0 \% )}$ & $\mathbf{1 9 2 7}(100,00 \%)$ \\
\hline
\end{tabular}

Em relação à condição de alta dos pacientes, é possível observar que mais de $50 \%$ dos pacientes apresenta alguma sequela, indo de limitações moderadas a 
graves, enquanto cerca de $35 \%$ dos pacientes teve uma boa recuperação (Tabela 21).

Tabela 21. Condição de alta dos pacientes vítimas de trauma

\begin{tabular}{lcccc}
\hline Condição de alta & $\mathbf{2 0 0 6}$ & $\mathbf{2 0 0 7}$ & $\mathbf{2 0 0 8}$ & $\mathbf{2 0 0 9}$ \\
\hline Óbito & $96(4,02 \%)$ & $85(4,42 \%)$ & $88(4,04 \%)$ & $96(4,98 \%)$ \\
Estado vegetativo persistente & $0(0,00 \%)$ & $2(0,10 \%)$ & $3(0,14 \%)$ & $2(0,10 \%)$ \\
Limitações graves & $27(1,13 \%)$ & $26(1,35 \%)$ & $33(1,51 \%)$ & $23(1,19 \%)$ \\
Limitações moderadas & $1191(49,90 \%)$ & $963(50,03 \%)$ & $1166(53,49 \%)$ & $993(51,53 \%)$ \\
Boa recuperação & $941(39,42 \%)$ & $740(38,44 \%)$ & $755(34,63 \%)$ & $695(36,07 \%)$ \\
Transferência & $108(4,52 \%)$ & $95(4,94 \%)$ & $117(5,37 \%)$ & $109(5,66 \%)$ \\
Evasão & $15(0,63 \%)$ & $9(0,47 \%)$ & $10(0,46 \%)$ & $5(0,26 \%)$ \\
Alta a pedido & $9(0,38 \%)$ & $5(0,26 \%)$ & $8(0,37 \%)$ & $4(0,21 \%)$ \\
Ignorado & $0(0,00 \%)$ & $1(0,05 \%)$ & $0(0,00 \%)$ & $0(0,00 \%)$ \\
\hline Total & $\mathbf{2 3 8 7}(100,00 \%)$ & $\mathbf{1 9 2 5}(100,00 \%)$ & $\mathbf{2 1 8 0 ( 1 0 0 , 0 0 \% )}$ & $\mathbf{1 9 2 7}(100,00 \%)$ \\
\hline
\end{tabular}

Em relação à utilização dos exames radiológicos, em média, cada paciente atendido realizou exames de radiologia convencional de, pelo menos 2 regiões do corpo. A utilização de radiografia simples de coluna cervical, tórax e bacia foi respectivamente de $30,17 \%, 47,74 \%$ e $34,20 \%$. Este valor manteve-se estável no período de 2006 a 2009. (Tabela 22).

Tabela 22. Quantidade de exames de radiologia convencional por ano

\begin{tabular}{lccccc}
\hline Região do corpo & $\mathbf{2 0 0 6}$ & $\mathbf{2 0 0 7}$ & $\mathbf{2 0 0 8}$ & $\mathbf{2 0 0 9}$ & Total \\
\hline Coluna cervical & $741(31,04 \%)$ & $638(33,13 \%)$ & $657(30,14 \%)$ & $504(26,15 \%)$ & $2540(30,17 \%)$ \\
Tórax & $1071(44,87 \%)$ & $979(50,83 \%)$ & $1049(48,12 \%)$ & $921(47,79 \%)$ & $4020(47,74 \%)$ \\
Bacia & $755(31,63 \%)$ & $719(37,33 \%)$ & $778(35,69 \%)$ & $628(32,59 \%)$ & $2880(34,20 \%)$ \\
Crânio & $74(3,10 \%)$ & $31(1,61 \%)$ & $21(0,96 \%)$ & $16(0,83 \%)$ & $142(1,69 \%)$ \\
Face & $181(7,58 \%)$ & $104(5,40 \%)$ & $104(4,77 \%)$ & $52(2,70 \%)$ & $441(5,24 \%)$ \\
Membros superiores & $824(34,52 \%)$ & $659(34,22 \%)$ & $753(34,54 \%)$ & $597(30,98 \%)$ & $2833(33,65 \%)$ \\
Membros inferiores & $587(24,59 \%)$ & $471(24,45 \%)$ & $631(28,94 \%)$ & $542(28,13 \%)$ & $2231(26,50 \%)$ \\
Demais colunas & $449(18,81 \%)$ & $401(20,82 \%)$ & $466(21,38 \%)$ & $439(22,78 \%)$ & $1755(20,84 \%)$ \\
Total de exames & 4682 & 4002 & 4459 & 3699 & 16842 \\
Total de pacientes & 2387 & 1926 & 2180 & 1927 & 8420 \\
Exames por paciente & 1,96 & 2,08 & 2,05 & 1,92 & 2,00 \\
\hline
\end{tabular}


Em pacientes com trauma leve (ISS entre 1 e 8 ), os exames de radiologia convencional foram realizados em $68,07 \%$ dos casos (Tabela 23 ).

Tabela 23. Utilização de exames de radiologia convencional de acordo com a faixa de ISS

\begin{tabular}{lccc}
\hline \multicolumn{1}{c}{ ISS } & Total de casos & Fizeram RX & $\%$ \\
\hline $\mathbf{1}$ a $\mathbf{8}$ & 5512 & 3752 & $68,07 \%$ \\
$\mathbf{9}$ a $\mathbf{1 5}$ & 1782 & 1575 & $88,38 \%$ \\
$\mathbf{1 6}$ a $\mathbf{2 4}$ & 590 & 549 & $93,05 \%$ \\
$\mathbf{2} \mathbf{2 5}$ & 536 & 441 & $82,28 \%$ \\
\hline Total & $\mathbf{8 4 2 0}$ & $\mathbf{6 3 1 7}$ & $\mathbf{7 5 , 0 2} \%$ \\
\hline
\end{tabular}

A realização de exames de radiologia convencional de coluna cervical, tórax e bacia estão apresentados na Tabela 24 abaixo, mostrando grande porcentagem de utilização dos mesmos nos traumas leves (faixa de ISS entre 1 e 8).

Tabela 24. Radiografia simples de coluna cervical, tórax e bacia por ISS

\begin{tabular}{lcccc}
\hline \multicolumn{1}{c}{ ISS } & Total de casos & RX coluna cervical & RX tórax & RX bacia \\
\hline $\mathbf{1 ~ a ~} \mathbf{8}$ & 5512 & $1294(23,48 \%)$ & $1871(33,94 \%)$ & $1311(23,78 \%)$ \\
$\mathbf{9}$ a $\mathbf{1 5}$ & 1782 & $667(37,43 \%)$ & $1230(69,02 \%)$ & $1032(57,91 \%)$ \\
$\mathbf{1 6}$ a $\mathbf{2 4}$ & 590 & $315(53,39 \%)$ & $491(83,22 \%)$ & $350(59,32 \%)$ \\
$\mathbf{2} \mathbf{2 5}$ & 536 & $264(49,25 \%)$ & $428(79,85 \%)$ & $287(53,54 \%)$ \\
\hline
\end{tabular}

Em pacientes com escore de 15 na escala de coma de Glasgow, a radiografia simples de coluna cervical foi realizado em $24,57 \%$ dos pacientes (1777 pacientes).

Em relação à quantidade de exames de tomografia computadorizada (TC) utilizadas no atendimento inicial do paciente traumatizado, foram realizadas 0,78 exames de qualquer região do corpo por paciente. No período do estudo foram realizadas tomografia computadorizadas de crânio em 34,68\%, tomografia computadorizadas de tórax em 4,87\%, tomografia computadorizadas de abdome em 11,22\% e tomografia computadorizadas de tórax/abdome em 3,60\% dos pacientes. Exceto pela tendência de manutenção do percentual de exames de tomografia computadorizadas de crânio que manteve-se estável de 2006 a 2009, os demais estão sendo utilizados em quantidade maior a cada ano (Tabela 25). 
Tabela 25. Quantidade de exames de tomografia computadorizada realizados por ano

\begin{tabular}{lccccc}
\hline Região do corpo & $\mathbf{2 0 0 6}$ & $\mathbf{2 0 0 7}$ & $\mathbf{2 0 0 8}$ & $\mathbf{2 0 0 9}$ & Total \\
\hline Crânio & $757(31,71 \%)$ & $742(38,53 \%)$ & $772(35,41 \%)$ & $649(33,68 \%)$ & $2920(34,68 \%)$ \\
Tórax & $46(1,93 \%)$ & $46(2,39 \%)$ & $126(5,78 \%)$ & $192(9,96 \%)$ & $410(4,87 \%)$ \\
Abdome & $171(7,16 \%)$ & $187(9,71 \%)$ & $268(12,29 \%)$ & $319(16,55 \%)$ & $945(11,22 \%)$ \\
\hline Abdome + tórax & $27(1,13 \%)$ & $26(1,35 \%)$ & $97(4,45 \%)$ & $153(7,94 \%)$ & $303(3,60 \%)$ \\
Face & $169(7,08 \%)$ & $144(7,48 \%)$ & $194(8,90 \%)$ & $183(9,50 \%)$ & $690(8,19 \%)$ \\
Membros superiores & $13(0,54 \%)$ & $27(1,40 \%)$ & $47(2,16 \%)$ & $30(1,56 \%)$ & $117(1,39 \%)$ \\
Membros inferiores & $33(1,38 \%)$ & $37(1,92 \%)$ & $76(3,49 \%)$ & $62(3,22 \%)$ & $208(2,47 \%)$ \\
Coluna cervical & $115(4,82 \%)$ & $111(5,76 \%)$ & $263(12,06 \%)$ & $240(12,45 \%)$ & $729(8,66 \%)$ \\
Demais colunas & $52(2,18 \%)$ & $50(2,60 \%)$ & $94(4,31 \%)$ & $82(4,26 \%)$ & $278(3,30 \%)$ \\
Total de exames & 1383 & 1370 & 1937 & 1910 & $6600(78,38 \%)$ \\
Total de pacientes & 2387 & 1926 & 2180 & 1927 & 8420 \\
Total de exames/paciente & 0,58 & 0,71 & 0,89 & 0,99 & 0,78 \\
\hline
\end{tabular}

Os exames de tomografia computadorizada de qualquer região do corpo foram utilizados em $34,27 \%$ dos pacientes com trauma leve (ISS entre 1 e 8 ) - Tabela 26.

Tabela 26. Utilização de exames de tomografia computadorizada conforme a faixa de ISS

\begin{tabular}{lccc}
\hline \multicolumn{1}{c}{ ISS } & Total de casos & Fizeram TC & \% \\
\hline $\mathbf{1}$ a $\mathbf{8}$ & 5512 & 1889 & $34,27 \%$ \\
$\mathbf{9}$ a $\mathbf{1 5}$ & 1782 & 989 & $55,50 \%$ \\
$\mathbf{1 6}$ a $\mathbf{2 4}$ & 590 & 448 & $75,93 \%$ \\
$\mathbf{2} \mathbf{2 5}$ & 536 & 393 & $73,32 \%$ \\
\hline Total & $\mathbf{8 4 2 0}$ & $\mathbf{3 7 1 9}$ & $\mathbf{4 4 , 1 7 \%}$ \\
\hline
\end{tabular}

A utilização de tomografia computadorizada de crânio ocorreu em 34,68\% dos pacientes. Nos pacientes com escore de 15 na escala de coma de Glasgow, o resultado da tomografia computadorizada de crânio mostrou lesões AIS = 1 em 83,28\% e AIS $=2$ em $6 \%$ dos pacientes, sendo que nenhum deles foi submetido a qualquer procedimento neurocirúrgico. Em pacientes adultos, a soma deste percentual de lesões AIS = 1 e 2 foi de $86,96 \%$ e em crianças ( $\leq 12$ anos) foi de 95,25\%. Na faixa de pacientes com trauma leve (ISS entre 1 e 8), 27,23\% (1501) dos pacientes foram submetidos a tomografia computadorizada de crânio (Tabela 27). 
Tabela 27. Utilização de tomografia computadorizada de crânio de acordo com a faixa de ISS

\begin{tabular}{lccc}
\hline \multicolumn{1}{c}{ ISS } & Total de casos & Total com TC crânio & \% \\
\hline $\mathbf{1}$ a $\mathbf{8}$ & 5512 & 1501 & $27,23 \%$ \\
$\mathbf{9}$ a $\mathbf{1 5}$ & 1782 & 706 & $39,62 \%$ \\
$\mathbf{1 6}$ a $\mathbf{2 4}$ & 590 & 355 & $60,17 \%$ \\
$\mathbf{2} \mathbf{2 5}$ & 536 & 358 & $66,79 \%$ \\
\hline Total & $\mathbf{8 4 2 0}$ & $\mathbf{2 9 2 0}$ & $\mathbf{3 4 , 6 8 \%}$ \\
\hline
\end{tabular}

Em pacientes com escore de 15 na escala de coma de Glasgow com lesões AIS = 1, a utilização de radiologia convencional do tórax foi de 40,05\% (2782) e a de TC de tórax foi de $50,24 \%$ (206). A tendência à utilização do TC de tórax tem sido crescente no período de 2006 a 2009 (Tabela x).

Tabela 28. Utilização da TC de tórax de acordo com o AIS das lesões traumáticas encontradas

\begin{tabular}{ccccccc}
\hline AIS & $\mathbf{2 0 0 6}$ & $\mathbf{2 0 0 7}$ & $\mathbf{2 0 0 8}$ & $\mathbf{2 0 0 9}$ & Total & \% resultados \\
\hline $\mathbf{1}$ & 19 & 19 & 61 & 107 & 206 & $50,24 \%$ \\
$\mathbf{2}$ & 2 & 1 & 13 & 9 & 25 & $6,10 \%$ \\
$\mathbf{3}$ & 16 & 23 & 40 & 56 & 135 & $32,93 \%$ \\
$\mathbf{4}$ & 8 & 3 & 11 & 17 & 39 & $9,51 \%$ \\
$\mathbf{5}$ & 1 & 0 & 1 & 3 & 5 & $1,22 \%$ \\
\hline Total & $\mathbf{4 6}$ & $\mathbf{4 6}$ & $\mathbf{1 2 6}$ & $\mathbf{1 9 2}$ & $\mathbf{4 1 0}$ & $\mathbf{1 0 0 , 0 0 \%}$ \\
\hline
\end{tabular}

Em pacientes com escore de 15 na escala de coma de Glasgow com lesões AIS $=1$ foi de $74,33 \%$ (391), sendo 3 pacientes submetidos à laparotomias não terapêuticas. Nos pacientes com escore de 15 na escala de coma de Glasgow que foram submetidos a cirurgias extra-abdominais, respectivamente, 42,59\% e 63,39\% tinham lesões AIS = 1 em cirurgias ortopédicas e neurocirúrgicas.

Houve um aumento progressivo da utilização de TC combinada de tórax e abdome no período de estudo, com aumento de 373,10\% entre 2007 e 2008 e de $63,4 \%$ entre 2008 e 2009. Em 43,56\% dos casos, houve a combinação de lesões de tórax AIS = 1 ou 2 e as lesões de abdome AIS = 1, não sendo necessária nenhuma intervenção terapêutica. Em $69,31 \%$ dos casos, a TC combinada tinham lesões de abdome AIS $=1$ e lesões de tórax AIS $\leq 3$, sendo necessária apenas a drenagem pleural. Levando em consideração apenas o resultado da TC de tórax, $88,78 \%$ dos casos tinham AIS $\leq 3$. 
O uso de ultrassom móvel na sala de trauma à beira do leito - Focused assessment with sonography for trauma (FAST) em pacientes com trauma contuso foi de $24,55 \%$ em pacientes com instabilidade hemodinâmica (pressão arterial sistólica < $90 \mathrm{mmHg}$ ), com $61 \%$ dos pacientes sendo submetido a cirurgia, sendo $29,3 \%$ à cirurgias abdominais e $31,7 \%$ à cirurgias extra-abdominais (ortopedia ou neurocirurgia), tendo taxa de mortalidade de 51,21\%. Nos pacientes traumatizados com estabilidade hemodinâmica na admissão (pressão arterial sistólica $\geq 90 \mathrm{mmHg}$ ), o ultrassom FAST foi realizado em $8,04 \%$ dos pacientes, sendo que 40,1\% também realizaram TC de abdome, com 49,31\% dos pacientes sendo submetido a cirurgia, sendo $8 \%$ à cirurgias abdominais e $41,32 \%$ à cirurgias extra-abdominais (ortopedia ou neurocirurgia), tendo taxa de mortalidade de $14,63 \%$.

A utilização de exames laboratoriais séricos na admissão dos pacientes traumatizados ocorreu em $63,67 \%$ dos casos. Dos pacientes com trauma leve (ISS de 1 a 8 ), 47,75\% realizam exames sanguíneos (Tabela 29 ).

Tabela 29. Utilização de exames laboratoriais séricos de acordo com a gravidade do trauma

\begin{tabular}{lccc}
\hline \multicolumn{1}{c}{ ISS } & Total de casos & Fizeram exames séricos & $\%$ \\
\hline $\mathbf{1}$ a $\mathbf{8}$ & 5512 & 2632 & $47,75 \%$ \\
$\mathbf{9}$ a $\mathbf{1 5}$ & 1782 & 1678 & $94,16 \%$ \\
$\mathbf{1 6}$ a $\mathbf{2 4}$ & 590 & 568 & $96,27 \%$ \\
$\mathbf{2} \mathbf{2 5}$ & 536 & 483 & $90,11 \%$ \\
\hline Total & $\mathbf{8 4 2 0}$ & $\mathbf{5 3 6 1}$ & $\mathbf{6 3 , 6 7 \%}$ \\
\hline
\end{tabular}

Em relação a exames séricos específicos, a tipagem sanguínea foi realizada em $45,52 \%$ dos pacientes atendidos, sendo utilizada em $28,41 \%$ dos casos de trauma leve (ISS entre 1 e 8). O exame da coagulação denominado tempo de protrombina foi realizado em $5,44 \%$ dos trauma leves (ISS entre 1 e 8 ) e $58,79 \%$ dos traumas graves (ISS $\geq 16$ ). No período de estudo, a solicitação de coagulograma para traumas graves tem aumentado gradativamente chegando a 67,34\% em 2009 (Tabela 30). 
Tabela 30. Utilização de tipagem sanguínea e tempo de protrombina de acordo com a gravidade do trauma

\begin{tabular}{cccc}
\hline ISS & Total de casos & Tipagem ABO-RH & Tempo de Protrombina \\
\hline $\mathbf{1}$ a $\mathbf{8}$ & 5512 & $1566(28,41 \%)$ & $300(5,44 \%)$ \\
$\mathbf{9}$ a $\mathbf{1 5}$ & 1782 & $1315(73,79 \%)$ & $451(25,31 \%)$ \\
$\mathbf{1 6}$ a $\mathbf{2 4}$ & 590 & $512(86,78 \%)$ & $319(54,07 \%)$ \\
$\mathbf{2} \mathbf{2 5}$ & 536 & $440(82,09 \%)$ & $343(63,99 \%)$ \\
\hline Total & $\mathbf{8 4 2 0}$ & $\mathbf{3 8 3 3 ( 4 5 , 5 2 \% )}$ & $\mathbf{1 4 1 3 ( 1 6 , 7 8 \% )}$ \\
\hline
\end{tabular}


5 Discussão 

Esse estudo permite a observação dos casos de trauma atendidos através de diferentes ângulos: epidemiológico, avaliação da qualidade do atendimento, utilização racional de recursos diagnósticos, gestão hospitalar e clínica, aperfeiçoamento de software hospitalar e quanto ao papel da informática como ferramenta de apoio.

De uma maneira geral, é possível observar que os pacientes vítimas de trauma consistem, principalmente do sexo masculino, principalmente na idade produtiva (primeiras quatro décadas de vida), prevalecendo o trauma contuso, principalmente os mecanismos de trauma como quedas e acidentes de trânsito.

Esses dados oferecem importante auxílio para conhecer o perfil de pacientes, faixa etária, tipo de transporte pré-hospitalar, mecanismos de trauma e distribuição de casos ao longo dos dias da semana, observando maior quantidade de casos nos finais de semana.

Esses dados podem oferecer ao gestor de saúde importante embasamento para programar a atuação em diversos tipos de medidas: 1) de prevenção dos traumas conforme cada perfil de paciente, quer seja por sexo ou faixa etária, salientando as quedas e atropelamentos nos extremos de idade (< 12 e > 60 anos) e acidentes motociclísticos em qualquer faixa etária. 2) de atendimento pré-hospitalar e regulação médica, em relação ao correto encaminhamento de casos de maior gravidade para um hospital terciário com unidade de transporte compatível e 3) de atendimento hospitalar, em relação à adequação dos recursos diagnósticos e terapêuticos utilizados em cada caso de acordo com a gravidade que se apresenta.

Pensando na gestão do sistema de saúde e na regionalização, é possível o gestor de saúde utilizar essas informações para aperfeiçoamento do atendimento aos pacientes vítimas de trauma, melhor atuação do serviço de regulação e encaminhamento dos pacientes, tanto do município quanto daqueles trazidos de outras cidades, que em sua maioria, vêm em ambulâncias de suporte básico. O estudo da população de pacientes encaminhado de cada município e microrregião para a Unidade de Emergência do HCFMRP permite avaliar e discutir a adequação de tais encaminhamentos e propor acordos de transferência, na tentativa de melhorar as condições diagnósticas e terapêuticas e resolver os casos ao nível local ou de encaminhamento de casos leves e moderados para hospitais secundários, numa tentativa de resguardar o hospital de referencia terciária para os casos mais graves. 
$\mathrm{O}$ anunciado aumento gradual de unidades do SAMU em cidades da DRSXIII, compondo o SAMU regional pode vir a mudar esse cenário. Porém, é necessário que tanto a Central de Regulação quanto os hospitais conveniados para os atendimento aos pacientes traumatizados devem possuir adequado sistema informatizado para coleta de dados e completo com o cálculo dos índices de trauma e da utilização de recursos diagnósticos e terapêuticos.

Preferencialmente, a Unidade de Emergência do HCFMRP deve prioritariamente ser utilizada para atender pacientes de maior gravidade. Todavia os números demonstram considerável quantia de pacientes com traumas leves sendo atendidos no local. Embora estes casos de trauma se confirmem como leves após completar o atendimento inicial, a quantidade de exames utilizados em pacientes com ISS de 1 a 8 foram, respectivamente, $68,07 \% ; 34,27 \%$ e $47,75 \%$ para exames de radiologia convencional, tomografia computadorizada e exames laboratoriais séricos.

Quanto à qualidade do atendimento ao paciente vítima de trauma, a quantia de pacientes mortos ao chegar ou antes de 24 horas da admissão, quantidade de exames laboratoriais e radiológicos para pacientes com AIS 1 demandam atenção, podendo ser demonstrativo de atraso no diagnóstico e/ou instituição da adequada conduta terapêutica ou solicitação de exames sem a utilização de protocolos clínicos multiprofissionais.

A criação de protocolos de solicitação de exames radiológicos e laboratoriais, tomando como referência o tipo de trauma, os parâmetros clínicos de gravidade , principalmente o escore da escala de coma de Glasgow e a pressão arterial, bem como sintomas e sinais específicos do exame físico do paciente e a literatura médica específica sobre os diversos tipos de protocolos poderia trazer melhor indicação na solicitação e também proporcionar mais racionalização na utilização de recursos. Uma quantidade significativa de exames, tanto radiológicos quanto laboratoriais, foi utilizada para pacientes com AIS $=1$ e escore de 15 na escala de coma de Glasgow, com menos de 24 horas de internação e que não passaram por cirurgia. Esta quantidade excessiva de exames sobrecarrega os funcionários do laboratório para o processamento do material a ser examinado, a distribuição de transposte dos exames da sala de trauma até o laboratório, os técnicos da radiologia que realizam mais exames, os técnicos de enfermagem que transportam estes pacientes até o setor de 
radiologia e os médicos da radiologia que têm um excesso de exames a serem laudados. Além destes fatos, deve-se lembrar também do desgaste desnecessário dos equipamentos radiológicos e laboratoriais, maior depreciação destes equipamentos, risco de radiação a que estão expostos os pacientes e os funcionários, sem falar do custo financeiro dispensado.

Existe uma série de estudos na literatura médica que enfatizam medidas para a redução da utilização de exames radiológicos desnecessários, salientando a economia de gastos e os riscos da exposição à radiação pelos pacientes e funcionários com risco futuro de neoplasias. A tomografia computadorizada expõe os pacientes a uma dose de radiação muito maior que os exames radiológicos convencionais. Os pacientes com múltiplos traumas recebem uma dose substancial de radiação e tem um efeito cumulativo. O baixo risco individual de câncer torna-se um assunto de saúde pública quando multiplicada por um grande número de exames radiológicos.

O Advanced Trauma Life Support (ATLS) preconiza a sistematização da avaliação da coluna cervical em pacientes com escore de 15 na escala de coma de Glasgow e sóbrio. Nestes pacientes, se não houver dor cervical referida ou alteração do exame físico cervical, pode-se retirar o colar cervical e não está indicada a realização da investigação radiológica da coluna cervical. Embora neste estudo não tenha sido considerado dados de queixas dos pacientes e do exame físico, $24,57 \%$ dos pacientes ( 1777 casos) com Glasgow = 15 fizeram exames radiológicos simples da coluna cervical.

Nos pacientes com escore menor que 15 na escala de coma de Glasgow, é indicada a utilização de investigação radiológica da coluna cervical devido a pouca confiabilidade nas informações do paciente e no exame físico. Um problema atual bastante pesquisado é estabelecer critérios para selecionar os pacientes que farão TC cervical quando o escore de Glasgow não permite avaliação confiável, dúvidas na interpretação do exame radiológico convencional, além de inexplicados e persistentes sintomas clínicos.

Os estudos sobre trauma cranioencefálico leve procuram estabelecer critérios e fatores de risco para a seleção de pacientes que necessitam da realização da TC de crânio, procurando definir o percentual de presença de lesão intracraniana, lesões cerebrais clinicamente significativas e a necessidade de intervenção neurocirúrgica, tanto em adultos como em crianças. No presente estudo, 34,68\% (2920) dos 
pacientes atendidos foram submetidos à TC de crânio. Os pacientes adultos com escore de 15 na escala de coma de Glasgow tiveram 86,96\% de lesões AIS = 1 ou 2 , enquanto que as crianças ( $\leq 12$ anos) tiveram 95,25\%. Nenhuma intervenção neurocirúrgica foi realizada nestes pacientes.

Vários estudos sobre a utilização de radiologia convencional e tomografia computadorizada no trauma do tórax mostraram que em pacientes alertas e sem fatores de risco (dor à palpação da parede torácica, esforço respiratório, redução do murmúrio vesicular e necessidade de ventilação mecânica), a TC de tórax não suplanta a radiografia simples de tórax no diagnóstico das lesões traumáticas. Isto é suportado pelo fato de que a grande maioria das lesões torácicas são tratadas pela simples observação clínica e pela drenagem pleural. Em pacientes sem qualquer fator de risco poderia ser reduzida a utilização de TC de tórax em até $18 \%$ sem redução do diagnóstico de lesões torácicas clinicamente relevantes. No presente estudo, a TC de tórax foi utilizada em $56,34 \%$ dos pacientes com escore de 15 na escala de Glasgow com lesões AIS = 1 ou 2.

Na suspeita de trauma abdominal, o Advanced Trauma Life Support (ATLS) preconiza a utilização do ultrassom FAST em pacientes hemodinamicamente instáveis, particularmente no trauma contuso, a menos que a indicação cirúrgica seja evidente. Neste estudo, apenas em $24,55 \%$ dos pacientes nestas condições realizaram ultrassom FAST. Vários estudos têm mostrado que a ultrassonografia torácica, como parte do ultrassom FAST à beira do leito detecta 92 a $100 \%$ de todos os pneumotórax e representam uma simples extensão do exame físico.

Em vários estudos, os fatores de risco para a presença de lesão intra-abdominal são: escore de Glasgow < 14, dor na rebordo costal, dor abdominal, fratura de femur, hematúria, hematócrito $<30 \%$ e a presença de qualquer alteração no raio $X$ de tórax (pneumotórax ou fratura costal). A ausência destes fatores de risco tem valor preditivo negativo de $98,6 \%$, sendo que os pacientes não se beneficiariam da utilização da TC de abdome. Neste estudo, $74,33 \%$ dos pacientes com escore de Glasgow e que foram submetidos à TC de abdome tiveram lesões AIS = 1. Destes pacientes, 3 foram submetidos à laparotomia não terapêutica.

Alguns estudos discutem a utilização de TC de corpo total (crânio e junções crânio-cervical e cérvico-torácica sem contraste endovenoso, e tórax, abdome e pelve com contraste) em pacientes estáveis hemodinamicamente apresentando múltiplos traumas com suspeita de lesões AIS $\geq 3$ em 2 ou mais segmentos corpóreos. 
Na maioria dos estudos, a utilização de exames laboratoriais de rotina na admissão dos pacientes traumatizados não deve ser uma prática, pois normalmente não há utilidade clínica na informação providenciada pelos resultados destes exames, tanto em pacientes adultos quanto em crianças. Alguns estudos mostram que a categorização dos pacientes baseada em critérios fisiológicos e anatômicos é uma alternativa que torna mais racional a indicação destes exames, através de uma abordagem mais minimalista em termos de números de exames solicitados, sem comprometer a qualidade da assistência prestada. No presente estudo, os exames bioquímicos séricos foram utilizados em $63,67 \%$ dos pacientes admitidos. Dentre os pacientes com traumas leves (ISS entre 1 e 8), 47,75\% realizaram exames laboratoriais séricos, sendo que $28,41 \%$ fizeram tipagem $A B O$, mesmo com baixa probabilidade de hemotransfusão. De modo inverso, nos pacientes com traumas graves (ISS $\geq 16$ ), mesmo com o risco de coagulopatia do trauma, foi solicitado o tempo de protrombina em apenas $58,79 \%$ dos casos.

Especificamente em relação aos exames radiológicos e laboratoriais, no momento da solicitação do exame, o módulo do sistema hospitalar do HCFMRP poderia apresentar grupos de exames pré-definidos conforme o tipo de trauma e gravidade estimada inicialmente, além de informar na tela caso já exista um exame igual ao que está sendo solicitado e seu respectivo resultado. Essas simples ações poderiam gerar redução da solicitação de exames.

Os índices ISS, RTS e TRISS, de acordo com extensa literatura médica sobre trauma nas últimas décadas demonstraram confiabilidade quanto aos seus indicadores. A real predição das faixas de gravidade do ISS de pacientes atendidos, mostra a validade de sua utilização com índice prognóstico e que deve ser realizado sistematicamente.

Em relação a software hospitalar, o IntegraVep mostrou-se um software adequado, trazendo agilidade, maior produtividade aos funcionários, redução de erros e maior facilidade para recuperação e cruzamento de informações.

A posterior obtenção dos dados de exames radiológicos e laboratoriais demonstrou que o IntegraVep pode ser considerado um bom software para o qual foi concebido e oferece grandes possibilidades de estatísticas à medida que tiver uma maior quantidade de dados sendo unificados e incorporados ao mesmo. 
O IntegraVep somente foi possível com a integração de pessoas com formação em diferentes áreas de conhecimento (epidemiologia, cirurgia do trauma, informática). Assim, fica claro a importância da integração entre profissionais de medicina e informática com especialidade em desenvolvimento de software.

Mais do que ser desenvolvido um software para o armazenamento de dados, deve ser desenvolvido um software com foco no conhecimento que se deseja obter a partir dos dados disponíveis desde as primeiras etapas de seu desenvolvimento. Para isso, é altamente recomendado que um analista de sistemas ou pessoa competente esteja acompanhando e planejando a modelagem do sistema com foco nas informações que se deseja obter. $O$ banco de dados não deve servir apenas para o armazenamento dos dados. Este armazenamento deve ser pensado de forma para que se possam tirar informações a respeito do atual estado do conhecimento e indicando futuras áreas de pesquisa e investigação, visando a aplicabilidade das informações obtidas para a melhoria da prática assistencial.

O projeto de mestrado aqui apresentado evidencia a importância de uma forma sistematizada de armazenamento e análise de múltiplos enfoques dos dados de trauma ocorridos na região de Ribeirão Preto e atendidos na Unidade de Emergência do HCFMRP. Os resultados e conhecimentos obtidos a partir de tais dados poderão ser de vital importância para ações práticas e efetivamente fundamentadas, para elaboração de propostas de intervenção visando à prevenção e, consequentemente, possível redução da ocorrência de trauma e para a racionalização do emprego de recursos diagnósticos e terapêuticos de acordo com a gravidade dos casos.

Ao observar neste momento algumas das principais dificuldades encontradas no uso do IntegraVep como a necessidade de ir pessoalmente à Unidade de Emergência para a instalação nos computadores, necessidade de ajuste dos nomes de campos das tabelas ou dados em decorrência de novas versões poderiam ser reduzidos com o uso de um software executável no navegador ao invés de um software instalado no computador ou um melhor planejamento do sistema antes de seu desenvolvimento e um acompanhamento contínuo no desenvolvimento.

A utilização da linguagem Java com o desenvolvimento focado para uma aplicação executável nos computadores pode ser um limitante frente aos diversos sistemas operacionais atualmente no mercado, sendo necessária a instalação do software em cada computador. No caso da Unidade de Emergência, como os computa- 
dores funcionam com permissão de usuário, a cada vez que o software necessitava ser reinstalado em atualizações de versão, era necessário o suporte da equipe de informática para ter acesso como administrador ao computador. Isso poderia ser facilmente contornado usando tecnologias que permitam o desenvolvimento de um sistema que seja executado em um navegador de internet.

O fato da base do IntegraVep e do sistema hospitalar do HCFMRP serem separadas pode apresentar diferença de dados à medida que as informações do banco de dados do Sistemas HCFMRP são alteradas como por exemplo doença preexistente, sexo e endereço. Essas informações necessitariam ser atualizadas também no IntegraVep ou acessadas diretamente do banco de dados do sistema hospitalar do HCFMRP, a fim de evitar possíveis divergências em estatísticas que usem dessas variáveis.

Os resultados dos exames, tanto laboratoriais quanto radiológicos, são armazenados em texto simples, sendo que o resultado dos exames radiológicos é um texto livro e o resultado dos exames laboratoriais é um texto formatado, com marcações e campos específicos. O fato de ser um campo texto dificulta estatísticas mais refinadas caso exista interesse de se analisar os números existentes nos resultados. Uma solução poderia ser armazenar o resultado laboratorial não em texto, mas com seus valores numéricos ou textuais em cada campo correspondente.

Observando o formato de armazenamento dos dados do banco de dados do HCFMRP, fica a ideia de que se trata de um software que foi pensado para ser funcional, de forma a oferecer a informatização aos setores que o utilizam, todavia, a maneira que os dados são armazenados ou mesmo a falta de determinados dados dificulta a geração de estatísticas refinadas.

O trabalho envolvendo os dados inicialmente existentes no IntegraVep e associados aos dados de exames radiológicos e laboratoriais não se limita aos pacientes vítimas de trauma. O mesmo trabalho pode ser ampliado para todos os pacientes da Unidade de Emergência ou de todo o Hospital das Clínicas de Ribeirão Preto. Esse trabalho pode ser facilmente reproduzido em setores do hospital que atendem outros perfis de pacientes como, por exemplo, o CTI e centro cirúrgico. A criação de um software de análise dos dados atualmente armazenados no banco de dados do HCFMRP pode trazer ao conhecimento informações importantes. 
É possivel concluir que é grande a importância de haver um software alinhado com as necessidades de coleta e análise dos dados obtidos. Cada vez mais é nítida a importância da informática ser vista como fator estratégico e não simplesmente como ferramenta de trabalho.

Essa mudança de visão, associada às reuniões periódicas entre os desenvolvedores do software e os médicos especializados oferece ganho significativo de qualidade no software final. Isso permite que possa ser produzido um software que atenda de melhor maneira às demandas de obtenção de estatísticas, permitindo melhor gestão e poder de decisão para, identificando os pontos críticos, permitir rápida ação a fim de melhorar a qualidade de atendimento ao paciente e obter melhores indicadores. 
6 Conclusões 

Considerando os objetivos iniciais deste trabalho de identificar e caracterizar o perfil dos pacientes, calcular as medidas de frequência de trauma, descrever a evolução do trauma, verificar a existência de relação entre mecanismo e gravidade, verificar a existência de relação entre gravidade do trauma e demanda de exames laboratoriais e radiológicos e verificar a existência de relação entre a utilização de exames laboratoriais e radiológicos em casos de trauma leve, particularizando alguns exames específicos (radiologia simples de coluna cervical, tórax e bacia; tomografia computadorizada de crânio, tórax e abdome, e tipagem sanguínea e coagulograma), foram feitas análises descritivas considerando os pacientes admitidos no período de 2006 a 2009 na Unidade de Emergência do HCFMRP.

Foi possível observar a distribuição de pacientes vítimas de trauma quanto ao sexo, prevalecendo pessoas do sexo masculino, principalmente até 40 anos, onde o trauma contuso (principalmente quedas e acidentes de trânsito) foi mais frequente, principalmente nos finais de semana.

A ideia aqui apresentada quanto aos dados analisados pode ser materializada em um software para o uso dos profissionais de saúde, de forma que bastaria escoIher as variáveis desejadas e o período, obtendo facilmente as tabelas e gráficos relacionados aos dados. Um software com esses recursos pode ser ferramenta de apoio para:

- Oferecer ao gestor de saúde informações que auxiliem para prevenção dos traumas conforme cada perfil de paciente;

- Fornecer informações do serviço de atendimento pré-hospitalar e regulação médica quanto ao encaminhamento de pacientes conforme sua gravidade aos hospitais mais adequadamente dimensionados;

- Informar quais recursos diagnósticos e terapêuticos estão sendo utilizados nos pacientes conforme sua gravidade de lesão.

Foi observado que, a Unidade de Emergência do HCFMRP deve prioritariamente ser utilizada para atender pacientes de maior gravidade, porém foi verificada considerável quantidade de pacientes com traumas leves sendo atendidos no local.

Durante esse estudo, foi notado que a quantidade de exames utilizados em pacientes com ISS de 1 a 8 foram, respectivamente, 68,07\%; 34,27\% e 47,75\% nos 
anos de 2006 a 2009 para exames de radiologia convencional, tomografia computadorizada e exames laboratoriais séricos, apesar desses pacientes terem sido caracterizados como trauma leve após o atendimento inicial. A criação e aplicação de protocolo multiprofissional de solicitação de exames radiológicos e laboratoriais durante o atendimento inicial ao trauma poderiam contribuir para melhor adequar este achado.

Um dos conhecimentos advindos a partir das quantidades de exames realizados neste estudo, demonstra que é preciso buscar por uma racionalização de sua solicitação visando a redução da utilização de exames desnecessários, principalmente radiológicos, devido à economia de gastos e os riscos da exposição à radiação pelos pacientes e funcionários com risco futuro de neoplasias, com especial destaque para a maior dose de radiação da tomografia computadorizada ao paciente.

Este estudo apresentou ainda sugestões para possíveis aperfeiçoamento nos sistemas de solicitação de exames do HCFMRP, em busca de redução de pedidos de exame sem impactar negativamente no atendimento.

Foi visto também que os índices ISS, RTS e TRISS demonstraram confiabilidade quanto aos seus indicadores.

Ficou clara a necessidade de que um software desenvolvido deve ser pensado quanto às informações que deverá oferecer ao usuário, desde sua concepção. Uma adequada modelagem do banco de dados pode ser crítico para conseguir ou não oferecer informações refinadas posteriormente. Como exemplo, podemos considerar os resultados dos exames, tanto laboratoriais quanto radiológicos, que são armazenados em texto simples, dificultando análises quanto à quantidade de exames normais realizados pelos pacientes.

Este estudo permitiu trazer à tona a importância da existência de um software como ferramenta de apoio para a transformação de dado em informação, apresentando o perfil dos pacientes vítimas de trauma no período de 2006 a 2009.

Evidenciou-se também a importância de planejar o desenvolvimento do sistema com base nas informações que serão necessárias a partir dos dados armazenados, somente assim será possível não haver limitação de cruzamento de dados devido a informações inconsistentes ou campos categorizados não existentes. Al- 
guns campos como data e hora da admissão, por exemplo, uma vez que não sejam armazenados, não será possível obtê-los posteriormente.

Este estudo trouxe ainda o incremento das informações de exames radiológicos e laboratoriais aos dados do IntegraVep, através do cruzando dos dados dos pacientes vítimas de trauma existentes no IntegraVep com os exames radiológicos e laboratoriais solicitados dentro do sistema do HCFMRP durante a internação.

A principal conclusão desse trabalho é que, assim como o IntegraVep armazena e oferece informações a respeito de pacientes vítimas de trauma, é viável criar um software de análise dos dados existentes no banco de dados do HCFMRP, de forma que seja usado sistematicamente para todos os pacientes admitidos no Hospital das Clínicas de Ribeirão Preto, sendo planejado desde o início com base nas informações e conhecimento que se deseja obter. 



\section{Perspectivas de Trabalhos Futuros}



Esse estudo traz à tona várias possibilidades para futuros trabalhos de pesquisa, principalmente a elaboração de softwares.

A criação de um software que permita uma exportação fácil e customizada pelo usuário, alteração no módulo de pedido de exame permitindo a solicitação de exame radiológico ou laboratorial conforme o perfil de paciente que está sendo atendido. A possibilidade de checagem de resultados de exames anteriores semelhante ao que está sendo pedido, a fim de tentar reduzir a quantidade de exames com integração da base de dados do IntegraVep e do sistema hospitalar do HCFMRP pode favorecer para ter dados sempre atualizados. Outro importante avanço é o desenvolvimento de um software que permita a análise dos laudos dos exames, convertendo o resultado, que atualmente é armazenado em texto plano, para campos com valores individuais.

Pesquisas envolvendo a utilização de protocolos visando a racionalização da solicitação de exames radiológicos ou laboratoriais podem ser algumas opções de outros estudos derivados a partir desse trabalho. 

8 Referências 

AMERICAN COLLEGE OF SURGEONS. ACS. Comittee on Trauma. Advanced Trauma Life Support. Instructor manual. $6^{\text {th }}$ ed, Chicago; 1997.

ANKE, A. G. V.; Staghelle, J. K. ; Finset, A.; Roaldesen, K. S. ; Pilgran-Larsen, J.; Fugl-Meyer, A. R.. Long-term prevalence of impairments and disabilities after multiple trauma. The Journal of Trauma: Injury, Infection, and Critical Care 1997, v. 42, $n^{\circ} 1$, p. 54-61.

BOYD C. R., Tolson M. A. , Copes W. S.. Evaluating Trauma Care: The TRISS Method. Journal of trauma, 1987; 27(n.4):370-378.

COIMBRA R. S. M; Angle N.; Silva S. E.; Hoyt D. B.; Rasslan S. Índices de trauma: o que são e por que devem ser usados. Rev Col Bras Cir 1997; 24: 255-63.

CHIARA, O.; Cimbanassi, S. Protocolo para Atendimento Intra-Hospitalar do Trauma Grave. Rio de Janeiro: Elsevier, 2009.

DATE C. J. An Introduction to Database Systems. Sétima edição. AddisonWesley Longman Publishing Co., 1999. 938 p.

DEGANI, G. C. Trauma em idosos: características e evolução. Tese apresentada à Escola de Enfermagem de Ribeirão Preto - SP para obtenção de título de mestre, 2011.

DEGANI, G. C.. Trauma em idosos - características e evolução. Dissertação de mestrado apresentada à Escola de Enfermagem de Ribeirão Preto, 2011.

DEITEL H. M., Deitel P. J. Java: How to program. Segunda edição, Prentice Hall, 1998.

DRS-XIII. Regionais de saúde do estado de São Paulo. Disponível em: http://www.saude.sp.gov.br/ses/institucional/departamentos-regionais-desaude/regionais-de-saude. Acesso em 26 de janeiro de 2012.

EMS SQL Manager. SQLManager.net. Acessível em http://www.sqlmanager.net/products em 14 de fevereiro de 2012. 
Estatísticas de acidente de trânsito, 2007. Disponível em http://www.ribeiraopreto.sp.gov.br/transerp/estatistica/207estatistica.pdf, Acesso em outubro de 2008.

FABFORCE. Fabulous Force Database Tools. Acessível em http://fabforce.net em 16 de janeiro de 2012.

FERREIRA, A. B. H. Novo dicionário da língua portuguesa. $2^{a}$. ed. Rio de Janeiro: Nova Fronteira; 1999.

FEKETE, D. M.; Silva, L. T. N.; Oliveira, L. L.; Felipe, J. C.; Passos, A. D. C.; ALVES D. IntegraVepi - H: Sistema de Integração de Dados e Gerenciamento do Conhecimento para a Vigilância Epidemiológica Hospitalar. CBIS 2008.

FREE SOFTWARE. FSF - Free Software Foundation. Acessível em http://www.fsf.org/about/what-is-free-software em 12 de janeiro de 2012.

FUREY A., Pottjewid A. Search Software Quality. Acessível em http://searchsoftwarequality.techtarget.com/definition/integrated-developmentenvironment em 30 de janeiro de 2012.

GABBE, B. J.; Cameron, P. A.; Wolfe, R. TRISS: does it get better than this? Acad. Emerg. Med. v.11, n.2, p.181-186, Feb. 2004.

GARCÍA DELGADO, M.; Navarrete, P.; Rincón, M.D.; Muñoz Sánchez, A.; Jiménez Moragas, J. M.; Cosano Prieto, I. Análisi clínico-epdemiológico y de prática médica Del traumatismo grave em Andalucia. Estudo piloto. Proyeto GITAN. Medicina Intensiva 2001, v:25, $n^{\circ} 09$, p.327-332

GENNARELLI, T. A.; Wodzin, E. AIS. Abbreviated Injury Scake 2005, Update 2008. Edição 2008 - Association for the advancement of Automotive Medicine, Barrington, IL, USA.

GUIA DE VIGILÂNCIA EPIDEMIOLÓGICA. 6ed. Ministério da Saúde. 2005. Disponível em: http://portal.saude.gov.br/portal/arquivos/pdf/Guia_Vig_Epid_novo2.pdf . 
GULA E. A.; Pereira Junior G. A.; Passos, A. D. C.; Belavenuto F.; Alves D. Utilização de um sistema informatizado para a Vigilância Epidemiológica na Unidade de Emergência do HCFMRP, CBIS 2010.

HCFMRP. Apresentação da Unidade de Emergência do HCFMRP. Disponível em: http://www.hcrp.fmrp.usp.br/sitehc/informacaogaleria.aspx?id=67\&ref=5\&refV=46. Acesso em 24 de janeiro de 2012.

IBGE. Censo 2010. Instituto Brasileiro de Geografia e Estatística. Disponível em http://www.censo2010.ibge.gov.br/primeiros_dados_divulgados/index.php?uf=35 em 06/05/2012.

IPEA. Instituto de Pesquisa Econômica Aplicada. Impactos sociais e econômicos dos acidentes de trânsito nas aglomerações urbanas - Síntese da pesquisa. Brasília, maior de 2003.

IUNES, R. F. Impacto econômico das causas externas no Brasil: um esforço de mensuração. Rev. Saúde Pública. v.31, n.4, p.36-46, ago. 1997.

MEDRONHO, Roberto A.; Block K. V.; Luiz R. R.; Werneck G. L. Epidemiologia. $2^{a}$ edição, 2009. Editora Atheneu. P 12-30

MINISTÉRIO DO PLANEJAMENTO, Orçamento e Gestão - Brasil. Instituto Brasileiro de Geografia e Estatística - IBGE. Diretoria de Pesquisas. Coordenação de População e Indicadores Sociais. Dinâmica demográfica e a mortalidade no Brasil no período 1998-2008. Brasília: Ministério do Planejamento, Orçamento e Gestão, 2009.

MOLLER A.; schwartzbach L. M. An Introduction to XML and Web Technologies. Primeira edição. Addison-Wesley, Janeiro 2006. 568 p.

$\begin{array}{llll}\text { NETBEANS. Netbeans. } & \text { Acessível em }\end{array}$ http://www.netbeans.org/features/index.html em 14 de fevereiro de 2012.

NHE-HCFMRP.

Acessível em http://www.fmrp.usp.br/nhe/index.php?option=com_content\&view=article\&id=46\&lte mid=29 em 12 de maio de 2012. 
OMS. Organização Mundial da Saúde. Classificação Internacional de doenças e problemas relacionados à saúde - CID. $10^{\text {a }}$ revisão. São Paulo: Editora da Universidade de São Paulo, 1994. Cap. XIX e XX, p. 891-1013.

ONU. Violência: um problema de saúde pública mundial. Lisboa, Boletim $n^{\circ}$ 14, ago/set, 2002.

PLACCO, V. Representações sociais de jovens sobre violência e a ação da escola na prevenção. . III Jornada Internacional e I Conferência Brasileira sobre Representações Sociais. CD-ROM. Rio de Janeiro, set.2003, p.1780-1794.

PEREIRA JUNIOR. G. A.; Scarpelini, S.; Aquino, A. M.; F.; Santiago, R. C.; Negrini B. V. M.; Passos, A. D. C. Caracterização dos pacientes traumatizados atendidos na Unidade de Emergência do Hospital das Clínicas de Ribeirão Preto da Universidade de São Paulo utilizando os indices de gravidade RTS, ISS E TRISS, em 2006/2007; Bepa 2009;6(62):4-11.

PEREIRA JUNIOR. G. A.; Scarpelini, S.; Basile-Filho, A.; Andrade, J. I. Índices de trauma (Trauma Severity Indices). Medicina, Ribeirão Preto, 32: 237-250, jul./set. 1999.

PGADMIN. PGAdmin, PostgreSQL Tools. Acessível em http://www.pgadmin.org/ em 22 de dezembro de 2011.

PGADMIN. pgAdmin 1.12 online documentation. Acessível em http://www.pgadmin.org/docs/1.12/index.html em 12 de fevereiro de 2012.

PORDEUS, A. M. J.; Fraga, M. N. O.; Faco, T. P. P. Ações de prevenção dos acidentes e violências em crianças e adolescentes, desenvolvidas pelo setor público de saúde de Fortaleza, Ceará, Brasil. Cad. Saúde Pública, Rio de Janeiro, 19(4): 1201-1204, jul-ago, $2003 . \quad$ Disponível em: http://www.who.int/violence_injury_prevention. Acesso em outubro 2002.

PRESSMAN, R. Software Engineering: A practitioner's Approach. Sexta edição, McGraw-Hill, 2005. 
POSTGRESQL,

2012.

Acessível

em

http://wiki.postgresql.org/wiki//ntrodu\%C3\%A7\%C3\%A3o_e_Hist\%C3\%B3rico em 02 de fevereiro de 2012.

POWEL, G. Beggining Database Design. Wiley Publishing Inc. Primeira edi

ção, 2006.

RASSLAN, S. Emergência: normas e condutas. In: Coimbra RSM, Soldá SC, Casaroli AA, Rasslan S, organizadores. Emergências traumáticas e não traumáticas. São Paulo: Atheneu; 1998. p.215-26.

REICHENHEIM, M.E.; Souza, E.R.; Moraes, C.L. et al. Violência e lesões no Brasil: efeitos, avanços alcançados e desafios futuros. Lancet. Saúde no Brasil. n.5, p.75-89, maio 2011.

SALES, L. D. F.; Fugimoto, P. M.; Passos A. D. C., Pereira Junior, G. A.; Alves, D.; Baranauskas, J. A.; Análise da Metodologia TRISS em Pacientes Traumatizados do Hospital das Clínicas da Faculdade de Medicina de Ribeirão Preto. CBIS 2010.

SALES L. D. F. Análise da Metodologia TRISS e Criação de Novos Modelos para Predição de Probabilidade de Sobrevida de Pacientes Traumatizados do Hospital das Clínicas da Faculdade de Medicina de Ribeirão Preto. Monografia de conclusão de curso apresentada em 2010, p. 24.

SÃO PAULO (Estado). Decreto n. 13.297, de 5 de março de 1979. Dispõe sobre o regulamento do Hospital das Clínicas da Faculdade de Medicina da Universidade de São Paulo. Disponível em: http://www.hcrp.fmrp.usp.br/sitehc/arqs/pdf/REGULAMENTO_VIGENTE_II.pdf. Acesso em: 22 de janeiro de 2012.

SÃO PAULO (Estado). Decreto n. 13.297, de 5 de março de 1979. Dispõe sobre o regulamento do Hospital das Clínicas da Faculdade de Medicina da Universidade de São Paulo. Disponível em: http://www.hcrp.fmrp.usp.br/sitehc/arqs/pdf/REGULAMENTO_VIGENTE_II.pdf. Acesso em: 22 de janeiro de 2012. 
SECRETARIA DA SAÚDE (Estado). Regionais de saúde do estado de São Paulo. Disponível em: http://www.saude.sp.gov.br/ses/institucional/departamentosregionais-de-saude/regionais-de-saude. Acesso em 26 de janeiro de 2012.

SOMMERVILLE, I. Engenharia de Software. Sexta edição. Editora Pearson, 2003.

TEIXEIRA, P. G. R.; Inaba, K.; Hadjizacharia, P. et al. Preventable or potentially preventable mortality at a mature trauma center. J. Trauma. v.63, n.6, p.13381347, Dezembro de 2007.

TRUNKEY D. D. Trauma. Sci Am 1983; 249: 20-35.

TRUNKEY D. D. Trauma care systems. Emerg Med Clin North Am 1984; 2: 913-22.

TAMBELLINI, A.T.; Osanai, C. H. Epidemiologia do trauma. In: FREIRE, E. Trauma: a doença dos séculos. São Paulo: Atheneu, 2001. p.47-76.

UTYIAMA EM, BIROLINI D. Ressuscitação cardiopulmonar no trauma. Rev Soc Cardiol Est São Paulo 1997; 1: 121-9.

VIEIRA, G. O.; Assis, M. M. A.; Nascimento, M. M. A.; Vieira, T. O.; Netto, P. V. S. Violência e mortes por causas externas. Ver. Brás Enferm., Brasilia (DF) 2003; $56(1) ; 48-51$.

WHITAKER, Y.I.; Gutiérrez, M. G. R;, Koizumi, M.S. Gravidade do trauma avaliada na fase pré-hospitalar. Rev Assoc Med Bras. 1998 abr/jun;44(2):111-9. Disponível em: http://www.scielo.br/php?script=sciarttext\&pid=S010423019980002000087 Ing=ptnrm= iso. 


\section{Referência de Apoio}

BRINK M, Kool DR, Dekker HM, Deunk J, Jager GJ, van Kuijk C, Edwards MJ, Blickman JG. Predictors of abnormal chest CT after blunt trauma: a critical appraisal of the literature. Clin Radiol. 2009 Mar;64(3):272-283.

BRINK M, Deunk J, Dekker HM, Edwards MJ, Kool DR, van Vugt AB, van Kuijk C, Blickman JG. Criteria for the selective use of chest computed tomography in blunt trauma patients. Eur Radiol. 2010 Apr;20(4):818-828.

DEUNK J, Brink M, Dekker HM, Kool DR, Blickman JG, van Vugt AB, Edwards MJ. Predictors for the selection of patients for abdominal CT after blunt trauma: a proposal for a diagnostic algorithm. Ann Surg. 2010 Mar;251(3):512-520.

FENTON SJ, Peterson DN, Connors RC, Hansen KW, Metzger RR, Scaife ER. A standard pediatric trauma laboratory panel: a plea for a minimalist approach. J Trauma. 2009 Mar;66(3):703-6.

HARNAN SE, Pickering A, Pandor A, Goodacre SW. Clinical decision rules for adults with minor head injury: a systematic review. J Trauma. 2011 Jul;71(1):245251.

HOLMES JF, Wisner DH, McGahan JP, Mower WR, Kuppermann N. Clinical prediction rules for identifying adults at very low risk for intra-abdominal injuries after blunt trauma. Ann Emerg Med. 2009 Oct;54(4):575-584. Hui CM, MacGregor JH, Tien HC, Kortbeek JB. Radiation dose from initial trauma assessment and resuscitation: review of the literature. Can J Surg. 2009 Apr;52(2):147-52.

JACOBS IA, Kelly K, Valenziano C, Chevinsky AH, Pawar J, Jones C. Cost savings associated with changes in routine laboratory tests ordered for victims of trauma. Am Surg. 2000, Jun;66(6):579-584.

KELLER MS, Coln CE, Trimble JA, Green MC, Weber TR. The utility of routine trauma laboratories in pediatric trauma resuscitations. Am J Surg. 2004 Dec;188(6):671-8. 
KOKABI N, Raper DM, Xing M, Giuffre BM. Application of imaging guidelines in patients with suspected cervical spine trauma: retrospective analysis and literature review. Emerg Radiol. 2011 Jan;18(1):31-38.

NISHIJIMA DK, Simel DL, Wisner DH, Holmes JF. Does this adult patient have a blunt intra-abdominal injury? JAMA. 2012 Apr 11;307(14):1517-1527.

NAMIAS N, McKenney MG, Martin LC. Utility of admission chemistry and coagulation profiles in trauma patients: a reappraisal of traditional practice. J Trauma. 1996 Jul;41(1):21-25.

PANCZYKOWSKI DM, Tomycz ND, Okonkwo DO. Comparative effectiveness of using computed tomography alone to exclude cervical spine injuries in obtunded or intubated patients: meta-analysis of 14,327 patients with blunt trauma. Neurosurg. 2011 Sep;115(3):541-549.

PANDOR A, Goodacre S, Harnan S, Holmes M, Pickering A, Fitzgerald P, Rees A, Stevenson M. Diagnostic management strategies for adults and children with minor head injury: a systematic review and an economic evaluation. Health Technol Assess. 2011 Aug;15(27):1-202.

PAPA L, Stiell IG, Clement CM, Pawlowicz A, Wolfram A, Braga C, Draviam S, Wells GA. Performance of the Canadian CT Head Rule and the New Orleans Criteria for predicting any traumatic intracranial injury on computed tomography in a United States Level I trauma center. Acad Emerg Med. 2012 Jan;19(1):2-10.

RICHARDS PJ, Summerfield R, George J, Hamid A, Oakley P. Major trauma \& cervical clearance radiation doses \& cancer induction. Injury. 2008 Mar;39(3):347356.

RODRIGUEZ RM, Hendey GW, Mower W, Kea B, Fortman J, Merchant G, Hoffman JR. Derivation of a decision instrument for selective chest radiography in blunt trauma. J Trauma. 2011 Sep;71(3):549-553. 
SHARMA OP, Oswanski MF, Sidhu R, Krugh K, Culler AS, Spangler M, Ethington M, Stombaugh HA, Lauer SK. Analysis of radiation exposure in trauma patients at a level I trauma center. J Emerg Med. 2011 Dec;41(6):640-648.

SHARMA OP, Oswanski MF, Sidhu R, Krugh K, Culler AS, Stombaugh HA, Lauer SK. Radiation trends in trauma patients. Am Surg. 2011 Feb;77(2):193-7.

SMITS M, Dippel DW, Nederkoorn PJ, Dekker HM, Vos PE, Kool DR, van Rijssel DA, Hofman PA, Twijnstra A, Tanghe HL, Hunink MG. Minor head injury: CTbased strategies for management--a cost-effectiveness analysis. Radiology. 2010 Feb;254(2):532-540.

TASSE JL, Janzen ML, Ahmed NA, Chung RS. Screening laboratory and radiology panels for trauma patients have low utility and are not cost effective. J Trauma. 2008 Nov;65(5):1114-6.

TRAUB M, Stevenson M, McEvoy S, Briggs G, Lo SK, Leibman S, Joseph T. The use of chest computed tomography versus chest X-ray in patients with major blunt trauma. Injury. 2007 Jan;38(1):43-47.

TORTELLA BJ, Lavery RF, Rekant M. Utility of routine admission serum chemistry panels in adult trauma patients. Acad Emerg Med. 1995 Mar;2(3):190-194.

WISBACH GG, Sise MJ, Sack DI, Swanson SM, Sundquist SM, Paci GM, Kingdon KM, Kaminski SS. What is the role of chest X-ray in the initial assessment of stable trauma patients? J Trauma. 2007 Jan;62(1):74-8; discussion 78-9.

WILKERSON RG, Stone MB. Sensitivity of bedside ultrasound and supine anteroposterior chest radiographs for the identification of pneumothorax after blunt trauma. Acad Emerg Med. 2010 Jan;17(1):11-7.

WURMB TE, Frühwald P, Hopfner W, Keil T, Kredel M, Brederlau J, Roewer $\mathrm{N}$, Kuhnigk $\mathrm{H}$. Whole-body multislice computed tomography as the first line diagnostic tool in patients with multiple injuries: the focus on time. J Trauma. 2009 Mar;66(3):658-665. 
WURMB TE, Quaisser C, Balling H, Kredel M, Muellenbach R, Kenn W, Roewer N, Brederlau J. Whole-body multislice computed tomography (MSCT) improves trauma care in patients requiring surgery after multiple trauma. Emerg Med J. 2011 Apr;28(4):300-304. 


\section{Anexo 1 - Ficha de atendimento do trauma}

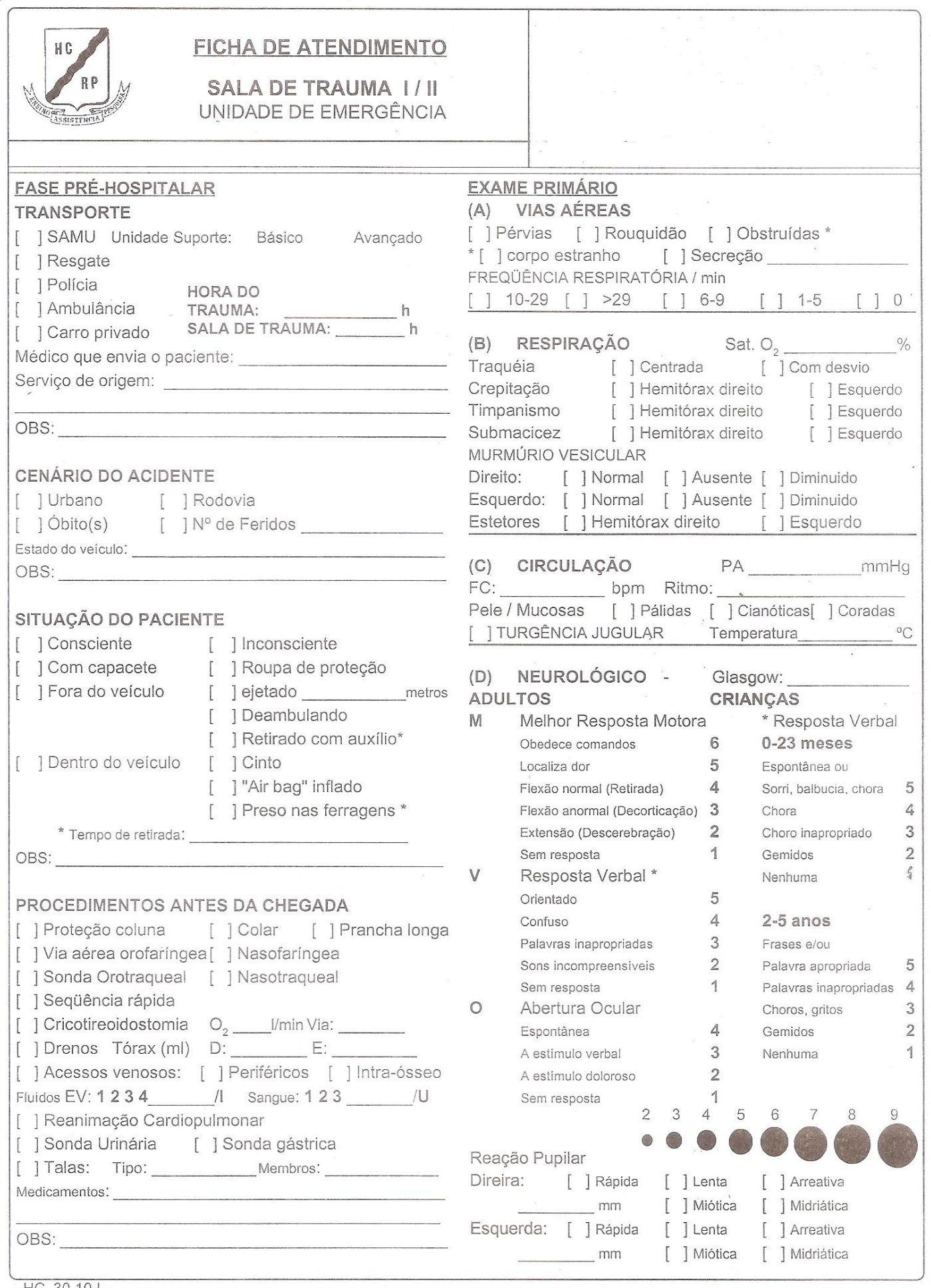

HC. 30.10 I- 


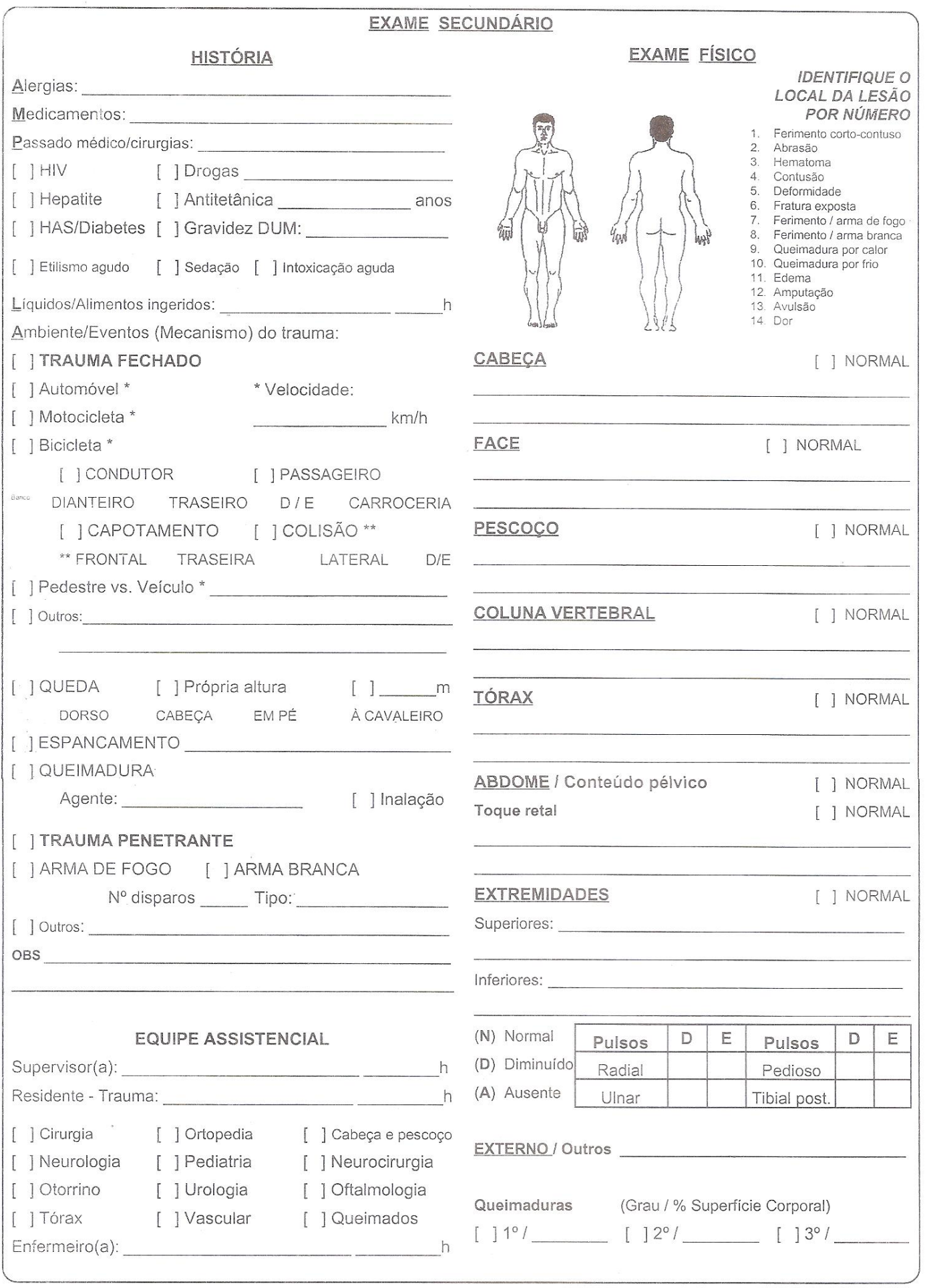


FICHA DE ATENDIMENTO

SALA DE TRAUMA II/ II

UNIDADE DE EMERGÊNCIA

MEDIDAS TOMADAS NA REANIMAÇÃO INTRA = HOSPITALAR

PROCEDIMENTOS

[ ] Oxigênio

I Intubação

CATETER

MÁSCARA $1 / \min$

] Seqüência Rápida:

] Criocotireoidostomia

ORAL

NASAL

] Respirador:

[ - ] Drenagem Tórax

[ ] Direito

[ ] Esquerdo

] Pericardiocentese

] Toracotomia

[ ] Acesso Venoso

ORAL

[ ] Diurese

Sondagem

- Espaço intercosta $\mathrm{ml} /$

${ }^{\circ}$ Espaço intercosta

] Cirúrgica

[ ] Lavado Peritoneal

[ ] Positivo

[ ] MMSS

[ ] MMII

[ ] Suturas:

[ ] Imobilizações:

[ ] Outros:

\begin{tabular}{|c|c|c|c|c|c|c|}
\hline \multicolumn{4}{|c|}{ EXAMES } & \multirow{3}{*}{ RESULTADOS ALTERADOS } & \multirow{2}{*}{\multicolumn{2}{|c|}{$\begin{array}{r}\text { EXAMES } \\
\text { LABORATORIAIS }\end{array}$}} \\
\hline \multicolumn{2}{|c|}{ RADIOLÓGICOS } & \multirow{2}{*}{ 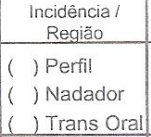 } & \multirow{2}{*}{$\frac{\text { Normal }}{[\quad]}$} & & & \\
\hline$[1]$ & $\begin{array}{l}\text { Rx. Coluna } \\
\text { Cervical }\end{array}$ & & & & {$\left[\begin{array}{ll}1 & ]\end{array}\right]$} & Plaquetas: ${ }^{\mathrm{Ht}}$ \\
\hline$\left[\begin{array}{ll}1 \\
\end{array}\right.$ & Rx. Tórax & & [ ] & & {$\left[\begin{array}{ll}1 \\
\end{array}\right.$} & $\begin{array}{l}\text { Contra prova } \\
\text { Tipo sanguineo: }\end{array}$ \\
\hline [ ] & Rx. Bacia & & [ ] & & [ ] & Amilase \\
\hline$[-]$ & Rx. Abdome & & [ ] & & {[]} & Glicemia \\
\hline[] & Rx. Outros & & [ ] & & [ ] & Gravidez \\
\hline$\left[\begin{array}{ll}1 & 1\end{array}\right.$ & CT & $\begin{array}{l}\text { ( ) Crânio } \\
\text { ( ) Tórax } \\
\text { ( ) Abdome }\end{array}$ & [ ] & & [ ] & $\begin{array}{l}\text { Gaso arterial } \\
\mathrm{pH}:=\mathrm{pCO}_{2} \\
\mathrm{pO}_{2} \longrightarrow \mathrm{HCO}_{3}\end{array}$ \\
\hline$\left[\begin{array}{ll}1 & 1\end{array}\right.$ & US & 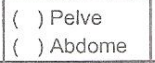 & [ ] & & [ ] & Alcoolemia / Tóxico \\
\hline$[1]$ & Arteriografia & & [ ] & & {$[\quad]$} & Urina tipo I \\
\hline$[1]$ & \begin{tabular}{l|} 
Uroyiafia \\
Uretrocistografia
\end{tabular} & $\begin{array}{l}\text { ( ) Excretora } \\
\text { ( ) Injetora }\end{array}$ & 11 & & [ ] & Lavado peritoneal \\
\hline$\left[\begin{array}{ll}1 & 0\end{array}\right.$ & Outros: & & [ ] & & {$[$ ] } & Outros: \\
\hline
\end{tabular}




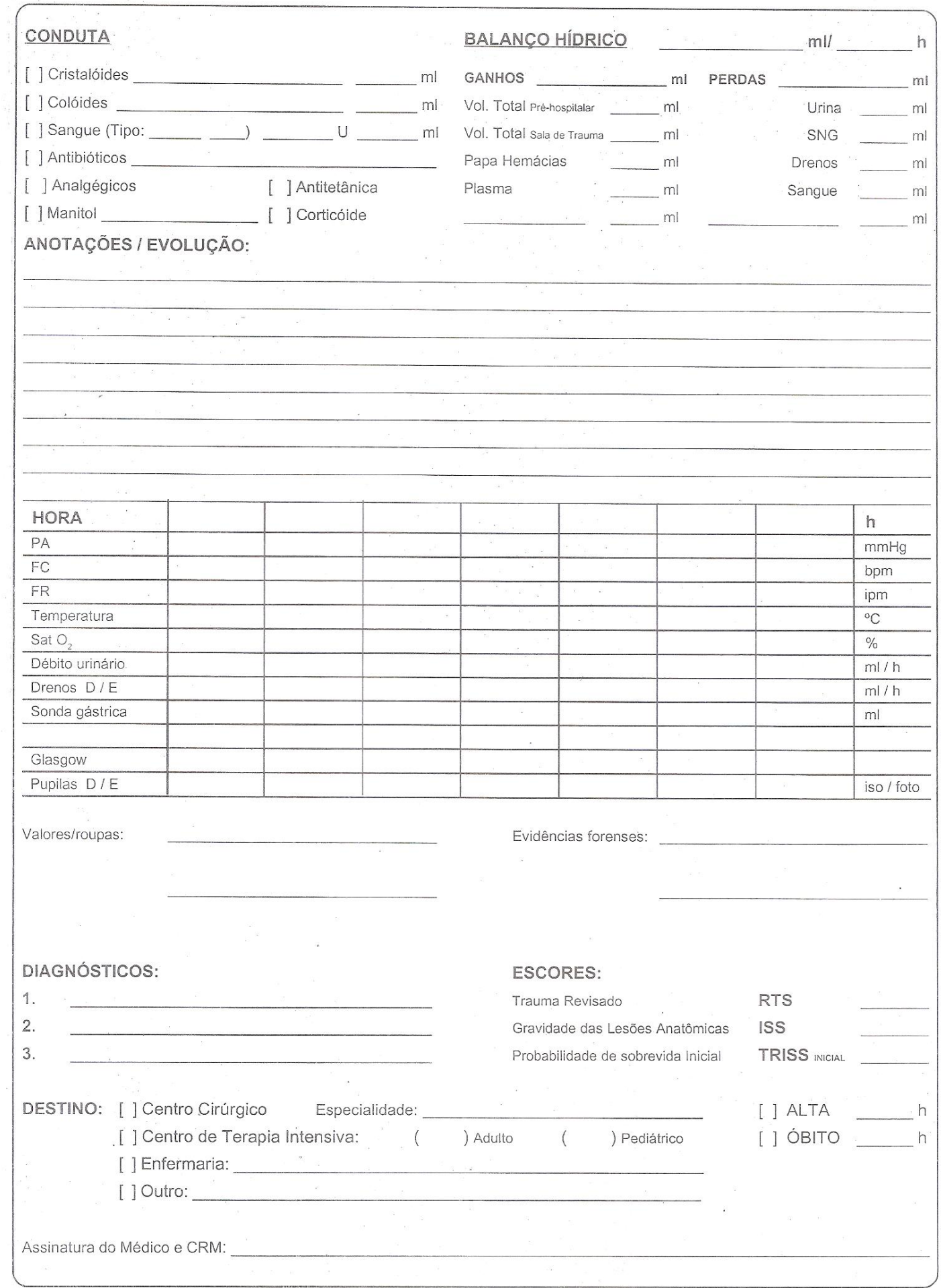




\title{
Anexo 2 - Ficha de notificação de trauma
}

\author{
VIGILÂNCIA EPIDEMIOLÓGICA DOS TRAUMAS
}

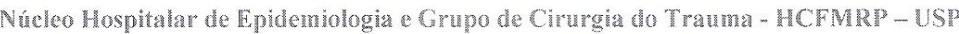

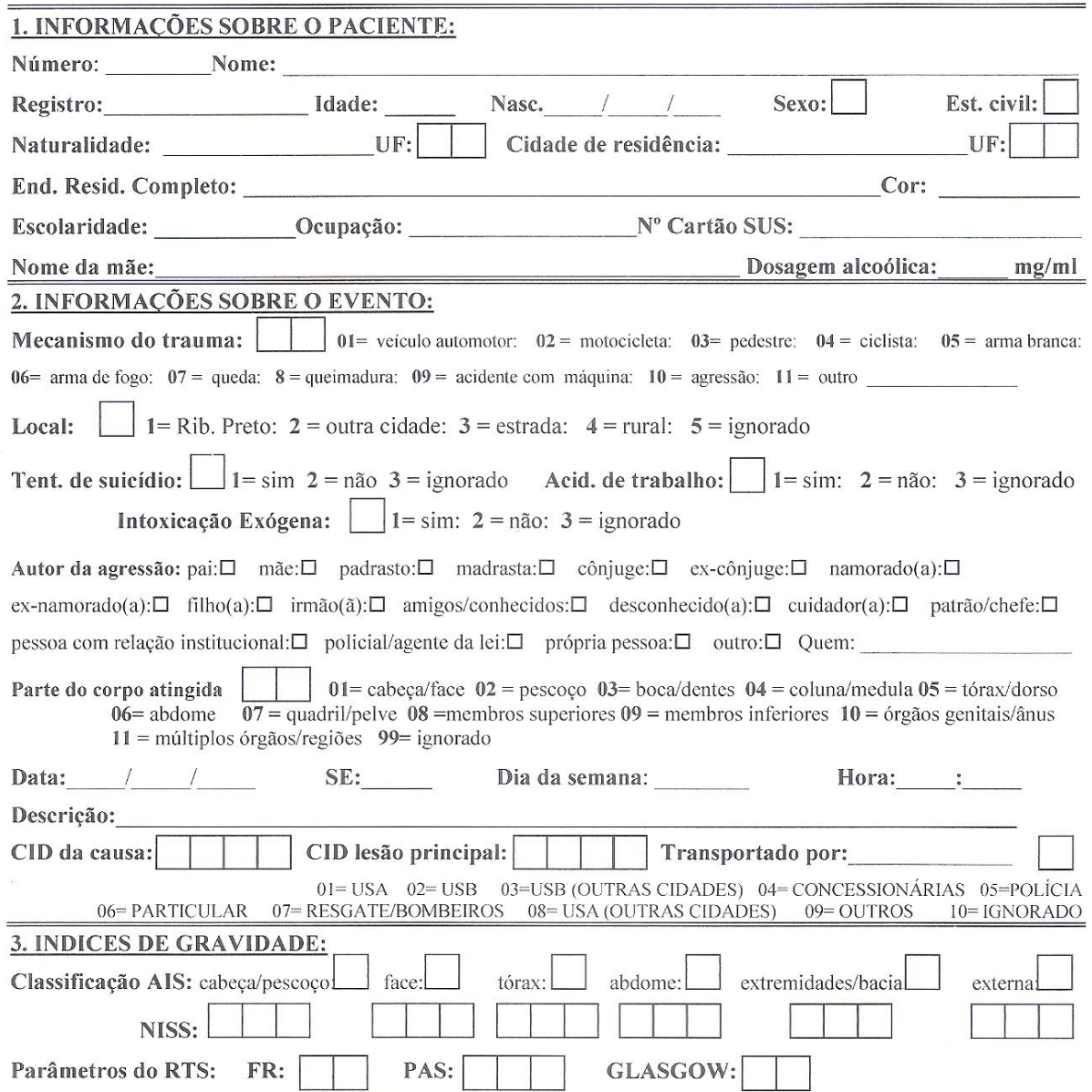

Parâmetros do RTS: FR: \begin{tabular}{|l|l|l|l|l|}
\hline & PAS: \\
\hline & & \\
\hline
\end{tabular} GLASGOW: \begin{tabular}{|l|l|}
\hline \\
\hline
\end{tabular}

Fator de alteração dle consciência: $\square$ 1=alcoolizado: 2 = sedado: 3 = sedado+ intubado: $4=$ epiléptico: $5=$ outro Patologias: $\square$ 1=sim: 2 =não: $9=$ ignorado

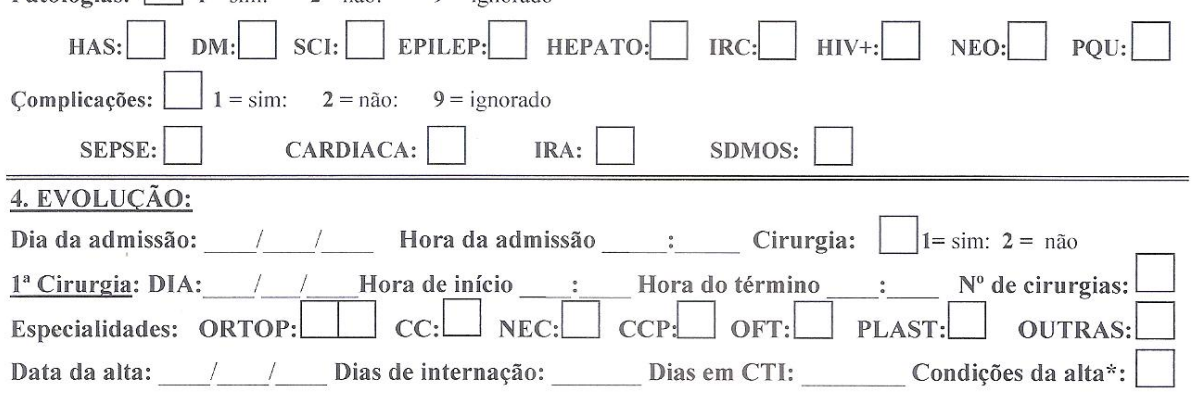

Locall do o

Razão(ões) do óbito:

Responsável pello preenchimento:

Data: / /

"Condições da alta: Corisiderar 8 categorias: $1=$ óbito; $2=$ estado vegetatívo persistente; $3=$ limitações graves; $4=$ limitações moderadas; $5=$ boa recuperaçãa; $\quad 6=$ transferência: $7=$ evasão; $8=$ alta a pedido. Óbito e estado vegetativo persistente: são condiçōes que se autodefinem. Limitações graves, moderadas e boa recuperacão:ver definiç̣ôes disponiveis no Serviço. 


\section{Anexo 3 - Resumo de diferentes graus de lesão pelo AIS}

\begin{tabular}{|c|c|c|c|}
\hline S & 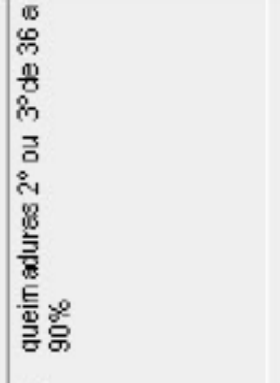 & 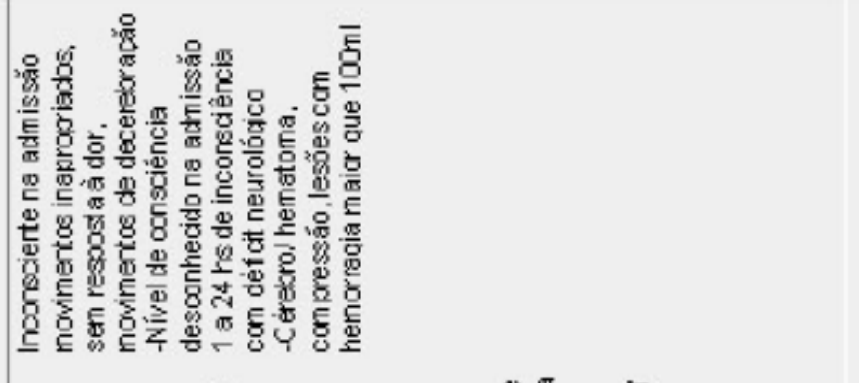 & 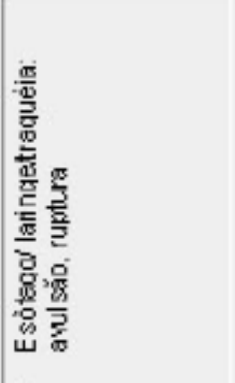 \\
\hline 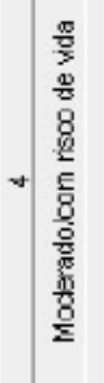 & 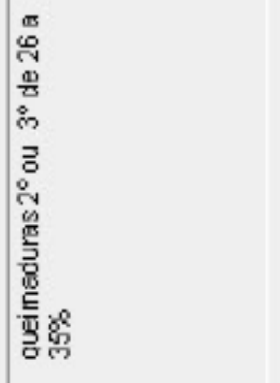 & 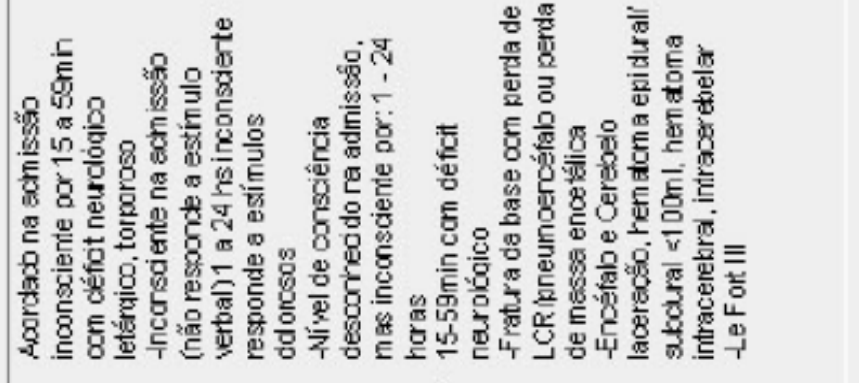 & 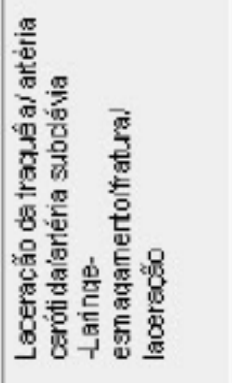 \\
\hline 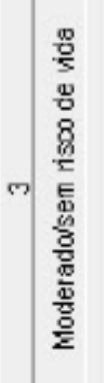 & 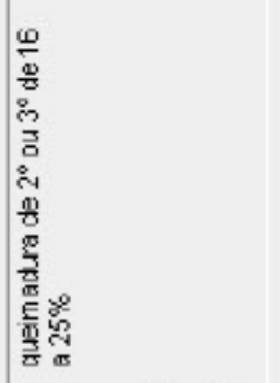 & 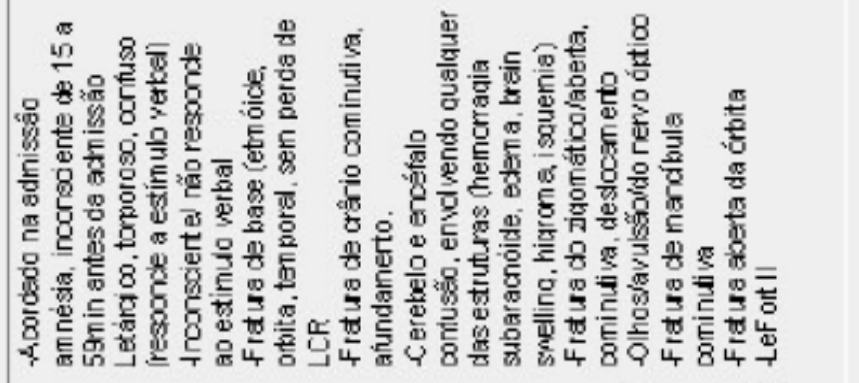 & 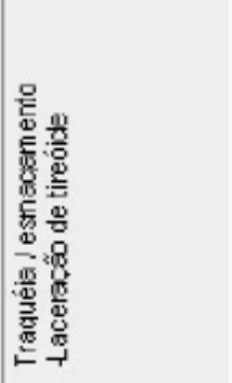 \\
\hline 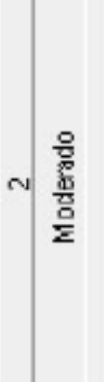 & 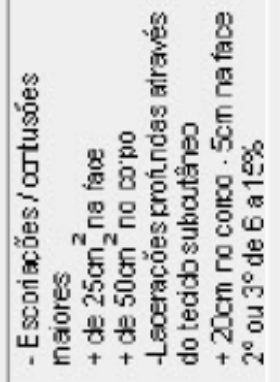 & 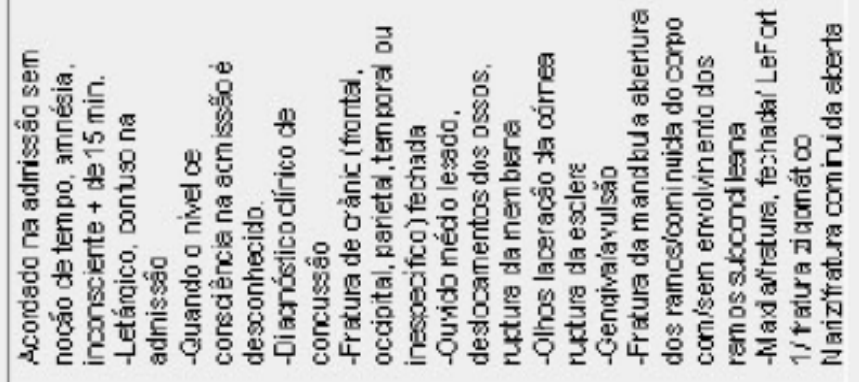 & 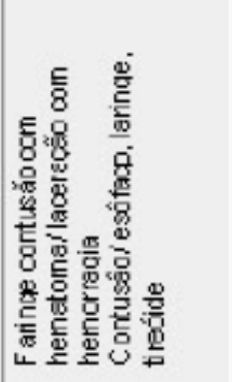 \\
\hline - & 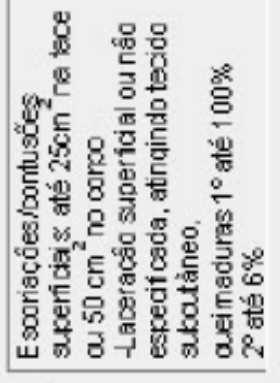 & 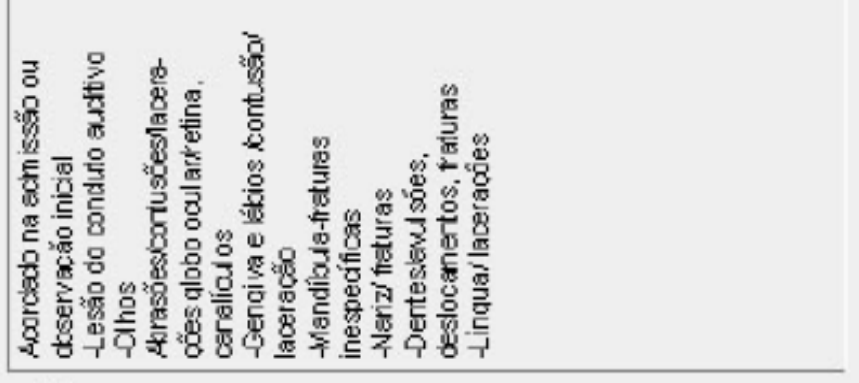 & 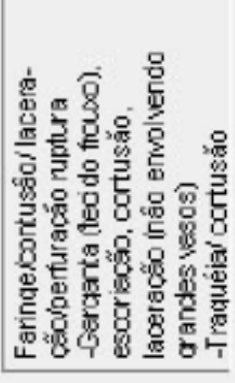 \\
\hline 向 & 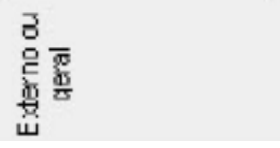 & 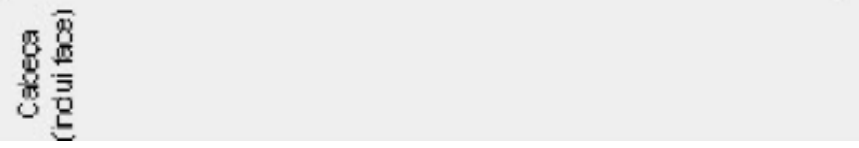 & $\begin{array}{l}8 \\
\\
\end{array}$ \\
\hline
\end{tabular}




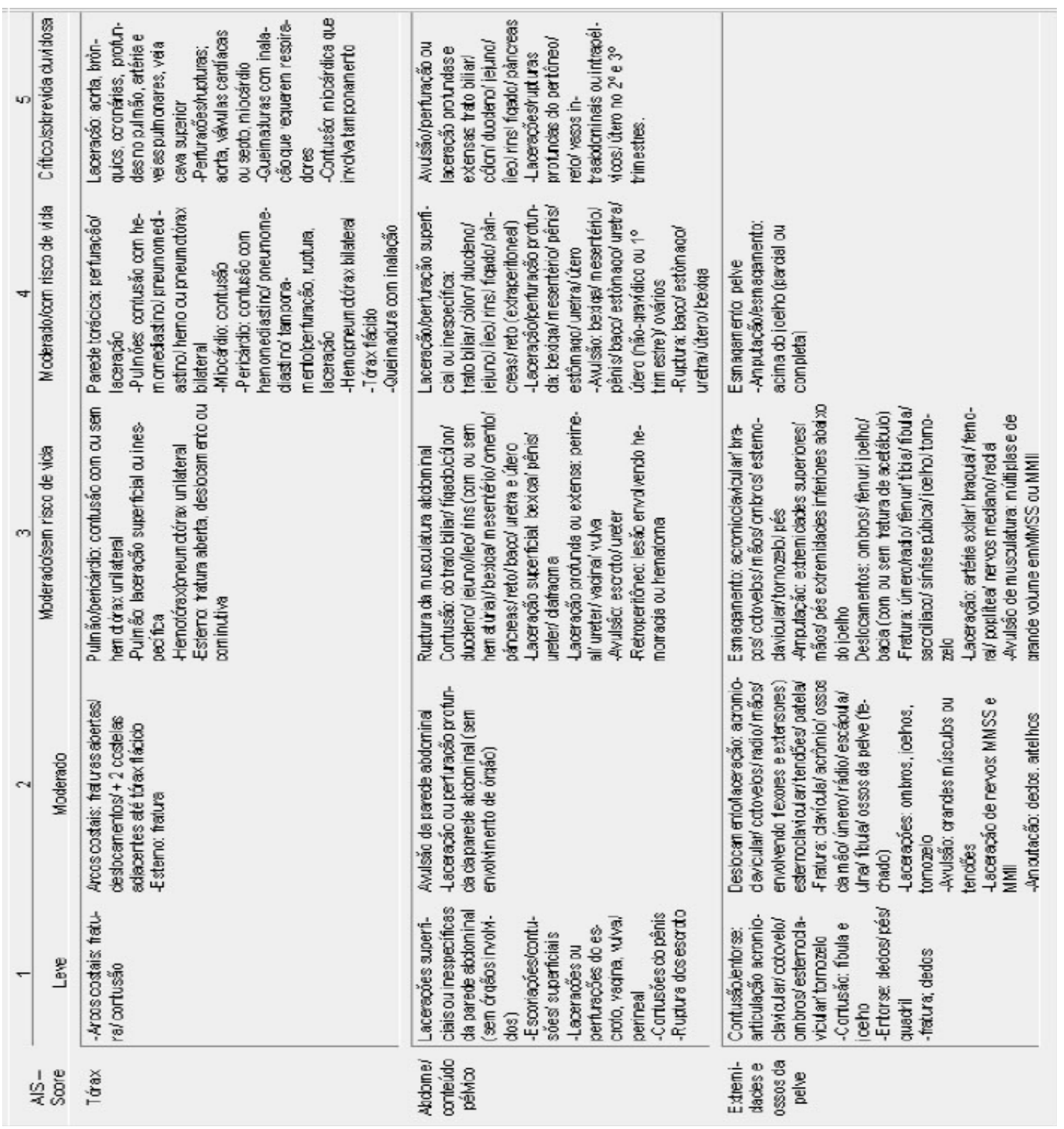




\section{Anexo 4 - Parecer do CEES da Unidade de Emergência do HCFMRP}

\begin{tabular}{|c|c|c|}
\hline SII & $\begin{array}{c}\text { HOSPITAL DAS CLINICAS DA FACULDADE DE MEDICINA } \\
\text { DE RIBEIRÃO PRETO DA UNIVERSIDADE DE SÃO PAULO } \\
\text { UNIDADE DE EMERGENCIA } \\
\text { CENTRO DE ESTUDOS DE EMERGENCIA EM SAÚDE }\end{array}$ & 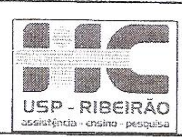 \\
\hline \multicolumn{2}{|c|}{$\begin{array}{l}\text { Fone: (16) } 36021225 \text { / Fax: (16) } 36021248 \\
\text { cees@hcrp.fmrp.usp.br } \quad \text { www.hcrp.fmrp. usp.br }\end{array}$} & $\begin{array}{l}\text { no de Campos, } 1000 \\
\text { Ribeiräo Preto } \mathrm{SP}\end{array}$ \\
\hline
\end{tabular}

\section{CENTRO DE ESTUDOS DE EMERGÊNCIA EM SAÚDE DA U.E.-HCFMRP-USP}

PARECER

O trabalho intitulado "INTEGRAÇÃO DE INFORMAÇÕES E ANÁLISE EPIDEMIOLÓGICA PARA PACIENTES VÍTIMAS DE TRAUMA NA UNIDADE DE EMERGÊNCIA DO HCFMRP, apresentado sob a responsabilidade da Profo. Dro. Domingos Alves como Projeto de Pesquisa a ser realizado na Unidade de Emergência, pelo mestrando Eduardo Alexandre Gula , foi aprovado pelo Conselho Científico do CEES.

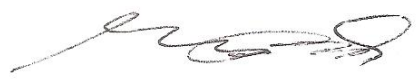

Prof. Dr. MARCOS DE CARVALḦO BORGES Coordenador do CEES UE-HCFMRP-USP 


\section{Anexo 5 - Aprovação do Comitê de Ética do HCFMRP}

HOSPITAL DAS CLÍNICAS DA FACULDADE DE MEDICINA

Ofício $n^{0} 1397 / 2012$

CEP/MGV

Prezados Senhores,

O trabalho intitulado "INTEGRAÇÃO DE INFORMAÇÖES E ANÁLISE EPIDEMIOLÓGICA PARA PACIENTES VITIMAS DE TRAUMA NA UNIDADE DE EMERGENCIA DO HCFMRP", foi analisado pelo Comitè de Ética em Pesquisa, em sua $343^{a}$ Reunião Ordinária realizada em 09/04/2012, e enquadrado na categoria: APROVADO, de acordo com o Processo HCRP no $15104 / 2011$

Este Comitê segue integralmente a Conferência Internacional de Harmonização de Boas Práticas Clínicas (IGH-GCP), bem como a Resolução $n^{\circ}$ 196/96 CNS/MS.

Lembramos que devem ser apresentados a este CEP, o Relatório Parcial e o Relatório Final da pesquisa.

Atenciosamente.

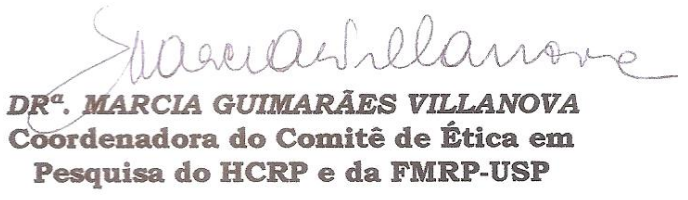

Ilustrissimos Senhores

EDUARDO ALEXANDRE GULA

PROF. DR. DOMIN COS ALVES(Orientador)

Depto. de Medicina Social 



\section{Apêndice A - Tabelas utilizadas para os gráficos}

Tabela 31. Pacientes vítimas de trauma por sexo

\begin{tabular}{lrrrr}
\hline & $\mathbf{2 0 0 6}$ & $\mathbf{2 0 0 7}$ & $\mathbf{2 0 0 8}$ & $\mathbf{2 0 0 9}$ \\
\hline Masculino & 1778 & 1362 & 1607 & 1398 \\
Feminino & 609 & 564 & 573 & 529 \\
\hline Total & $\mathbf{2 3 8 7}$ & $\mathbf{1 9 2 6}$ & $\mathbf{2 1 8 0}$ & $\mathbf{1 9 2 7}$ \\
\hline
\end{tabular}

Tabela 32. Internações de pacientes vítimas de trauma por dia da semana

\begin{tabular}{lcccc}
\hline Dia da semana & $\mathbf{2 0 0 6}$ & $\mathbf{2 0 0 7}$ & $\mathbf{2 0 0 8}$ & $\mathbf{2 0 0 9}$ \\
\hline Domingo & $392(16,42 \%)$ & $314(16,30 \%)$ & $342(15,69 \%)$ & $314(16,29 \%)$ \\
Segunda-feira & $338(14,16 \%)$ & $234(12,15 \%)$ & $290(13,30 \%)$ & $250(12,97 \%)$ \\
Terça-feira & $315(13,20 \%)$ & $221(11,47 \%)$ & $266(12,20 \%)$ & $242(12,56 \%)$ \\
Quarta-feira & $307(12,86 \%)$ & $252(13,08 \%)$ & $320(14,68 \%)$ & $254(13,18 \%)$ \\
Quinta-feira & $290(12,15 \%)$ & $257(13,34 \%)$ & $296(13,58 \%)$ & $259(13,44 \%)$ \\
Sexta-feira & $347(14,54 \%)$ & $290(15,06 \%)$ & $300(13,76 \%)$ & $288(14,95 \%)$ \\
Sábado & $398(16,70 \%)$ & $358(18,59 \%)$ & $366(16,79 \%)$ & $320(16,61 \%)$ \\
\hline Total & $\mathbf{2 3 8 7 ( 1 0 0 , 0 0 \% )}$ & $\mathbf{1 9 2 6 ( 1 0 0 , 0 0 \% )}$ & $\mathbf{2 1 8 0 ( 1 0 0 , 0 0 \% )}$ & $\mathbf{1 9 2 7}(\mathbf{1 0 0}, \mathbf{0 0} \%)$ \\
\hline
\end{tabular}

Tabela 33. Distribuição dos pacientes por gravidade de lesões

\begin{tabular}{lcccc}
\hline ISS & $\mathbf{2 0 0 6}$ & $\mathbf{2 0 0 7}$ & $\mathbf{2 0 0 8}$ & $\mathbf{2 0 0 9}$ \\
\hline $\mathbf{1}$ a $\mathbf{8}$ & $1736(72,73 \%)$ & $1245(64,64 \%)$ & $1354(62,11 \%)$ & $1177(61,08 \%)$ \\
$\mathbf{9}$ a $\mathbf{1 5}$ & $407(17,05 \%)$ & $437(22,69 \%)$ & $536(24,59 \%)$ & $402(20,86 \%)$ \\
$\mathbf{1 6}$ a $\mathbf{2 4}$ & $118(4,94 \%)$ & $135(7,01 \%)$ & $144(6,61 \%)$ & $193(10,02 \%)$ \\
$\mathbf{2 5}$ & $126(5,28 \%)$ & $109(5,66 \%)$ & $146(6,70 \%)$ & $155(8,04 \%)$ \\
\hline Total & $\mathbf{2 3 8 7}(\mathbf{1 0 0 , 0 0 \% )}$ & $\mathbf{1 9 2 6}(\mathbf{1 0 0 , 0 0 \% )}$ & $\mathbf{2 1 8 0 ( 1 0 0 , 0 0 \% )}$ & $\mathbf{1 9 2 7}(\mathbf{1 0 0 , 0 0 \% )}$ \\
\hline
\end{tabular}

